\title{
Archaeologies of Gossip
}

\author{
AIDS in Contemporary Gay Fiction
}

By

Emily Sutton

A thesis submitted to the Victoria University of Wellington in fulfilment of the requirements for the degree of Master of Arts in English Literature

Victoria University of Wellington

2015 


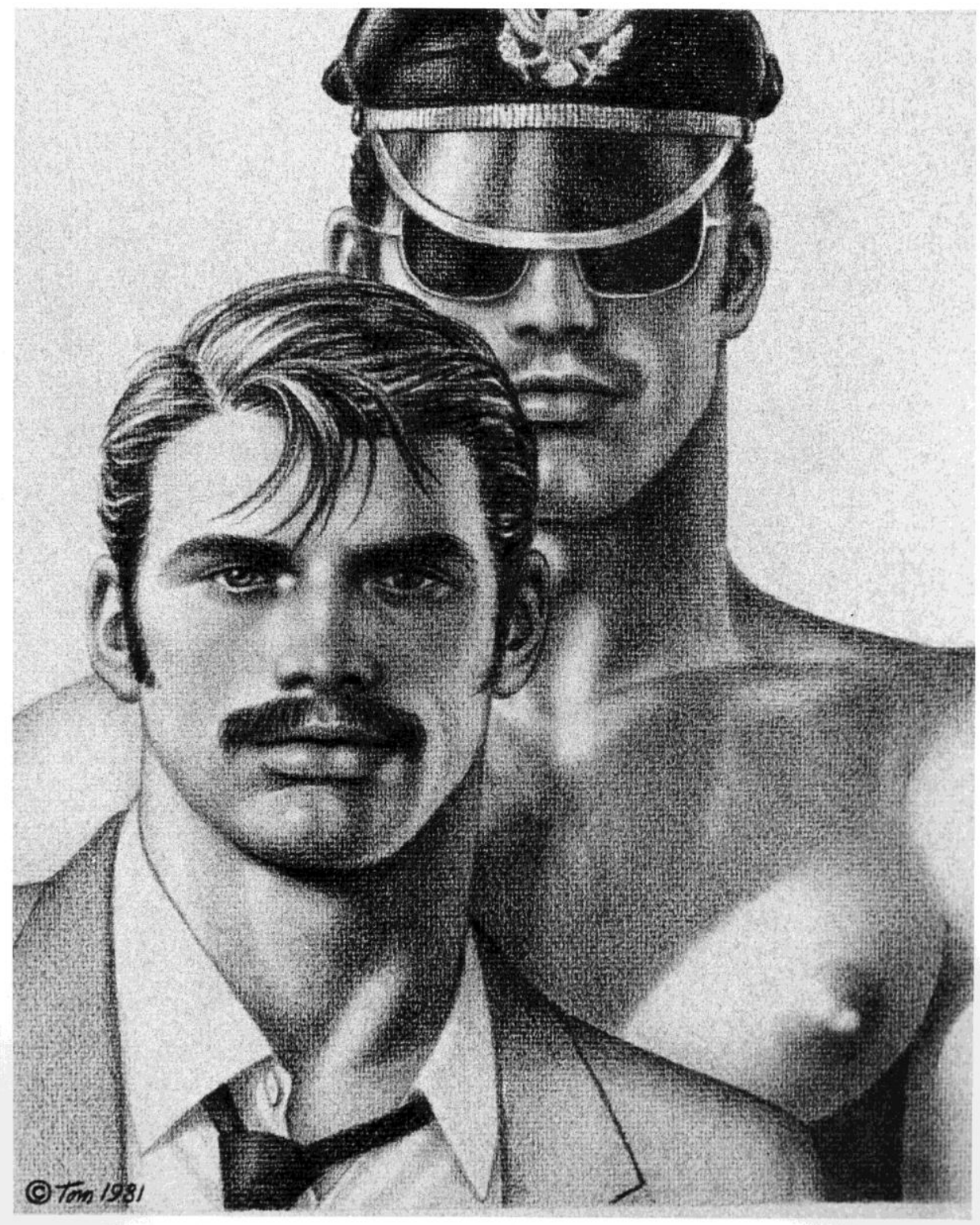

Tom of Finland - Coming of Age (1981)

"Language is a skin: I rub my language against the other. It is as if I had words instead of fingers, or fingers at the tip of my words. My language trembles with desire. The emotion derives from a double contact: on the one hand, a whole activity of discourse discreetly, indirectly focuses upon a single signified, which is "I desire you," and releases, nourishes, ramifies it to the point of explosion (language experiences orgasm upon touching itself); on the other hand, I enwrap the other in my words, I caress, brush against, talk up this contact, I extend myself to make the commentary to which I submit the relation endure. “ 


\section{Contents}

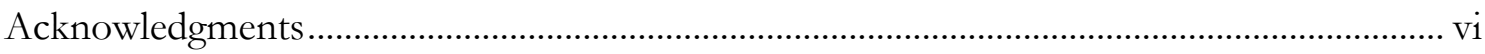

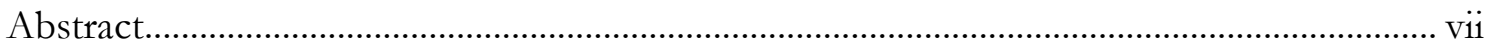

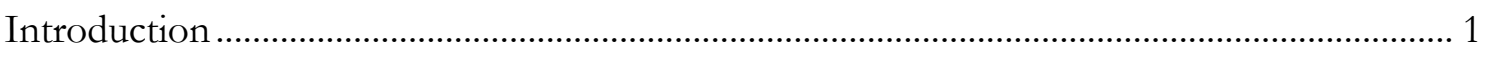

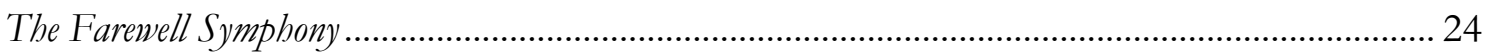

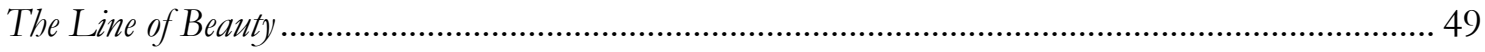

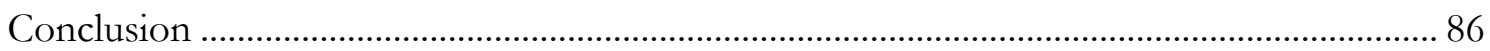

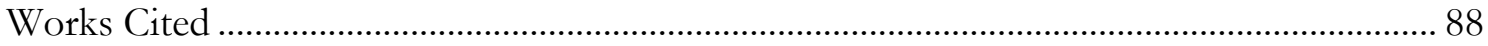




\section{Acknowledgements}

I am extremely grateful for the outstanding supervision of Charles Ferrall and Dougal McNeill, thank you.

Thank you to Reece, Mum, Dad and Sean for your love and support.

Thank you, also, to Andrew and Ros for your friendship, humour and advice.

I am grateful to Victoria University for the support of a Masters by Thesis

Scholarship and funding that enabled me to present a portion of this thesis at The Prosaic Imaginary conference at the University of Sydney in July 2014. 


\begin{abstract}
Queer criticism is now in its third decade and, as critical orthodoxy, running up against its own limitations. What, for example, is a discipline preoccupied with the unspoken, the marginal and the blurring of gender boundaries to do with Edmund White's unambiguously gay, masculine "red unsheathed fury of the third penis of the afternoon"? The Western AIDS novel is, overwhelmingly, a product of a historically precise, explicitly gay, male experience. This thesis seeks unapologetically to engage with this writing on its own terms, eschewing the queer critical lens as insufficient, and, rather, reading for a specifically gay aesthetic. Grounded in a broader overview of both AIDS novels and existing criticism, this thesis consists of extended close readings of two exemplary AIDS novels: Edmund White's The Farewell Symphony and Alan Hollinghurst's The Line of Beanty. Firstly, I articulate the centrality of the gay sexual body to the representation of AIDS in The Farewell Symphony, tracing its representation of the disease through the epidemiological mapping of the virus itself, within the highly specific culture of gay New York in the 1970s. Secondly, I examine the way in which the re-imagination of a selective tradition of gay literary predecessors in The Line of Beauty, specifically Henry James and Oscar Wilde, provides an aesthetic solution to articulating AIDS.
\end{abstract}




\section{Introduction}

Le Sexy $\sim$ Sexiness

"Different from secondary sexuality, the sexiness of a body (which is not its beauty) inheres in the fact that it is possible to discern (to fantasise) in it the erotic practice to which one subjects it in thought (I conceive of this particular practice, specifically, and of no other).

Similarly, distinguished within the text, one might say that there are sexy sentences: disturbing by their very isolation, as if they possessed the promise which is made to us, the readers, by a linguistic practice, as if we were to seek them out by virtue of a pleasure which

knows what it wants."

Roland Barthes - Roland Barthes (164)

I

Will Beckwith, protagonist of Alan Hollinghurst's The Swimming Pool Library (1988), describes an encounter with a lover as follows:

I turned him over and started to nose around his bum. It was deeply beautiful, creamily smooth when slack and when he clenched his buttocks almost cubic with built muscle. There was still the dust of Trouble for Men on the hairs in his crack, which I oiled back with my tongue, and sniffed through the dry smell of the talc to his own rectal smell - a soft stench like stale flower-water. His asshole was a clean pale purple, and shone with my saliva. (107)

This is delicately wrought, exquisite prose. It lingers over the male body with evident, tactile delight in skin and muscle and is unmistakably gay in its frank anal eroticism. This is the prose of somebody who notices, slyly funny in the recognition of Trouble for Men, the popular cologne that has been irritating the protagonist throughout the novel. The reference to "stale flower-water" has shades of the persistent image of gay man as connoisseur of interior decor, deftly signalling and gently parodying a lineage of gay imagery even as it situates itself in the macho aesthetics of liberated gay culture. Such writing - overtly gay and male, aesthetically refined and unblinkingly sexual - preoccupies this thesis. Hollinghurst's The Line of Beauty and Edmund White's The Farewell Symphony are the exemplary contemporary, gay AIDS novels. They are, crucially, driven by this same obsessive attention to bodies and sentences. AIDS writing and its criticism need not disavow beauty or, 
indeed, eroticism. Instead, I argue for a renewed attention to both specifically gay content and aesthetics in the realist AIDS novel. This is reading squarely: both looking directly at gay bodies and sexuality and overzealously lingering over prose.

Existing criticism of AIDS fiction, on the other hand, has evaded the realities of its object of study. Just as the myth of a crisis of representation haunts the literary scholarship of World War I and the Holocaust, so too does criticism of AIDS literature reiterate the belief that the disease is somehow un-narratable. Critics have assumed that there is something inherently different about AIDS writing that demands the revision of conventional understandings of how we produce and consume literature. The origins of this critical trope can be traced to Simon Watney's 1987 statement that "AIDS is not only a medical crisis on an unparalleled scale, it involves a crisis of representation itself, a crisis over the entire framing of knowledge about the human body and its capacities for sexual pleasure" ( 9 , italics mine). This oft-cited claim has proliferated and mutated, like a photocopy of a photocopy. Lee Edelman claims that "AIDS, then, resists our attempts to inscribe it as a manageable subject of writing - exceeding and eluding the medical, sociological, political, or literary discourses that variously attempt to confront or engage it" ("Mirror" 10); Suzanne Poirier asserts that the contributors to her Writing AIDS "are nearly unanimous in their assertion that AIDS has irremediably changed the way that gay literature can be either written or read" (3); Michael Denneny claims that AIDS writing is "startlingly different from our normal understanding of writing and books in this society" (44); Michiko Kakutani suggests in the New York Times that "the very awfulness of AIDS poses a daunting challenge to the imagination" (C29). What is it, precisely, that engenders this recitation of AIDS-as-unrepresentable? The lucid prose of Primo Levi and the sheer quantity of trench poetry render arguments about literature's inability to represent the Holocaust and the First World War moot. So too does the richly literary and accomplished fiction of Hollinghurst and White defy the belief that AIDS is a slippery, unspeakable rupture in the fabric of literary representation. I argue that the realist novel has specifically proven its capacity to represent AIDS: it is expansive and flexible rather than hackneyed or impotent. There is, further, a remarkable continuity of representational strategies between earlier gay fiction and AIDS writing. 
Parallel to the critical assumption that AIDS is unrepresentable has been a narrowing of the bounds of literary scholarship into didacticism and an emphasis on content over form. The two assumptions do not necessarily exist within the same arguments, but collectively build a critical climate that deems AIDS impossible to represent while also demanding its politically appropriate representation. The conviction that "we judge literary AIDS by different standards because the emergency is so great" drives this urgent, content-focussed criticism (Pastore, "Introduction" 20). This assumption is evident in Andrew Holleran's prediction that: "writing about AIDS will appear, and in the short term will inevitability be judged, I suspect, as writing published in wartime is: by its effects on the people fighting - in other words, as propaganda, not art" (83-84). Not even wartime writing is assessed in this way. Some early critics display a marked aversion to the aesthetic. The exemplary text in this respect, while not discussing literature per se, is Susan Sontag's AIDS and Its Metaphors. Sontag prefaces her argument with the recognition that "of course, one cannot think without metaphors. But that does not mean there aren't some metaphors we might well abstain from or try to retire" (5). Yet the essay seems to strive towards this very dream of direct reference to illness, stripped of overly negative figurative language (as if such a thing were possible). ${ }^{1}$ She asserts that "even the disease most fraught with meaning can become just an illness" (93). The most simplistic AIDS criticism replicates Sontag's belief that "with this illness, one that elicits so much guilt and shame, the effort to detach it from these meanings, these metaphors, seems particularly liberating, even consoling” (94). This is, in some ways, the opposite of the "crisis of representation" model of literary criticism: AIDS is representable, if only we strip back the negative imagery and cultural myths that surround it, uncovering some kind of raw, appropriate, essential truth. But I argue that both ends of the critical spectrum are equally guilty of insufficient attention to AIDS writing as it actually exists.

Extended studies of AIDS literature, as Richard Canning notes in his 2012 overview of the field, have been sparse since the mid-1990s. (141) The text that Canning identifies as the most important monograph on the subject, Stephen F Kruger's AIDS Narratives (1996), now appears outdated, focussing as it does on texts such as John Weir's The Irreversible Decline of Eddie Socket and Paul Reed's Facing It, both out of print and little discussed outside of critical overviews of AIDS literature.

${ }^{1}$ Not to mention, as D.A Miller notes, the essay's bizarre lack of engagement with homosexuality (13) 
A disregard of form characterises much of the early critical overviews, which offer limited engagements with the aesthetics of depicting AIDS. Certain works such as Richard Dellamora's erudite reading of White's short story "An Oracle” in light of Foucauldian understandings of Greek sexuality and prophetic form serve as a reminder that it is possible to read AIDS literature with a dual attentiveness to form and the specifics of gay male culture. But work such as this is striking for its rarity. The relative lack of criticism dealing with AIDS novels published in the last twenty years certainly invites further scholarship. However, this project is not interested in creating "a fuller and up-to-date account of the subject" by including more recently published novels, as Canning suggests to future critics (142). Rather, I want to shift the lens through which we look at AIDS fiction towards a renewed interest in literary form.

Sociological readings of AIDS literature, which draw few distinctions between the novel, the newspaper article, the television programme and cultural mythology, demonstrate the most marked inattention to the specifics of form. An instrumentalist bent inform some of the more naively sociological criticism, most notably the collection Confronting AIDS Through Literature (1993). Considering the ethical implications of the AIDS novel, Judith Pastore asks "whether reading imaginative literature about AIDS will really create more compassion and understanding. And perhaps more crucially... whether reading such literature will lead to active attempts to combat the disease" ("Introduction" 2). This understanding of AIDS literature as a straightforwardly didactic intervention into the political sphere subsumes the essentially literary nature of the texts themselves, Pastore asking, almost as an afterthought, if "beyond its didactic goals... literary AIDS [has] other, more traditional literary aims?” (“Introduction” 5) Pastore's didacticism extends to a somewhat bizarre meditation on whether "'serious' literature" is a viable means of reaching "poor, urban young people," whose "street codes of machismo and cool" necessitate "new kinds of literary AIDS" ("Representing" 24). Even work such as Joseph Cady's "Immersive and Counterimmersive Writing About AIDS” (1993), which details formal solutions to representing the disease, succumbs to the model of AIDS literature as instrumentalist intervention. Cady differentiates between "immersive" writing, such as Paul Monette's poetry which thrusts the reader into a direct confrontation with the horrors of illness, and the "counterimmersive," which distances the reader 
somewhat from a direct apprehension of the disease (244). This distinction, however valid as a means of categorising AIDS literature, is used to valorise the immersive as a more politically appropriate stance and to accuse those works which approach AIDS obliquely of facilitating denial. This concern with the usefulness and appropriateness of literary responses is not a sustainable or insightful mode of criticism. Both The Farewell Symphony and The Line of Beauty can be considered to approach AIDS obliquely. They certainly resist the lengthy detailing of physical symptoms and medical care on which Monette focuses. Yet to posit this approach as symptomatic of a phobic response to the disease is to radically circumscribe the formal potential of the AIDS novel.

While AIDS literature exists within a nexus of political and sociological concerns, one cannot reduce its scope to, as Michael Denneny suggests, "sounding the alarm, mobilising the community both politically and spiritually, delineating the shape of the disaster breaking over us, and initiating the discourse of AIDS in the face of the silence of the national media and institutionalised medicine" (39). This is neither to deny the very real value AIDS novels may have in these areas, nor the ways in which crisis can reshape the literary priorities of individual authors. Denneny's statement that "aesthetic appreciation is neither the intention nor the relevant response to such works" (45) suggests that reading AIDS fiction as literature is tantamount to taking pleasure in the epidemic itself. There is no necessary contradiction or tension between emotional, political and aesthetic responses to a text, nor is it possible to cleanly extricate a "message" about AIDS from the novelistic form which contains it. Concern with the aesthetics of the AIDS novel, even analysis itself, should not be synonymous with detachment or indifference. Detailed, closely attentive reading of a text that is arguably a far more sympathetic, loving mode of reading than the reduction of the AIDS novel to the same role as an informative pamphlet. It is, surely, a final indignity to deny AIDS fiction beauty.

Trauma theory, while initially appearing promising as an alternate critical methodology, makes uncomfortable assumptions about the readily transferrable nature of psychological theory into the realm of the literary. To ascribe the technique of narrative fragmentation and temporal looping to the mimicking of the psychic effects of trauma is fundamentally to misunderstand how literary prose operates 
(what, for example, of modernism?). When consciously deployed for literary effect this fragmentary technique is not the manifestation of traumatic symptomatology, as Roger Luckhurst suggests. Post-traumatic flashbacks are characterised by their very inability to be controlled and their deliberate rendition in literary contexts troubles the possibility of reading the text as symptom. Moreover, the bounds of a familiar narrative of post-traumatic collapse cannot necessarily contain the experience of the AIDS crisis. Much of the criticism of the 1990s, such as Timothy F. Murphy's “Testimony" (1993), focuses on AIDS literature as a means of bearing witness to both individual lives and a lost culture. However, the tendency for trauma theory to conflate the non-fictional and the literary again limits the critical capacity to read AIDS novel on its own terms. Shoshanna Felman, by equating Camus' writing and the testimony of Holocaust survivors in the documentary Shoah, risks subsuming the formal particularity and diversity of literary responses into the function of bearing witness. While the AIDS novel certainly does bear witness to the trauma of the disease, it is, above all, a work of art. Even The Farewell Symphony, autobiographical and invested in imaginatively reconstructing gay culture before AIDS, is more than simply White's testimony.

Just as the psychological and literary should not be conflated, it should also be a matter of course that queer political praxis and queer literary studies are not strictly interchangeable. That understandings of queer emerged symbiotically with ACT UP does not necessitate that AIDS literature be read through the lens of queer politics. This is not to deny the entanglement of the literary and the political but to advise the exercising of caution when extrapolating or transposing one to the other. The most recent overview of AIDS literature, Monica B Pearl's AIDS Literature and Gay Identity (2013), conflates theories of sexual identity with literary form. For Pearl, queerness is synonymous with postmodern narrative techniques, the blurring of boundaries between the fictional and the non-fictional, and melancholia.(55-59). Conversely, older models of gay identity are conflated with realism, reassurance and mourning (25-27). Pearl considers realist novels to provide "a reassuring illusion of objectivity, veracity and familiarity." Further, she suggests that "the realism of the gay AIDS fiction creates narrative order and the reassurance of the whole, unfragmented, objective self' (27). For Pearl, the realist novel is contained within the familiar instrumentalist framework of making "the experience recognisable, able to be shared therefore and comfortingly ordered" (25), a means of holding the reader's 
hand through the process of mourning. Pearl's limited vision of the potentiality of the realist novel reveals her division of the canon as informed less by substantive differences in formal innovation than by taste: realism is virtually synonymous with boredom, queerness with works Pearl considers more formally interesting. The most cursory of glances at the great realist novels of the nineteenth century is enough to call into question this reductive vision of the imaginative capacity of realism. What, for example, do the infinitely subtle ironic machinations of Emma do to reassert comfortable narrative order?

Pearl's transposition of understandings of sexual identity into the domain of form is often arbitrary: Edmund White and Hubert Sorin's collaborative memoir Sketches from Memory is deemed queer by virtue of it synthesis of image and text and non-linearity yet the interaction between the novelistic and the autobiographical in The Farewell Symphony, a characteristic supposed integral to queer literature, is ignored and the text subsumed under the slightly dismissive category of gay realism (71). While the novels analysed in this thesis are both realist and predicated on gay models of identity, they are far too formally interesting to be integrated into Pearl's reductive paradigm. The realist novel often proves itself to be "queerer" than expected, its form more capable of an innovative, transgressive aesthetic than Pearl suggests. To reduce a realist (and decidedly un-queer) novel as rich in allusion, attuned to historical currents and formally accomplished as The Line of Beanty to the role of fictional comfort for the confused is radically to underestimate the scope and sophistication of realist fiction. While both Hollinghurst and White are indebted to a gay, realist tradition, to suggest that form and sexual identity are causally related in the manner that Pearl suggests is unconvincing.

"Some signs are so evidently clear and full of meaning that no initiation is needed to understand them."

Anonymous - Teleny, or The Reverse of the Medal (80)

I do not intend to rebuke queer theory. Rather, I seek to shift the lens through which we view contemporary gay fiction towards the cultural and literary specificity of the gay male experience. The bravura close reading practice of Eve Kosofsky Sedgwick stands as an exemplary model of the heights queer literary criticism can 
achieve. Her reading, for example, of Henry James" "The Beast in the Jungle" meticulously traces the negative space of James" "homosexual panic" and lays indispensable groundwork for my understanding of James' presence in The Line of Beanty. This obsessively detailed, literary work does not characterise the existing body of criticism on AIDS literature, queer or not. This thesis is as much a project of resisting naively unliterary appraisals of AIDS writing as it is the assertion of the limitations of queer reading. The way in which a critic such as Pearl applies queer theory is a kind of "unreading," turning the scrupulous practice of the best queer criticism into the awkward transposition of political models into the literary. I do not wish simply to replicate political arguments advanced against queerness, such as in James Penney's After Queer Theory (2014), which performs a far more totalising attack on the theoretical foundations of queer. Even more pressingly, I am loath to repeat arguments such as Larry Kramer's denunciation of queer theory as a betrayal of a historically unchanging, essential gay identity. Work such as Leo Bersani's Homos (1995), which reasserts the specificity of the gay male experience (and particularly the physical realities of gay sex) in the face of a perceived "degaying" of queer politics, are certainly related to my own. ${ }^{2}$ This project is an immanent reading, rather than the imposition of an ill-fitting critical or political paradigm, and my resistance to queer theory as methodology is a response to the logic of the novels themselves. This is a matter of best fit rather than a wholesale critique of the discipline of queer theory.

My understanding of queerness is best summarised in Sedgwick's description of the term as signifying "the open mesh of possibilities, gaps, overlaps, dissonances and resonances, lapses and excesses of meaning when the constituent elements of anyone's gender, of anyone's sexuality aren't made (or can't be made) to signify monolithically" (Tendencies 8). If queerness is to be understood as the radical destabilisation of gender and sexual identity categories, then a queer reading of those texts which are invested in a distinctly gay culture and identity must undo their foundations, revealing the historically contingent and unstable nature of the sexual identities that undergird them. While it is not wrong to emphasise, say, the masculine sexual world of 1970s gay New York, as socially constructed and historically specific, this approach can be self-limiting when encountering texts so openly gay - where does one go next? It is what texts do with this identity, constructed all the way down

\footnotetext{
2 Although Bersani's approach to the work of leading queer theorists can be reductive and ungenerous.
} 
though it may be, which is of greater interest to me. The tendency for critics to use "queer" as a substitute for the older and more unwieldy "lesbian and gay" has resulted in a certain watering down of the critical potency of the term. To retain its political and critical efficacy, the term, Annemarie Jagose asserts, must remain in a certain degree of flux and formation, and refuse to solidify or to become comfortably institutionalised (129). But this instability can also be understood as a historically specific response to the perceived hegemonic conception of gayness established by the 1980s. As a means of resisting orthodox gay culture it was certainly potent, however when one turns the critical lens onto literature which is immersed in precisely the gay culture which queer criticism sought to confront there is limited room for a response which does not simply replicate historical political tensions. The gay culture of the 1970s and 1980s is no longer the norm that queer theory resists but a historical entity in itself. It is time to approach this period, and indeed male gay culture, with a new sense of curiosity stripped of negative associations, to instead ask, "what exactly does being gay look like at this moment in time?”

David Halperin's How to Be Gay (2012) illustrates the critical potential of looking at gay culture head on. He takes as his starting point the "obvious" existence of a distinctly gay culture (8), he draws out "the sexual politics of form" (403) shaping canonical gay artefacts. Halperin argues that, of course, gay culture is not a monolith encompassing all gay men's sensibilities, just as connoisseurship of wine is not representative of all French people (129). Rather, "the kind of coherence a culture has will not necessarily be reflected in any uniformity of attitude or behaviour on the part of a population" (130). This neat, common sense account of culture corresponds with my understanding of gay literature. There are unmistakable continuities, resonances and shared aesthetics within the gay canon, in spite of (and not logically incompatible with) the texts which defy these models. Halperin's focus on mainstream cultural forms that have been incorporated into gay sensibility Mildred Pierce, Broadway, divas - is different from my own. He suggests that these cultural forms can be far more personally resonant than explicitly gay literature, noting that students in a class on contemporary gay male literature "enjoyed appropriating and queering works of mainstream, heterosexual culture. In fact, they preferred doing that to reading gay novels" (110). His question becomes not why gay men cling to pre-Stonewall markers of gay identification, but "why would we want 
Edmund White, when we still have The Golden Girls?" (123) While Halperin's conclusions about the affective potential of "artefacts of mainstream culture" over "explicit, open, unencrypted gay male culture" are arresting (123), I turn Halperin's focus back in on itself in exploring an aesthetics of gayness, grounded in a distinct male tradition, precisely in Edmund White himself. Indeed, Halperin's argument serves, in some ways, to render "out" literature invisible once more, even as it acknowledges it within the context of a distinctly gay male culture.

The relative invisibility of post-Stonewall gay writing in queer criticism indicates the extent to which it must be appraised on different terms. Hugh Stevens notes that "while there is a large body of literary writing - gay fiction since the 1970s - in which men are represented as having sex with each other, queer theory has paid this writing surprisingly little attention” (93). This lack of fit between our preeminent critical understanding of homosexuality and the literature of "actually existing gayness" (106), as Hollinghurst puts it, is something of an uncomfortable sticking point. Within the field of AIDS studies, the disjuncture between literary texts and critical methodology has manifested itself in an aversion to examining literature itself. A considerable volume of cultural criticism surrounds both the disease itself and its mainstream cultural representations, often written by literary critics. Lee Edelman's essay “The Plague of Discourse” (1994) is representative of this inclination, and perhaps the most frank about it. He asserts that "though my subject necessarily involves literature and AIDS, my focus falls not on those literary works wherein the urgency of AIDS achieves thematic inscription, but rather on the inevitable inscriptions of the literary that mark the discourse on AIDS" (300).

Instead, the overwhelming focus of queer scholarship has been on deciphering the latent transgressive impulses in both pre-Stonewall "gay" literature and work within the mainstream, "heterosexual" canon. The essays comprising the pivotal queer anthology Novel Garing (1997) indicate the extent to which this writing is far more amenable to queer critical methodology than the openly gay. Work discussed include the canonical - Proust, Wilde, Balzac, Swinburne, Eliot, Woolf, Cather and James, the children's fiction of Thomas Day and T H White, William Gibson's Neuromancer and cold-war popular novelist Laura Z Hobson. Melvin Dixon is the only gay author writing fiction post-Stonewall treated at length, with James Baldwin's Giovanni's Room the only other distinctly gay texts examined. AIDS is 
considered only as subtext in Toni Morrison's Beloved. The anthology is exemplary of the creative, investigative and innovative work of the best queer literary criticism. In a book billing itself as "the first collection of queer criticism on the history of the novel," the relative absence of writing on post-Stonewall novels, explicitly detailing gay experience is striking. Just as Halperin's students find the examination of the queering of mainstream culture more enticing than the queer itself, the study of a canon of out literature can appear far less engaging than outing the canon. Indeed, the prevalence of queer as verb in criticism is indicative of this inclination - there is little value in queering the already queer. Instead, I take the openly gay male novel on its own terms, not simply subscribing to essentialist understandings of gay identity, but exploring what these novels do with and within their gay cultural framework. It is not a matter of reading against the grain, but rather with it. ${ }^{3}$

Rather than deconstructing binaries, there is interpretative potential in staying within them, at least temporarily. Just as strategic essentialism draws upon a stable identity around which to organise in spite of the poststructuralist dismantling of identity categories themselves, the literary equivalent offers something tangible upon which to hook one's reading. Queer theory has deconstructed both the division between male and female, and heterosexuality and homosexuality but the intersection of these binary divisions is a useful means of understanding the gay male novel. Overlaying the male/female and hetero/homosexual binaries results in the following diagram:

\footnotetext{
${ }^{3}$ I share my terminology here with Harry E Shaw's arguments about reading with the grain in Narrating Reality (1999), who notes that the term "reading against the grain" has become a commonplace and deserves fresh scrutiny, in particular, returning to its origin point in Walter Benjamin's comment that the historical materialist "brush[es] history against the grain". (136-137)
} 


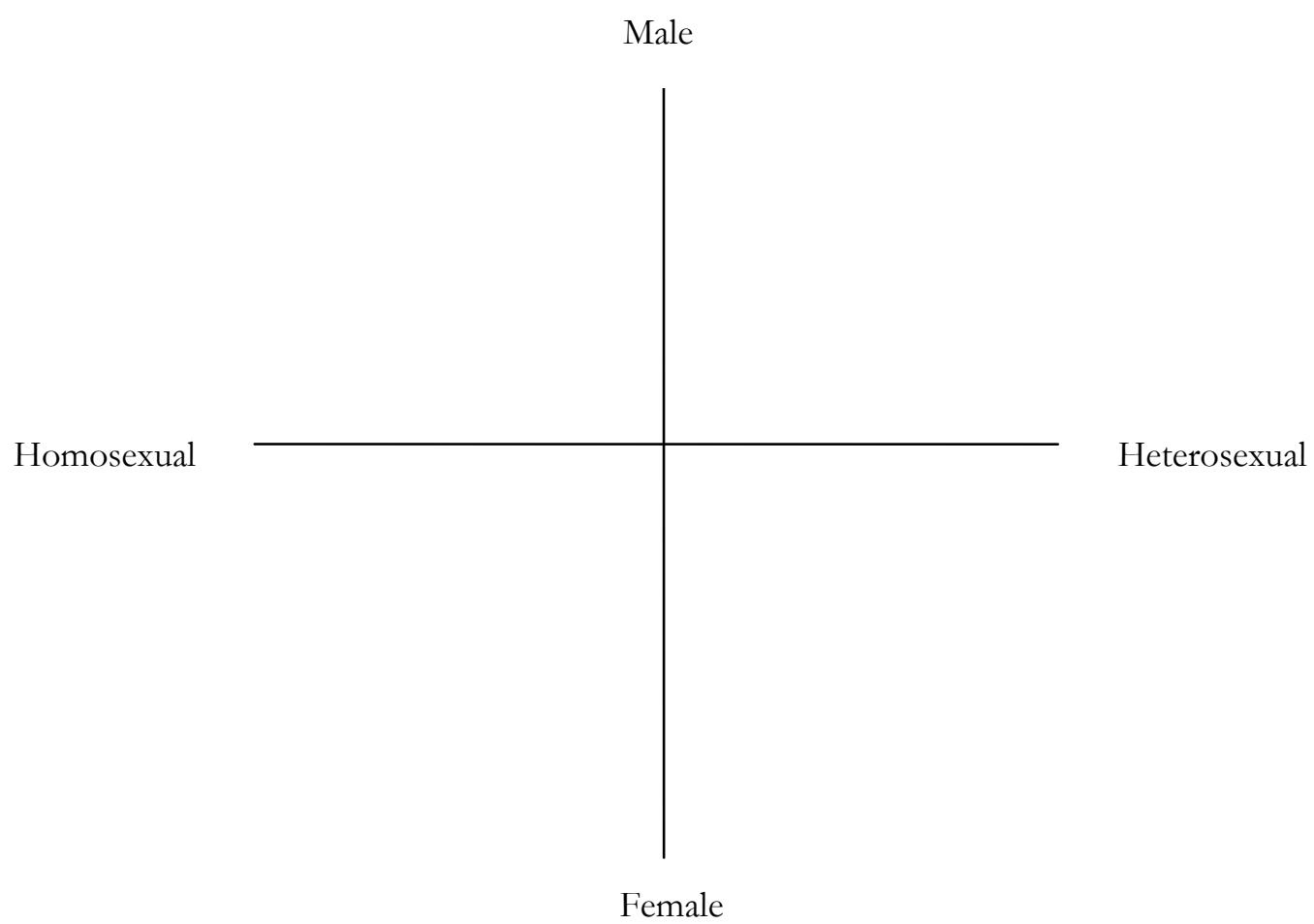

Both Hollinghurst and White's fiction obviously occupies the top left hand corner uncomplicatedly male but evidently not heterosexual. The leather daddy would sit in the furthest left hand corner, as would White's power-obsessed Clones. Mapping the distinction between the male/homosexual and male/heterosexual quadrants of the diagram, simple though it seems, grounds this study of a distinctly gay male aesthetic.

III

Art about AIDS has been diverse. I am thinking particularly of Tony Kushner's Angels in America, Thom Gunn's The Man with Night Sweats and the short stories of Adam Mars-Jones, as well as the photography of Robert Mapplethorpe, the video work of David Wojnarowicz and the avant-garde music of Diamanda Galas. However, my interest in this project is the AIDS novel rather than simply AIDS as artistic subject matter. The novel has a particular potency in writing the history of AIDS. Epidemics hover between official history and personal memory, precisely the domain of the realist, historical novel. It is both domestic enough to accommodate the lived experience of AIDS while being expansive enough to map the disease epidemiologically. Both The Farewell Symphony and The Line of Beanty are historical 
novels, yet they resist the strictures official history. Instead, the novel accommodates what Guy Davidson terms a "vernacular, collectivized databank of life histories" (49). History can fragment and disperse across the novel, drawing upon collective memory and half-remembered emotional truths. I also wish to introduce a degree of aesthetic discernment into the appraisal of the AIDS canon: the beauty of their prose unashamedly influences my choice of The Line of Beauty and The Farewell Symphony as in-depth case studies. These novels offer the most formally sophisticated solutions yet to the representation of AIDS in the contemporary, realist novel. That these two writers are the most pre-eminent gay authors of England and America respectively is not entirely coincidental. The texts in question are the consummate AIDS novels of their respective gay literary traditions. ${ }^{4}$

With the exception of a small number of novels such as Paul Reed's Facing It (1984), the initial literary response to AIDS was, for logical reasons of speed of production, theatre and short fiction. Facing It and plays such as Larry Kramer's The Normal Heart (1985) do, to a certain extent, adhere to the instrumentalist bent in AIDS criticism in their self-concept as, respectively, educational tool and exhortation to action. A novel such as Facing It, while important to note for historical reasons, has little to offer the contemporary critic. It should not necessarily diminish the historically appropriate urgency of the text to acknowledge that it has limited stylistic value. Even The Normal Heart, important as it is, must be acknowledged as by turns melodramatic, schmaltzy and often uncomfortably clunky. By at least the late 1980s AIDS fiction of a more literary bent was being published, Adam Mars-Jones and Edmund White's collection of short stories The Darker Proof (1988) being perhaps the earliest work of AIDS fiction by established (and accomplished) authors. As Pearl notes, 1988 marked a shift in AIDS writing (3), with the publication of Paul

\footnotetext{
${ }^{4}$ The gay male nature of the AIDS canon need not be a matter of extensive discussion - the bald reality of the disease's emergence in the Western world and proportional effects on the gay community rendering the overwhelmingly gay focus of AIDS literature fairly obvious. While sociologically focussed critics such as Pastore have agonised over diversity of literary representation, the debate is somewhat beside the point. Of course literature dealing with the experiences of diverse communities would be welcome, but it is not necessarily the place for criticism to demand what is or is not written and published. While not addressing AIDS fiction, Robert McRuer's misdirected critique of Edmund White's $A$ Boy's Own Story for focussing on white, middle class gay experience is indicative of the risks this line of criticism takes. White is effectively chastised for representing himself in an autobiographical novel - a position which is logically dubious at best. Therefore, the focus of this project is unashamedly on AIDS fiction as both part of a specifically gay culture and a specifically gay literary tradition, a fact which should not be taken as indicative of a lack of interest in or sympathy with non-Western, non-white, heterosexual communities affected by the disease.
} 
Monette's Borrowed Time and Robert Ferro's Second Son in particular signifying a move towards lengthier prose works. This particular moment in AIDS writing, less urgent or didactic but not yet historical, lasted (loosely) until1996, when the discovery of effective antiretroviral treatment drastically altered the nature of the disease itself. The title of John Weir's The Irreversible Decline of Eddy Socket (1989) is representative of the narrative arc of these novels - individualised narratives of the trajectory of AIDS. Paul Monette was arguably the foremost "AIDS writer" of this literary moment, producing a memoir of his lover's struggle with and death from AIDS Borrowed Time (1988), two AIDS novels Afterlife (1990) and Halfway Home (1991) and a collection of poetry Love Alone (1989), before his own death in 1995. His work, characterised by Joseph Cady as archetypally "immersive" AIDS writing, gives the lie to suggestions that AIDS in some way defies representation in its unflinching detailing of the prosaic realities of the disease. My decision not to focus on writing from this period is twofold. As noted above, AIDS criticism was at its most prolific in the early- to mid-1990s and, consequently, dealt with these earlier novels, leaving later novels relatively underserved. Secondly, these earlier works are often less accomplished as novels and display less of the formal sophistication that marks the later work of Hollinghurst and White.

Fiction published from the pharmaceutical watershed of the mid-1990s onward has, understandably, been retrospective in nature. This mode was arguably inaugurated by Felice Picano's decade-spanning Like People in History (1995), an expansive account of the gay experience of the latter half of the twentieth-century, framed by a single day in the 1991 marked by the suicide of the narrator's AIDS afflicted cousin and an ACT UP demonstration. Similarly, Alan Gurganus' Plays Well With Others (1997) is, alongside The Farewell Symphony, one of the first major novels to retrospectively treat the early years of the epidemic. Detailing the impact of AIDS on a group of three artist friends in New York, the novel is divided into two sections baldly titled "Before" and "After," a formal device that characterises the model of gay history emerging in novels of this period. The increased treatment of AIDS as historically situated epidemic rather than personal illness marks the retrospective turn in AIDS fiction. The return to the 1970s establishes a new, more oblique mode of engaging with AIDS - mastered in The Farewell Symphony - in which unprotected, utopian sexual experiences are reimagined with dramatic irony. Brad Gooch's The Golden Age of Promiscuity (1996), for instance, deals only with the gay culture of the 
1970s, yet its pointed title and the reader's own knowledge allow the text to be, in some ways, an AIDS novel. My periodization here is, obviously, generalised. Novels such as Michael Cunningham's Pulitzer Prize winning The Hours (1998) deal with the tail end of the "fatal" era of the epidemic, its character with AIDS too far advanced in the disease to experience the benefits of antiretroviral therapy. Similarly, Edmund White's The Married Man (2000) is not strictly retrospective, since it treats the death of the main character's lover during the mid-1990s, a period close enough to its publication to be roughly contemporary. What is notable, as Canning remarks, is the relative lack of texts dealing with the experiences of AIDS patients in the era of effective therapies (134). The writing of the 1990s more often returns to the early years of the crisis than it treats the disease as currently lived in the Western world, a fact Canning attributes to the simple formal problem of "describing the experience of quotidian living, however unexpected, in a way that is compelling” (134).

The Line of Beauty falls into a third and ongoing generation of writing, the properly historical AIDS novel, a development in the canon that has been less sharply demarcated than the shift from pre- to post- retroviral writing. While retrospective novels published in the 1990s tend to trace the disease from its emergence to the present day, the historical gay novel has the temporal distance to deal with the period as History rather than the more personal recent past. Paul Golding's Senseless (2004), released in the same year as The Line of Beauty, revisits the narrative of personal decline from a historical perspective, tracing the narrator's care for his dying friend with an obsessive level of prosaic detail. Similarly, Will Self's Dorian: An Imitation (2002), which is incidentally one of the few texts by a heterosexual author to deal with the epidemic among gay men, reimagines The Picture of Dorian Gray as an AIDS fable, tracing the disease from the 1980s to the mid-1990s. The recent spate of cinematic representations of AIDS may well be a harbinger of a reinvigorated desire to deal with this moment historically. Certainly recently published novels such as Tristan Garcia's Hate: A Romance (2010) and Max Schaefer's Children of the Sun (2010) demonstrate a continued tendency to return to the AIDS moment, whether as central concern or period detail. ${ }^{5}$

\footnotetext{
${ }^{5}$ Including multiple award winning Dallas Buyer's Club (2013), an HBO adaptation of The Normal Heart (2014), Liberace biopic Behind the Chandelier (2013), comedy about gay support of the 1984-1985 Miners' Strike Pride (2014), documentary account of the early years of AIDS in San Francisco We Were Here (2011) and twin ACT UP documentaries How to Survive a Plague (2012) and United in Anger (2012).
} 
Both The Farewell Symphony and The Line of Beauty adhere to general trends in AIDS writing at the time of their publication, The Farewell Symphony being one of several novels tracing the previous two decades of gay experience and The Line of Beauty a historicisation of the 1980s. In their formal execution, they differentiate themselves from the bulk of other, similar AIDS novels. White's tracing of the epidemiological prehistory of AIDS is subtle, relocating the history of the disease in the sexual body in a more sophisticated fashion than simply representing unprotected sex with a newfound dramatic irony. Hollinghurst's historicisation of the 1980s draws upon a literary tradition of gay predecessors that establishes AIDS as continuous with a far broader sense of gay history. Both novels are outstanding in the quality of their prose. Hollinghurst and White are consummate stylists and produce work highly conducive to the practice of sustained close reading. I wish to gesture towards a specifically gay male understanding of style and beauty, which reprivileges the aesthetic as an unusually powerful and culturally resonant force in the gay literary tradition.

IV

"What is there so peculiar about me?' I mused, 'that the fellow is ogling me in that way?"

Anonymous - Teleny, or The Reverse of the Medal (79)

A new approach to openly gay male fiction plays upon the double significations of "reading squarely". This is both reading at face value, looking at gayness squarely, and a reading that is "square" in its over-zealous ogling of the text. Put another way, my central focus is bodies and sentences: looking squarely at both the gay male body and the specifically formal representation of AIDS ignored by so much of the existing criticism. Reading squarely has some resonances with the model of "surface reading" established by Stephen Best and Sharon Marcus, who "take surface to mean what is evident, perceptible, apprehensible in texts; what is neither hidden nor hiding... A surface is what insists on being looked at rather than what we must train ourselves to see through" (9). Queer theory is often engaged in "symptomatic reading," taking as its object "outright absences, gaps, and ellipses in texts" which operate as "surface signs of the deep truth of a homosexuality that cannot be overtly depicted" (Best and Marcus 3). However, I agree with Carolyn Lesjak's description of surface reading's "fantasy of stepping outside the subject altogether" and statement that "neutral, objective, self-effacing, humbled before the text: this reader 
is, above all, benign" (28). Square reading is, in contrast, highly partial and historically contingent. It is emotionally invested and not content with striving to create, as Lesjak puts it, "more accurate descriptions" (28). When, in the case of the post-Stonewall gay novel, gayness is self-evident, we need not deploy queer theory's reading of gaps and silences. Yet this does not mean that criticism becomes less incisive or meaningful when no longer speaking the unspoken. Rather, a mode of criticism that looks directly at gayness is rich in potential. This is not an antitheoretical or, indeed, an anti-interpretative project. ${ }^{6}$

Reading squarely takes the gayness of a text for granted and asks not "is this gay?" but "what next?" It is, to paraphrase Barthes, the pursuit of the "sexy sentence," which yields to the reader exactly what they were seeking to find (164). It is not a question of reading whatever one wishes into any sentence, but rather delighting in that writing which perfectly coheres with what one wants. The experience is not coolly critical; it is sexy, emotionally charged. Neil Bartlett's Who Was That Man? articulates the excitement inherent in reading the unequivocally gay text:

We often assume (rightly) that homosexuality must be hidden, that it has to be found. But what are we free to search for if the author's sexuality is common knowledge... if the "homosexual meaning" of the texts is wellknown, obvious, taken for granted, unconcealed? On the street, there is only ever time to wonder, "Is he gay?"; in the bar, where the answer is already known, you can begin to wonder, "What is that man's story?" The game of reading between the lines begins to have different consequences. (33)

In Bartlett's reading, the apprehension of gayness is the stepping-stone to more engaging questions rather than the end in itself.

Reading squarely enables a sustained look at the gay body and an immersion in gay culture that is unabashed in its directness. D.A. Miller's comments on the

'I would differentiate my own work from that of Susan Sontag's in Against Interpretation, which develops a dichotomy between interpretation as mastery of a text and an erotics of art. Interpretation is "open aggressiveness" (7), which "tames" the work of art and makes it "manageable, conformable." (8) Gay male fiction, of all things, demonstrates the artificiality of this distinction. There is instead, perhaps, an erotics of mastery. Both White's leather daddies and Hollinghurst's reverence for "the Master" are attuned to, what White calls, "the complex satisfaction of dominating" and "the even more sophisticated pleasure of being dominated". (135) Interpretation can be as much the push and pull of artistic and affective power. The very act of tussling with a text can be a type of eroticism. 
liberal reluctance to look directly at the racially other's body are readily transferable to the gay context: "Now the white Western liberal characteristically refrains from taking any notice whatever of the racially other's body, under the assumption that no such notice can be taken without repeating or in some way reinforcing the abusive mythologisation of this body" (36). As a result, "the white Western liberal respect for the racially other takes the form of denying his body" (36). Square reading resists this denial and instead asserts that taking notice of the gay body and acknowledging (as Halperin does) the self-evident existence of a distinctive gay culture is not synonymous with the re-inscription of homophobic or essentialist ideologies. This mode of reading is concerned with acknowledging and articulating both difference and specificity. It resists both the liberal urge to subsume gayness under the aegis of heterosexual normality and the queer aversion to the distinct culture and patterns of gay male identity. There is something liberating in confronting the gay masculine sexual body without the prior assumption that it is a parodic disruption of masculinity itself. Just as Stevens emphasises gay literature as that in which "men are represented as having sex with each other," the realities of gay sex - and in the case, the means of transmitting HIV - should not be elided. In "Is the Rectum a Grave?," Bersani traces the critical evasion of the act of anal sex itself. It is not necessarily how much sex but rather what kind of sex gay men are having which creates societal discomfort (210-211). A square reading of AIDS is unafraid of acknowledging the reality that the disease is inextricable from anal sex, without succumbing to moralising and fatalism.

Square reading is sincere and unironic, but not naïve. The square reader immerses themselves in the erotic imaginary and the fantasies of a text and, consequently, experiences the attendant risks. Hollinghurst's black bodies are presented salaciously, daringly, to the reader expected to relish their almost taboo erotic savouring of the markers of racial difference as much as the narrator does. In The Line of Beauty, Nick remarks on "those shaving-bumps he had half-noticed on other black men" (29) and revels in the "generous softness" of his lover's lips, the “dry, dense firmness of his hair” (38). Similarly, White's power-driven sexual experiences invite the reader to take a pleasure in an erotics of domination which is more sensual than scholarly. White's narrator sheepishly admits that while the sex manual he writes counsels that role playing is passé, "when I was stoned I shouted, 'fuck that beef pussy' or dressed a skinny, naked twenty-year-old in my black leather 
jacket and whispered in his ear, 'I'm your cock-slave, sir."' (384) The square, obsessive reader - the fan as well as the critic - is dared to embrace these fantasies, to follow them through without irony and to inhabit the often uncomfortable places to which they lead. This mode of reading is not uncritical. Rather, it confronts the fantasy, the "surface" of the text, head on in order to understand it rather than to simply accept it, looking at and not through the novel's imaginary. It is an emotive model of close reading that at once dissects and relishes the text. It is the lingering over a text, the protracted gaze, the obsessive detailing which characterise this mode of engaging with the novel. The reader is like the narrator in The Swimming Pool Library, relishing the "mocking minute of tension before the languid unknotting of the drawstring, and the peeling down of the tiny garment, freeing the cock and balls in one of the most mundane and heartstopping moments there is" (15).

This reading is "square" in its excess: a fan's (a "square's") relationship with a text is one which remains a little too long, whose immersion is slightly too prolonged. In contrast to the supposition that close reading is anti-aesthetic, in that it dismantles the initial immersion in the text, square reading is a revelling in the aesthetic that takes pleasure in the cataloguing, hoarding and re-imagining of textual details. The square reader is also Sedgwick's ardent reader, with their "visceral nearidentification of the writing I cared for, at the level of sentence structure, metrical pattern, rhyme" (Tendencies 3). Close reading is a mode of fandom and reverence, much like Andy Warhol's conception of Pop Art as "a way of liking things." Close reading is, again, a loving response to the text that does not have to subscribe to an artificial distinction between critical and emotional response. As Sedgwick argues, “this strong formalist investment [doesn't] imply (as formalism is generally taken to imply) an evacuation of interest from the passional, the imagistic, the ethical dimensions of the texts, but quite the contrary" (Tendencies 4). AIDS fiction can be read with a level of scrutiny that does not detract from the affective but that is continuous with it. Indeed, to deem, as Denneny does, aesthetic appreciation an irrelevant approach to AIDS fiction is to deny the particular emotional resonances of an extended, aesthetic immersion in a text. Both The Farewell Symphony and The Line of Beauty are beautiful texts, an acknowledgement that should not be synonymous with an absence of critical scrutiny nor the assumption that one is taking pleasure in AIDS itself. 
This model of reading is not only a means of reading gay texts but also a gay way of reading in itself. In many ways, the gay man is the archetypal close reader, hyperattentive to surroundings, individuals, details and gestures. Like Bartlett's perennial question, "is he gay?," the practice of cruising, deciphering, is predicated on an ability to notice, to read a language of visual and cultural cues. Sedgwick's ardent close reader is preoccupied with reading "against the grain" - they are "perverse reader[s]" obsessed with "objects whose meaning seemed mysterious, excessive, or oblique in relation to the codes most readily available to us" (Tendencies 3-4). This reader is finely attuned to the particularly gay practice of noticing. However, square reading, in contrast, does not have to "smuggle queer representation in where it must be smuggled" (3). When reading texts that are explicitly gay there is less need to decode and more need to notice. These texts are not in polari and one does not need to read between the lines as much as look straight at them. Square reading is, perhaps, what happens to Sedgwick's ardent, young reader once they discover Edmund White rather than the Golden Girls.

The immersive, emotional mode of "square" reading allows for relationships between reader and text that transcend the purely critical. As a case in point, the styling of Henry James as "The Master" entails a specific, reverential relationship with James as gay antecedent in both The Line of Beauty and The Farewell Symphony that cannot be readily subsumed into the purely literary model of influence. The nickname is almost camp but with a little too much sincerity to be an entirely ironic gesture. Rather, it claims James for a particularly gay model of interacting with a selective literary tradition. Max Richards, The Farwell Symphony's gay literary elder statesman and the narrator's editor, is described as 'referring to 'the Master', who I realised must be Henry James, except that he spoke of him as though he were still living and about to knock discreetly at the door" (170). There is also, more slyly, the language of the leather daddy in this reverence for "the Master". This intensely personal relationship with James is made central in The Line of Beanty: Nick is writing on James for his doctorate, yet his relationship with the Master is always far more that of the fan than the researcher. To the remark made by a dinner party guest that her father calls James the Master, Nick replies "some of us do," "blink[ing] with the exalted humility of a devotee" (139). Who else is “us," perhaps, but a community of gay readers? The devotee, in line with Halperin's model of gay "ways of liking things," is, arguably, a highly specific gay model of literary appreciation. James is 
always just about to burst through the door, one of "us" - emotionally claimed and lingered over with a fondness that is as personal as it is literary.

My two chapters represent, respectively, this square focus on bodies and sentences. My reading of The Farewell Symphony seeks to ground the text's representation of AIDS in precisely the networks of gay male sexual experience that the novel traces throughout the 1970s. I will argue that the novel, far from evading the subject of AIDS, is constantly and obsessively representing it through the tracing of the erotic prehistory of the virus itself in the highly specific, unrepeatable moment of postStonewall, pre-AIDS urban gay culture. The plot of the novel, almost pornographic in its picaresque tracing of multiple, unrelated erotic contacts, traces a vast web of sexual transmission. It is possible to extrapolate a nexus of sexual contacts akin to the epidemiological diagram central to the narrative of Randy Shilts' bestselling account of the early years of AIDS, And the Band Played On, which established the disease's sexual transmission and enshrined Gaetan Dugas as "patient zero" of the epidemic. Although White's narrator serves as something of the novel's patient zero, the text, unlike Shilts, is neither didactic nor moralising. The intensely masculine sexual ideal of the 1970s is detailed lovingly and, while it becomes the very site upon which the disease plays out, it is elegised rather than pathologised. I approach White's vision of masculine sexuality, heavily invested in the power dynamics of penetration, frankly and refocus attention, after Bersani, on gay sex, specifically the inescapable reality of the disease's inextricability from the physical realities of gay sex. I argue that the text, far from constituting a crisis of representation, represents a nuanced and formally complex means of representing AIDS that transcends the representation of the domestic details of decline and care and resituates the disease within the sexual body. White's teasing of the reader with his "inability" to represent the illness and death of his lover must not be taken literally. While the novel treats this relationship sparingly and devotes relatively little space to the lived experience of AIDS itself in the 1980s, it is a mistake to assume that the narrator's protestations of inarticulacy are wholly sincere. Instead, the novel is a fiercely articulate and sophisticated formal negotiation of the history of the epidemic, a fact lost to the reader who takes White at his word. 
Whereas my analysis of The Farewell Symphony is far more invested in gay sexual culture, my reading of The Line of Beanty situates the disease within a selective, gay literary tradition. Using the framework of Raymond Williams' model of the selective tradition, I argue that Hollinghurst draws upon a specific lineage of gay literary predecessors as a means of negotiating the (now fabled) crisis of representation. While the novel's indebtedness to James is self-evident, I will argue that a second, more ghostly, presence is equally integral: that of Oscar Wilde. Wilde is never named, although his work is referred to throughout the novel. Yet the fraught personal and literary relationship between James and Wilde undergirds the text, establishing a central conflict between models of aestheticism which shape the protagonist, Nick's, self-concept as gay aesthete. Nick misreads James as Wilde, in that his sense of self is a far more informed by the model of apolitical aestheticism popularised by Wilde than James' deeply conflicted, morally uncertain relationship to aestheticism. The received dichotomy between James as repressed and closeted, and Wilde as the origin of contemporary models of liberated homosexuality establishes James as a far more socially expedient model for Nick to emulate within the social climate of conservative politics in the 1980s. But, beyond the level of character, this conflict between Jamesian and Wildean models of aestheticism within the character of Nick focalises the novel's relationship with the selective tradition as a means of representing AIDS. The novel's relationship to its literary predecessors is both personal and textual. It draws upon both the sexual politics of the relationship between James and Wilde and a series of subtle, rigorously textual, shifting referents to their work. The productive tension established by the biographical relationship between James and Wilde is manifested in a densely allusive text which, crucially, does not establish a direct conflict between the two figures. The novel draws closely upon James' model of representing illness and premature death in The Wings of the Dove, scrupulously avoiding too prolonged a glance at the diseased body and the realities of medical care. Rather than evade the physicality of the disease altogether, Hollinghurst repurposes Wilde's obsessive attention to the material details of interiors and objects as an indirect means of confronting the decaying body even as he resists the focus on physical decay central to The Picture of Dorian Gray. In representing the social, epidemiological aspect of AIDS, the novel draws upon Wilde's tracing of gossip and loaded allusions as a far more potent means of articulating gay subculture. The Line of Beanty's relationship to history is shifting, 
circling. The novel draws upon De Profundis as a framework for the relationship between Nick and his lover Wani yet transposes and refracts historical detail so as to refuse direct, textual allusion. Similarly, the novel traces and disperses historical figures such as Anthony Eden, conservative minister and the first prominent Briton to die of AIDS, rather than directly fictionalising them.

Both The Farewell Symphony and The Line of Beauty portray AIDS as a historical phenomenon and this historicisation takes place in the spaces between orthodox History and the personal, gossipy and inconsequential. Discussing his aversion to "official history," White's narrator states that "I didn't want to be a historian but rather an archaeologist of gossip" (431). I would like to imagine both texts as archaeologies of gossip, existing on the margins of the "properly" historical. The movement between the official and the unofficial, the important and the unimportant provides the historical impetus of both novels: White's treatment of Michel Foucault's illness and death skirts the edges of official biography and Hollinghurst's characters move in and out of the mainstream political narrative of Thatcherism. This model of history, operating at the interpersonal, sexual level, is amenable to both AIDS and gay culture: it is domestic, bodily, it is reading between the lines of obituaries citing ambiguous long illnesses. Chains of sexual transmission bear a certain allusive relationship with gossip itself, the inability (in many cases) to confirm the source and moment of infection necessitating a speculative, gossiping imaginative history of the course of the disease in one's own body. The perennial subject of gossip, who did what to whom, becomes unexpectedly burdened with signification and, indeed, historically significance. That gossip is culturally loaded with regard to the gay male is unavoidable. The reclaiming of an archaeology of gossip as a particularly gay means of negotiating the history of AIDS risks uncomfortable stereotyping. I argue that the model of the archaeology of gossip is particularly resonant with gay history for a reason: even in the "out" environment of urban, post-Stonewall gay culture, gay history still exists in a curious space between the personal and the public. In a community defined by sexual preference, the roles of gossip, personal memory and partially obscured narratives become far more prominent as means of transmitting cultural history.

Both authors, but particularly White, craft an archaeology of lost locations and details. White's gay New York of the 1970s is literally physically disappearing- 
the meatpacking district gentrified, the piers demolished, the bathhouses closed and repurposed - and The Farewell Symphony operates as a bulwark against this loss of a distinct moment in gay history (and indeed a unique nadir in New York's history). More than simply tracing the history of AIDS on an intensely personal level, this project resist the currents of unremembering that mark the post-Stonewall, preAIDS moment, both in literary criticism and the cultural conscious. The Line of Beauty undertakes a far more expansive project of looping, circling and toying with history. It draws upon the literary sub-history of James and Wilde's personal relationship as much as it traces their textual interrelationship, as well as gesturing towards gossip and sub-currents of the 1980s. The Line of Beanty refuses fully to disclose its referents and historical secrets. Instead it fragments and disperses them, alluding to a larger web of partial histories and inferences. This way of writing history is, moreover, novelistic. It is in the novel, as opposed to the conventional history of the epidemic, that the exploration of the unimportant and the sub-historical can properly flourish. Unsubstantiated but intensely felt half-truths can be alluded to and re-imagined in a manner unavailable to the conventional historian. The domestic, sexual and interpersonal currents so integral to the history of AIDS are the unquestionable domain of the novel. There is something in the form itself which is conducive to the historicisation of AIDS, just as there is something in creative prose which is better able to imaginatively reconstruct the lost historical moment of gay New York or the inner sanctum of Thatcherite London.

It is for this reason that the most fruitful means of reading the AIDS novel is close, attentive scrutiny to textual detail and teasing out and tracing the archaeology of gossip underlying the representation of the disease. It is the form of the novel itself, its capacity to transmit a particularly potent form of gay cultural remembering, firmly situated in an intensely felt erotics of gay masculinity, which is integral. Sociological and queer readings, in their evasion of the formal and the historical specificity of gay experience respectively, lack the critical power to engage with the central relationship between form and culture that, I argue, lies at the core of the exemplary AIDS novel. In 1988, Andrew Holleran wrote that,

-someday writing about this plague may be read with pleasure, by people for whom it is a distant catastrophe, but I suspect the best writing will be nothing more, nor less, than a lament: 'We are to the gods as flies to wanton 
boys; they kill us for their sport.' The only other possible enduring thing would be a simple list of names - of those who behaved well, and those who behaved badly, during a trying time. (85)

This supposedly elusive, aesthetic engagement with AIDS literature yields something far more richly literary, and indeed, affecting than that. 


\section{The Farewell Symphony}

"I had from my childhood a hankering for males of the prize-fighter's type, with huge limbs, rippling muscles, mighty thews; for brutal strength, in fact."

Anonymous - Teleny, or The Reverse of the Medal (32)

I

The Farewell Symphony begins its account of gay life in the second half of the twentieth-century with the narrator bedridden with hepatitis in Paris during April 1968, oblivious to that fact "that the coming revolution of students and workers would eradicate the last traces of the Belle Epoque" (6). He has, he remarks, "the rare capacity of sleeping through history" (6). This confluence of venereal disease and cataclysmic history clearly resonate with the AIDS epidemic foreshadowed in the novel's opening scene of the narrator grieving for his dead lover. However, there is more to it than that. The pun is obvious: history, for White, takes place on the level of the sexual. White is an "archeaeologist of gossip". He skirts the edges of "official" history, mapping instead the parallel enactment of gay history on the body itself. For a novel that so vividly documents multiple unprotected sexual encounters in the years directly before the outbreak of AIDS, it seems unusual that The Farewell Symphony has been read by many critics as a novel avoiding its subject. The narrator, as it were, sleeps through history. And yet the idea of a crisis of representation has been a persistent thread in critical responses to the novel.

Perhaps the bluntest expression of this motif is Richard Canning's observation that "ultimately the book doesn't say much about the experience of AIDS" (85). David Bergman, discussing the treatment of AIDS in The Farewell Symphony, asserts that White's supposed inability to narrate the disease is selfconscious, central, in fact, to the novel's composition:

White knew, while writing The Farewell Symphony, that he was unable to deal with the autobiographical material that was the proper conclusion to that novel and to which in some ways the entire novel was moving. In short one could say that he built into the novel his own failure. Or perhaps one could 
say The Farewell Symphony, like any novel, always moves toward the experience it does not have the power to assimilate into its structure. (Violet 250)

Bergman's view that the crisis of representation is a deliberate feature of the text is a more extreme versionof Ben Gove's notion of narrative collapse, that "the longflowing narrative eventually breaks down during [White's] description of the end of Brice's life" (Violet 181). The story of Brice, the narrator's lover who dies of AIDS, opens the novel and is tentatively proffered as the subject, the narrator wondering "whether I will have the courage to tell his story in this book" (4). Aspects of Brice's story are fragmented throughout the text and, admittedly, are never fully articulated. But the disease saturates the narrative structure itself. Far from limiting the novel, White explicitly toys with the crisis of representation as a narrative device. Reed Woodhouse, albeit more subtly, replicates the idea that White is uncharacteristically inarticulate when recounting the experience of AIDS. Woodhouse does not wholly subscribe to the crisis of representation model of AIDS criticism, asserting “one might claim that (as with the Holocaust) the subject of AIDS simply resists storytelling, and perhaps this is true. My account of the falling-off toward the end of The Farewell Symphony is slightly different" (38). However, he states "given the narrative usefulness of AIDS - we sense it looming over the horizon for hundreds of pages it is odd that, when it finally arrives in Chapter Eleven, it seems anti-climactic" (38). Further, he contends that "the writing is suddenly blank, the detail less telling, the memories less sharp" (38). Yet in looking only at the direct representation of the disease, Woodhouse misdiagnoses the text. It is the "looming" presence of AIDS, its ever-present ironising of the events of the 1970s, which constitutes the bulk of the novel's treatment with the disease. AIDS - its epidemiology and its experience governs the novel's structure.

Despite his status as "the finest and best known of the middle generation of gay American novelists" (Bergman Gaiety 192) White has received modest critical attention - the first book length study of his work, Nicholas Radel's Understanding Edmund White, was published as late as 2013. Although both Gove and Guy Davidson have read The Farewell Symphony for its representation of 1970s gay sexual culture, there has been relatively little criticism linking this to AIDS. Radel argues for an integrated approach, which, importantly, emphasises the biological: 
-one can hardly hear the narrator's defense of his many sexual contacts, and his reference to the traditional couple's disappearance to be replaced by 'new, polyvalent molecules of affection,' without at least pausing to think about those other molecules, viral ones, that were threatening to effect the disappearance not of a social convention but living and breathing human beings. (36)

Radel's reading can be expanded. I argue that the novel treats AIDS not as merely the next chapter in gay history or even as the ironic curtailing of post-Stonewall culture. Rather, the novel reads AIDS into the promiscuous culture of the 1970s.

As I learnt later in life, every city has its particular haunts - its square, its garden for such recreation. And the police? Well, it winks at it, until some crying offence is committed; for it is not safe to stop the mouths of craters.

Anonymous - Teleny, or The Reverse of the Medal (80)

The Farewell Symphony's fictional world exists in that distinctly gay, semi sub-historical space between the personal and the public. The text luxuriates and lingers in a highly specific period of American gay, urban culture - after Stonewall yet before AIDS. As the novel itself asserts, "gay life, just before AIDS, was both unprecedented and without sequel" (412). White's sex manual The Joy of Gay Sex (1977) is similarly emphatic in its assertion of the particularity of this moment, stating that "male homosexuality as it is today is a brand-new phenomenon" with "no antecedents" and which "would have made no sense at all to the homosexuals of the past" (9). The novel's account of the birth of this moment treats it as almost miraculous, the narrator describing his return to New York following six months in Rome in 1970 when "a friend met me at the airport in New York, popped some speed laced with a hallucinogen into my mouth, and led me on a tour of the new gay discos that had sprung up like magic mushrooms since my departure" (148). An alienated culture of "a few gay boys" transforms into "armies of men" (148), a "few skinny queens" become "thousands of [men], all similarly slender and moustachioed" (158). White summarises the rapid compression of history in his oft-repeated quip that "never had a group been placed on such a rapid cycle - oppressed in the fifties, freed in the sixties, exalted in the seventies and wiped out in the eighties" (494). This brief and 
extraordinary period of exaltation enabled gayness to be "if not enviable at least plausible" (472). White's States of Desire (1980), perhaps the most detailed nonfictional account of the period, captures the sheer desirability of this moment and its curious hold on the straight population. He argues that "straight teens want many of the same things many gay adult men already have - glamorous cars, sporty clothes, memberships in the best discos, sexual license, lots of spending money, access to drugs. It's not that the kids want to be gay, far from it. Indeed, the kids are disturbed precisely because the gay way of life is too close to the one they'd like to lead" (41). It is important, from the other side of the AIDS crisis, to emphasise the allure of this moment, its potentiality.

Patrick Moore's argument that the gay sexual culture of the 1970s was an experiment so radical it could be considered a form of art is akin to White's vision of the time. (xxiii) In "Esthetics and Loss" White unquestioningly includes "disco dancing, the sculpturing of the living body" as gay arts (69). Sex is a "reason for being," "a daily brush with the ecstatic, a rehearsal of forgotten pain under the sign of the miraculous" (69). The scale of sexual experimentation that took place in America during the brief, highly concentrated period between Stonewall and the outbreak of AIDS was remarkable. Commercial venues for sex proliferated in urban centres, with bathhouses providing a cheap, near-guaranteed source of multiple sexual partners. In New York, both the streets of the East Village and the abandoned piers and warehouses on the Hudson River served a similar, noncommercial role as a cruising ground and site for public sex. For White, the moment is characterised by both plenitude and specialisation - sex was both staggeringly abundant and diverse. As White notes in States of Desire, "the huge numbers of people permit[ted] specialisation" (252), most notably the theatrical "leather" scene, "so specialised, so shamelessly fetishised" in its highly codified and costumed embrace of a broad spectrum of sexual practices. (Farewell 231) The yet-to-be gentrified, industrial Meatpacking District was home to the radical vanguard of this sexual culture, and is described by White in ominous and bodily terms: "the pavement was gummy with dried blood and the air thick with the rich, gamy smell of fresh blood" (399). BDSM club "The Mineshaft," sat amidst warehouses and the abandoned, open metalworkers' trucks that provided the venue for darkened and anonymous encounters. The New York of the 1970s facilitated a sexual radicalism that embraced and re-appropriated the often dilapidated public spaces of a city at its 
financial and political nadir. Gay sexual culture produced a distinctive sexual geography outside the realm of orthodox history.

Christopher Castiglia and Christopher Reed (9) argue that AIDS prompted a project of "unremembering" within the gay community, as does Patrick Moore (xxii). Castiglia and Reed contest that the erasure of a collective memory of the experimental sexual culture of the 1970s constitutes a desire to minimise and renounce a no longer viable and, indeed, slightly shameful model of sexuality. Within this context, The Farewell Symphony's intense attention to the prosaic detail of lived gay experience is a deliberate act of reclamation, what Guy Davidson describes as the book's "imperative to recall and honor the New York gay world of the 1970s" (43). Key sexual locations, such as the Hudson piers and many bathhouses, sex clubs and discos, have now been demolished or repurposed, destroying the material traces of this culture, whose participants have been themselves devastated by the AIDS epidemic. The Farewell Symphony imaginative reconstructs the material, as well as human, facets of gay culture. Descriptions of these locations contain a documentarylike proliferation of detail, serving, in Barthes' terms, as functional acts as well as "indices" (Barthes 246). The extended description of The Mineshaft in the novel is both a revelling in erotic, sensational detail, such as the "paper cups full of Crisco" handed out at the door (399) and a deliberate mapping of the club as a lost cultural site, carefully detailing the layout and contents of each room so as to secure them in collective memory.

Similarly, White's continued attention to clothing, often the repetitive itemising of torn, dirty jeans and leather jackets, is more than period detail. The 1970s saw the proliferation of a distinctly masculine "Clone" aesthetic, with its uniform of "beltless tight black jeans, the fly half unbuttoned, a loose grey T-shirt and an old leather bomber jacket" (10). Of a particularly aggressive subset of this culture, White states that "the most distinctive thing about them was that they lived in an all-male society in which they adopted (and even exaggerated) a virile manner and an interest in sports. They took on hyper-male jobs (work in construction or the fire department)" (398). This hyper-masculinity is, however, indicative of a larger preoccupation with machismo. White is careful to distinguish the gay man of the seventies from his older, closeted counterparts who "hissed together over cocktails, skinny in black pegged pants and cologne-soaked pale blue angora sweaters" (11). 
Gayness at this moment in time looked different. The widening gap between the cultural practices and goals of gay men and lesbians in the seventies, and the sheer scale of gay communities in cities such as New York and San Francisco, created the possibility of an almost hermetically sealed, gay, masculine world. As White's narrator notes, "if I stayed in Greenwich Village month after month with forays out to Fire Island alone, I could convince myself that 'everyone' was gay" (91).

Ironically in light of the AIDS crisis, medical advances facilitated urban gay culture in the 1970s. Easily accessible antibiotics enabled a culture of numerous, anonymous sexual encounters, in which sexually transmitted disease could be swiftly treated. Indeed, in his history of gay literature Gregory Woods dubs the postStonewall, pre-AIDS sexual moment "the age of antibiotics" (336). The narrator of The Farewell Symphony notes with laconic ease that "I had sex with so many different men, usually a new one every night, that once a month I came down with a case of gonorrhoea" (76), yet "just as the pill freed women to do with their bodies what they wished, so antibiotics made us invulnerable to the puritanical menace of disease" (78). This biological freedom combined with what The Joy of Gay Sex calls "the whirling anonymity of the city" (13), facilitated a collective reimagining of sexual relationships. The Farewell Symphony, at its most indebted to theories of gay liberation, articulates this as an idealist striving towards "new, polyvalent molecules of affection or Whitmanesque adhesiveness" (414) and a belief in the genuine, transcendent intimacy of the anonymous experience. The narrator rejects the notion that "for those who never lived through the period (and most of those who did are dead), the phrase "anonymous sex" might suggest unfeeling sex, devoid of emotion" (299). However, an acknowledgment of the cultural taboo of "aping the heterosexual model" (299) and widespread disdain for "the couple" rests uneasily alongside an ardent investment in the "hopeless love affairs [that] were a specialty of my generation" (34). The novel is by no means utopian in its representation of the 1970s. Even as it delights in an idealist vision of gay fraternity, it is acutely conscious of the gap between the platonic ideal of gay experience and lived experience. The Farewell Symphony's narrator acknowledges that the commercialism of clone sexuality fostered an "elite hierarchy" (444) and allowed sex to become a corollary of consumption. He laments "how numerical desire is, all a matter of numbers of years, inches, dollars" (261), and indeed a premium on youth, beauty and sexual prowess stands in counterpoint to the idealistic vision of gay men as "sexual friends, loving 
comrades, multiple husbands in a whole polyandry of desire" (298). "Those who weren't white as well as the old, the poor, the ugly," (444) were not afforded access to the same utopian vision of gay society.

Many of the narrator's descriptions of the sexual culture of the seventies are presented in a ventriloquized collective voice. A paean to the promiscuous culture of the seventies will incorporate both the artfully crass language of the macho street cruiser, ("we didn't fall for any morality bullshit") and the stridency of the gay rights activist ("courtship was a con"). (298) Yet, White drops his channelling of the collective voice with a tangible sense of relief when confessing to a distinctly unliberated preoccupation with his current love, "of course the sermons I preached against love and jealousy were all the more absurd because I was so besotted with Kevin" (300). The novel contains lengthy passages describing his ardour for a string of lovers and expressions of the narrator's fantasies of living "as man and wife" (33) with "my boy-husband, my baby-master" (300). White genuinely considers postStonewall gay culture the vanguard for a radical shift in societal mores but his gaze is too sharp to allow for a romanticisation of the period.

White's account of this period is not to be conflated with the political history of gay liberation. It is instead personal and sexual, existing parallel with the growth of a modern gay politics but constituted more by gossip and personal memory than the historical record. When the narrator describes a lover whose job was to "oversee the total facelift of a sauna that had been a foul-smelling steambath for half a century" (394), the reader attuned to gay collective memory can recognise the renovation of the now lost New St Marks Baths. This is not political history but instead a sociable, sexual account of the era preoccupied by lost locations and lost bodies. The text contains a richly detailed web of referents available to the reader privy to this personal history. Returning to the notion of reading squarely, the information is not coded. It is rather available to those who linger and notice, who hoard the prosaic details of this historical moment. In articulating the "archaeology of gossip" as historical framework, the narrator resists the explicitly political: “Official history - elections, battles, legal reforms - didn't interest me, I who'd never voted and felt no connection with society. No, I didn't want to be a historian but rather an archaeologist of gossip" (431). The narrator states after his half-hearted attendance of consciousness raising groups: "it was only by pious convention that I 
signed a petition deploring the fire that had destroyed the Everard Baths and burned to death dozens of the homosexual clients inside" (181). It is precisely events such as this 1977 fire, on the fringes of the historical record, which preoccupy White's model of history. ${ }^{1}$ While a politicised response to the event is rejected, these halfforgotten incidents are central to the novel's tracing of a vernacular, gossipy gay history. The novel toys with the contradictions and of 1970s sexual culture but refuses to be circumscribed by politics - White's recognition of the failings of the period is more matter of fact than moralising. What emerges from the text is a decidedly intimate, gossipy history, grounded in the prosaic and the interpersonal. The experience of sex, the body and its geography, material that sits just outside the reach of the conventional historian, is readily accommodated. It is within this intimately realised history of the gay body that the novel situates its account of AIDS.

1 The fire has a particular literary history of its own, as it is the climax to both Andrew Holleran's Dancer from the Dance (1978) and Larry Kramer's Faggots (1978). 
III

The grounding of The Farewell Symphony within this specific historical moment, and its status as a decidedly "out" work of gay fiction, prevents an easy "queering" of the text. Firstly, the amorphousness of contemporary queer theory elides the particularity of the male homosexual experience in the post-Stonewall moment. A direct result of the queer theoretical and analytical vocabulary's resistance to a concrete definition is its frequent transformation into a new shorthand for communities and texts that might previously have been referred to as LGBT or "gay and lesbian." The tactical value of queer theory's diffuse, suggestive terms in suitable contexts is not in dispute here. But when applied to texts situated within a specifically gay male culture and aesthetic a too-hasty appropriation of queer terminology obscures other sexual codes and signals. Secondly, when taken more rigorously, queer criticism's central concern with transgression, concealment and the murkiness of boundaries does not provide the critical tools necessary to engage with a text in which male anatomy uncomplicatedly signifies masculinity and sexuality entails fascination with traditionally masculine power dynamics. White's writing, unambiguously gay, explicitly homoerotic and grounded in the politics and culture of a pre-queer sexual moment, resists queer orthodoxy and demands a new, historically grounded gay way of reading "out” literature. As Castiglia and Reed argue, queer theory is a direct product of the unremembering of the post-Stonewall moment, creating a queer subject that is "solitary and outside history" and which must be maintained by "disavowing a gay past" (5). This trend, combined with queer theory's aforementioned tendency to analyse older and more covertly gay writing, creates a distinct historical and literary gap between 1969 and 1981, a moment that demands renewed critical and literary attention.

The Farewell Symphony itself resists a queer reading. The strategic deployment of the word "queer" emphasises the novel's self-consciousness of its own resistance to queer readings. The narrator writes of the characters in his novels as "my queers" (34), yet grounds the statement so deeply in the cultural baggage of the preStonewall pathologisation of homosexuality that it resonates anachronistically as a marker of oppression rather than liberation. Similarly, White uses "queer" almost perversely as an adjective in its most original sense of the uncanny. Recalled childhood memories are rendered in a "new, queer light" (39) by the adult narrator 
in a deliberate stripping of the term's political resonances. Generational difference preoccupies the novel's contestation of queerness. The narrator's cohort of men, devastated by AIDS and the architects of the sexual radicalism of the 1970s, is set against a newer generation with a recognisably queer aesthetic: "the younger ones with their shaved skulls, pierced noses, tattoos and combat boots, appeared to belong to another race, militant, even military, too brusque and strident to be receptive to my elegies" (495). The narrator further confronts queer criticism of his own generation of writers when he states that "younger gays identified my generation with unreflecting conformist machismo, with greed and consumerism, with white supremacy and sexism" (411). In response to this critique, the novel reasserts the historically specific circumstances of the gay culture of the 1970s, even as it recognises its limitations. The narrator argues that, "the assertion of the clone look had originally been a political act, a way of signalling that gay men did not have to be sissies... the clone look was a tribal look, a way of saying to one another, 'We're brothers. We're the men we've been looking for."' (412) White's grounding of gay identity in a specific historical moment - deliberately not essentialising it establishes a precedent for reading the novel: it must be approached on its own terms. The contestation between older models of gay identity and queerness are a generational conflict as much as a philosophical one in the novel, opening up the possibilities of reading historically rather than ideologically. Now that Clone culture is historical rather than hegemonic, the critical lens can move away from a combative deconstruction to a more measured, "square" appraisal of post-Stonewall culture as a moment in time.

Robert McRuer criticises White's writing as insufficiently queer, its oppositional potential "ultimately undercut by the "apositionality," or invisibility, of whiteness in the text" (40). He perceives White as sustaining a hegemonic vision of gayness in creating an artificial "unitary, essential gay subject position" (42) in which racial differences are effaced in favour of the "appropriation" of "representative 'outcast' status" (44). This understanding of White elides the specificity with which White locates himself culturally. The gay subject position that White's fiction adopts is historical, evident both in the awareness of the unprecedented nature of the generation it describes and the exhaustive, detailing of sexual culture and geographically precise locations. As Davidson notes, White's writing is fundamentally concerned with the "interplay of particularity and typicality" (39) - 
that is, with the more complex relationship between the individual and their subculture rather than universal notions of gayness. Reading The Farewell Symphony through a specifically gay lens does not entail an uncomplicated embrace of an essentialist model of sexuality but rather reads the work in the terms it sets for itself. It does not retrospectively or anachronistically apply the logic of queerness to his novels. This is not a regressive move or an attempt to erase the valuable political work of the queer movement. Rather, it is an attempt to move beyond the limitations of queerness as literary criticism through a refocusing on the cultural and sexual specifics of the text.

IV

It was big without having the proportion of an ass's; it was thick and rounded, though slightly tapering; the glans - a fruit of flesh and blood, like a small apricot - looked pulp, round and appetising.

Anonymous - Teleny, or The Reverse of the Medal (90)

The Farewell Symphony is replete with descriptions of the male sexual body, both delicately drawn and lyrical, and pornographically stark. For White, the gay male sexual body is uncomplicatedly cisgendered, male genitals uncomplicatedly signify masculinity. However, this gay masculinity is not a direct transposition of heterosexual machismo. It is, rather, specifically gay. The narrator traces the cumulative influence of sexual memories in sketching out the characteristics of his own gay male body: "I had no tattoos or piercings but my nipples had a history, they were enlarged and they stiffened when brushed by a callused hand, just as my ass arched and filled out in my skintight jeans under a man's admiring scrutiny and my cock stiffened after a third glance back" (68). Gay experience subtly recodes the male sexual body without queering or feminising masculinity. Clone sexuality has been widely interpreted as either having a parodic, subversive relationship with heterosexual machismo or regressively clinging to heteronormative role play (Bersani 206-207). Yet there is a degree of heterosexism in the belief that gay machismo can always only be a warped interpretation of the masculine. Rather, the gay sexuality eulogised in The Farewell Symphony is engaged in a far more sincere erotic response to the hypermasculine. Bersani notes that the concept of a leather queen must remain an oxymoron to be sexually viable. Asserting that parody is an erotic turn off, he stresses the dead seriousness of the gay commitment to machismo (206-207). Gay 
machismo's tribute to a male ideal is sincere, as Bersani notes, since it was intended to sexually excite others and continued to be adopted for the simple reason that it worked (207). While White is not unselfconscious enough to be unable historically to locate and analyse Clone sexuality, the novel's erotic investment in masculinity is genuine.

White cumulatively builds a collective portrait of the bodies of a generation of gay men. He is preoccupied both by the obviously sexual genitals and unexpectedly erotic body parts - a loving engagement with the whole body, newly accessible to a "liberated" post-Stonewall generation. In detailing his tricks, "most of them... dead now," the narrator shifts fluidly between the erotic and the romantic, the stark and the lyrical, the traditionally sexual and the unexpected: he remembers "the small and big penises, sheathed and circumcised, the hairy Italian and Puerto Rican chests, the ardour, the kisses, the whispered secrets" and "memorised the intricate fittings of their knee bones, felt the burning ears and cold hands, burning scrotum and cold buttocks, kissed their feet and the crease where smooth bum joined hairy leg, dug my fingers into their intricate ringed anuses too tight, then too loose" (13). These bodies are uncomplicatedly masculine - marked by hairy chests, legs, cocks - and yet detailed with an intricacy and delight that creates a distinctly gay erotic. What is different about the gay male body is not necessarily the fact that it is less masculine, but that it is, as D.A Miller puts it, "visible to desire" (30). It is a masculinity repositioned from the role of invisible gazer to the object of the gaze.

White's delight in the body reads as a deliberate reclamation of the sexual experiences of a generation. Just as the detailing of the physical locations of postStonewall culture works to preserve a lost culture, the attention to the lost bodies which peopled it becomes an act of salvage. Descriptions of genitals are lovingly detailed, such as a "long clean cock rising up out of a blond's light cloud of brown pubic hair dusting an unusually red scrotum," (136) and become miniature character sketches. White's prose is at its most refined and astute when describing sexual encounters. His description of an orgy renders the participants as a joyous litany of sexual body parts: "back then, in that bedroom... they were just wide cocks or thin, balls light and tender as seedless grapes or big and veined like walnuts, insensitive and straining in their leathery sac; they were a short-sleeved coat of black hair as closely woven as a knight's mail singlet" (296). Descriptions of the genitals and 
bodily fluids are celebratory - a partner's "fist foamed over with spurts of sperm" (217), dirty jeans stiff with semen become intensely desirable, sexual experience becomes the "sticky semen-glue that bound us together" (445).

The narrator's descriptions of the male body as animal-like invoke an essentialist, hyper-masculinism that draws upon the aesthetics of Clone culture. "Muscle-bound" men cruising each other are directly equated to the exuberant mating displays of male animals: "everyone had to be unambiguous, as glowing as a peacock's tail and as towering as a stag's antlers, secondary sexual characteristics evolved on the principle that more is more, even if the lyre-bird's seductive tail so encumbers him that he can no longer escape a predator" (11). While this hypermasculine body - "pumped up so laboriously" (11) - is acknowledged as man-made, something of a costume, there is also an essentialist thrill to the dynamics of animalistic sex. The narrator describes a lover as a dog, his actions attributed to an elemental masculinity: "loss of cortical control had left the big red setter with just two automatic responses, positioning and grasping with the powerful forepaws and a strong thrust with the pelvis... I could even feel the head of his penis, dog-like, swelling inside me" (128).

This animalistic violence is a facet of White's preoccupation with a power dynamic that reads as overtly male, though again not synonymous with heterosexual masculinity. In States of Desire, he historicises this obsession, stating that "the unisex of the Sixties has been supplanted by the heavy sex in the Seventies, and the urge towards fantasy has come out of the clothes closet and entered the bedroom or back room. The end to role-playing... well, it never happened" (267). However, he later wonders whether "perhaps violence or at least domination is the true subtext of all sex, straight or gay" (268). This tension between a self-consciousness of the historical nature of desire and an erotic investment in essentialism plays out throughout The Farewell Symphony. Descriptions such as "the red unsheathed fury of the third penis of the afternoon" (68) evoke a particular breed of violent, male sexuality. An obsessive return to the dynamics of domination and submission drives the majority of the sexual encounters in the novel, both in the simple sense of topping and bottoming and more complex sado-masochistic fantasies. There is sometimes a wry self-awareness to this obsession, evident in the narrator's halfjoking contemplation of a lover: "did he want to be a top topped by a still stronger 
top?" (319) Mostly, however, this power play is in earnest: the narrator is emphatic in his celebration of "the simple joy of penetrating and the complex satisfaction of dominating" and "the even more sophisticated pleasure of being dominated". (135) Sex in the novel is charged with an intense awareness, and a celebration of, this masculine model of sexual power relations. It is often violent, "pounding," and "pile-driving" (217), the narrator's "asshole the object of... abusive lust" (128).

For White, this power dynamic is not a simulacrum of heterosexuality but rather its hyper-masculine other. The narrator's encounter with a straight man makes the overtly male nature of this concept of domination explicit and denies its resemblance to a "straight" sexual dynamic. Initially the man "treated me as he'd obviously been trained to treat women, with little fluttering kisses along my brow, a tender tracing of my erect nipple." There follows a palpable shift between malefemale and male-male sexual behaviour, "when he found himself fucking me brutally and slapping my ass, he was so horrified by his violence, and my pleasure, that he hurried into his clothes and still half-undressed, half-erect, ran away". (299) Roleplaying between men takes place in the realm of fantasy, largely stripped of the gendered power relations that complicate heterosexual sexual dynamics. As States of Desire puts it, "the adoration of machismo is intermittent, interchangeable, between parentheses. Today's top is tomorrow's bottom. We are more interested that the ritual be enacted than concerned about which particular role we assume" (268). The sheer freedom of this position is exemplified in the remarkably frank comment from the narrator that - "I made an effort to understand that what for me was an idle if persistent fantasy constituted a real danger to women - but the effort failed, since the minute I contemplated, soberly, disapprovingly, the idea (or the image) of rape, I immediately became aroused" (140). The litany of potential fantasies offered to the narrator by a trick is replete with unsettling racial and incestuous scenarios, "fatherson, sailor-slut, older brother-younger brother, back rapist-white secretary, truckerhitchhiker and a virgin couple on their wedding night" (402). The only scene in which the narrator has an unwanted sexual experience, being forcibly administered an enema by a jealous and violent lover (419), is of a strikingly different character to these playful flirtations with genuine power imbalances and emphasises their status as creative expressions of gay sexuality, however problematic. 
The sexual body in this novel is not queer. White's gay masculinity is often animalistic, at times essentialist, framed by traditional associations of masculinity with dominance and submission. But this model of sexuality is celebrated as a distinct historical product, precise in nature. The sincerity of the novel's investment in this historically specific masculinity resists queerness - this is precisely the understanding of homosexuality which queer theory sought to contest. This male sexuality is not tangential to a discussion of the novel's representation of AIDS. Rather, if the novel is an epidemiological history, then it is precisely these male-male sexual encounters that are central to its depiction of the disease. AIDS in The Farewell Symphony is grounded entirely in the male sexual culture of the 1970s, spread through its sexual networks and devastating the core generation who shaped it. Reading AIDS into The Farewell Symphony requires an unabashed return to the physical realities of transmission: fucking, anal sex. The virus is omnipresent in penetration, the obsession with topping and bottoming: as the narrator later states on the subject of safe sex, "most of the smart gay money lay on the idea that getting come up your ass was fatal and sucking was safe" (467). The crudeness of the language is central here - White lyrically celebrates gay sex but does not shy from its specificity. Importantly, the imbrication of AIDS within the sexual culture of the 1970s is not a moralising move. It is, instead, matter of fact, a square look at the reality of the disease for urban gay men.

"And those luminous eyes, in which an innate, sullen fire seemed to temper the lust of the carnal mouth, just as his cheeks, almost childlike in their innocent, peachy roundness, contrasted with the massive throat so full of manly vigour -"
}

Anonymous - Teleny, or The Reverse of the Medal (135)

The Farewell Symphony considers AIDS directly for less than a quarter of its total length but the disease is omnipresent in the extensive sexual networks mapped by the narrator. White tracks HIV itself. While both critics and White himself have noted the promiscuity of the narrative structure, this structure has not been considered in relation to its representation of AIDS. Davidson describes the work as "digressive and protracted," a "multifaceted and episodic narrative" (44), while Gove argues that the "digressional fragmentations and considerable length of the text... mirror the promiscuity of its subject matter" (181). Nicholas Jenkins describes the 
text as having "almost a nineteenth-century vision of the novel as a 'great web' rather than the thread of an individual's destiny," "proliferating goallessly" as it draws in more and more gay history and anonymous sexual experience (23). White himself imagines the text in relation to the immense, episodic and densely populated medieval Japanese work, The Tale of Genji, only with "twenty, not five hundred" of these sexual encounters (surely an understatement) (Gay Fiction 87). Davidson's observation that this narrative structure serves as a "vernacular, collectivized databank of life histories" (49) is certainly correct but, there is more to the narrative structure than simply historical reconstruction.

Gove positions "the web of these promiscuous tales" (181) as a means of compensating for the narrator's present situation of loss in the mid-1990s and as a way to "hold at bay" the realities of AIDS (182). While it is true that the overwhelming bulk of the text is devoted to detailing the promiscuous seventies rather than the catastrophic eighties, an epidemiological reading of the plot challenges Gove's assumption that the novel avoids AIDS. Near the end of the novel the narrator states: "I've probably been positive since the late seventies, or whenever it all started. You know, they're unfreezing the blood samples of people who participated in a hepatitis study in the late seventies and they're finding that many of them were already positive back then" (497). This detail is historically substantiated and quite probably taken from Randy Shilts' And the Band Played On, which states that a long-running San Francisco hepatitis B study revealed that 4.5 percent of its gay subjects were positive in 1978 and 20 percent by 1980 (553). In fact, the first cases of AIDS in the gay community began to appear in 1979 (Shilts 37). This clinical reality recasts gay history through the lens of AIDS, just as, structurally, the novel foregrounds its historicisation of the post-Stonewall period in the recent death of its narrator's lover. The numerous unprotected sexual encounters of the seventies become a vision of the virus in transmission and the recounting of the narrator's own infection. The narrator observes that, now that most of the men of his generation have died, he finds himself figuratively "fucking the dead" (21) when he masturbates over past lovers. This phrase is starkly literalised in the novel's multiple sexual encounters. HIV has an extended latency period, usually several years, before it rapidly destroys the body's immune system and the novel structurally mirrors this clinical history. The core of the plot consists of recounting the narrator's sexual experiences during this generalised latency period, with the brief, direct 
confrontation with the disease at the novel's end paralleling the accelerated collapse of both the gay male body and a distinct sexual culture. Form mirrors content in a subtle and unexpected way, the male sexual body that preoccupies the narrator informing a biologically driven narrative structure.

White's parade of secondary characters and loosely connected sexual encounters are picaresque and episodic. The novel's plotting is often arbitrary and devoted to an accumulation of what White describes as "half-scenes, quarter-scenes" (Gay Fiction Speaks 91). The narrator is preoccupied by prosaic details of gay culture, its locations and sexual exploits. Moreover, just as a scrap of gossip may prove to be either illuminating or worthless, the events in the novel challenge narratological notions of function and causality. What appears to be a plot comprised largely of "indices," atmospheric and characterising details, is, in another light, replete with more subtle chains of causation. Tracing the trajectory of one of the novel's secondary characters, scattered in a handful of scenes throughout the novel, demonstrates the ways in which sexual encounters are weighted with medical significance. The narrator's account of an orgy contains the almost gossipy observation that - "one man would never join in. He crouched in a corner, naked, chin in hand, despairing as Blake's Job, looking at us with huge eyes" (297). When considered in light of the transmission of HIV, this detail becomes laden with dramatic irony - the exception who dramatizes the potential death of the other participants. Yet, this character unexpectedly re-enters the narrative in the figure of Dennis, the narrator's roommate and former sexual partner Kevin's lover (301), reinserting him into the narrator's nexus of sexual contacts. He again resurfaces when he is revealed to have died of AIDS (391) and is last mentioned in a passage noting that his hitherto unmentioned wife claims he was "infected during a blood transfusion" (486). Dennis becomes emblematic of the multitude of figures which appear in one sex scene and never reappear, leaving only a further link in the epidemiological chain of sexual transmission. In choosing to trace him, the novel gestures towards the multitude of other figures in the epidemiological web mapped by the novel. Moreover, he demonstrates the cumulative manner in which causation establishes itself in the plot, through the retrospective inscription of historical significance onto prosaic detail. 
White's biological representation of the disease, so preoccupied with the unseen virus itself, is substantiated in "Esthetics and Loss." He notes that "death in its submicroscopic, viral, paranoid aspect... shadows every pleasure" (214). This convergence of the clinical and the literary underpins the novel's plot structure and is made explicit in the narrator's calculation that 'if I had sex, say, with an average of three different partners a week from 1962 to 1982 in New York, then that means I fooled around with 3,120 men during my twenty years there" (299). The narrator becomes a node in an epidemiological web, with his sexual encounters clinically enumerated. There is, arguably, a gesture here towards the bestselling non-fictional account of the early years of the AIDS crisis -Shilts' And the Band Played On. The book details the CDC's amazement at the possibility, and the prosaic ordinariness of, having over 2000 sexual partners in a lifetime ("how on earth do they manage that?") (88) Further, the book's most publicised story concerns the so-called "patient zero" of the AIDS crisis in America, the gorgeous, blond Canadian flight attendant Gaetan Dugas who was one of the first, though not the first, to bring the disease to the USA. His role in the crisis centres on the potent image of the epidemiological graph published in a 1984 journal article establishing the sexually transmitted nature of HIV that linked 40 of the first 280 AIDS cases to Dugas in a nexus of sexual contacts (Figure 1). Shilts writes that Dugas "figured he had 250 sexual contacts a year. He'd been involved in gay life for about ten years and easily had had 2,500 sexual partners" (83). ${ }^{2}$ The resonances with The Farewell Symphony are evident, the narrator's phrasing almost directly mirroring Shilts'. Indeed, the novel could easily be quantified in a similar graph of sexual contacts to that depicted here, extending outward from the narrator as "patient zero." The novel's charting of Dennis, the figure emblematic of so many of White's encounters, can be easily transposed into such a graph - the cluster of participants in the orgy linked to one another and Dennis standing apart, only to be reinserted into the chain through Kevin, the intermediary between Dennis and White. One could, in fact, map the entire novel. ${ }^{3}$

\footnotetext{
${ }^{2}$ Dugas has himself appeared in a number of other literary works - including Brad Gooch's The Golden Age of Promiscuity (298-301) and Jane Delynn's short story "Patient Zero". Allan Gurganus' Plays Well With Others is more subtle. It features a scene in which the narrator encounters a French speaking flight attendant - "perfect as any Platinum Aryan poster-maker's hope for his own one son" - at the baths and intuitively rejects his sexual advances, his own "beasty instinct" warning him "NO. Not this one! Wrong move, wrong." (80-81) The protagonist's HIV-negative status is allusively linked to his rejection of Dugas, who becomes emblematic of ominous, unwitting viral transmission.

3 There is a clear visual semblance here to Franco Moretti's work mapping the interactions between literary characters. An epidemiological map of The Farewell Symphony may well resemble one of the spidery graphs in his 'Network Theory, Plot Analysis."
} 
The prosaic, lived reality of the narrator's sexual experience here collides with the public record and the charting of a pandemic. This is history as an archaeology of gossip, transpiring in the bedroom and the body.

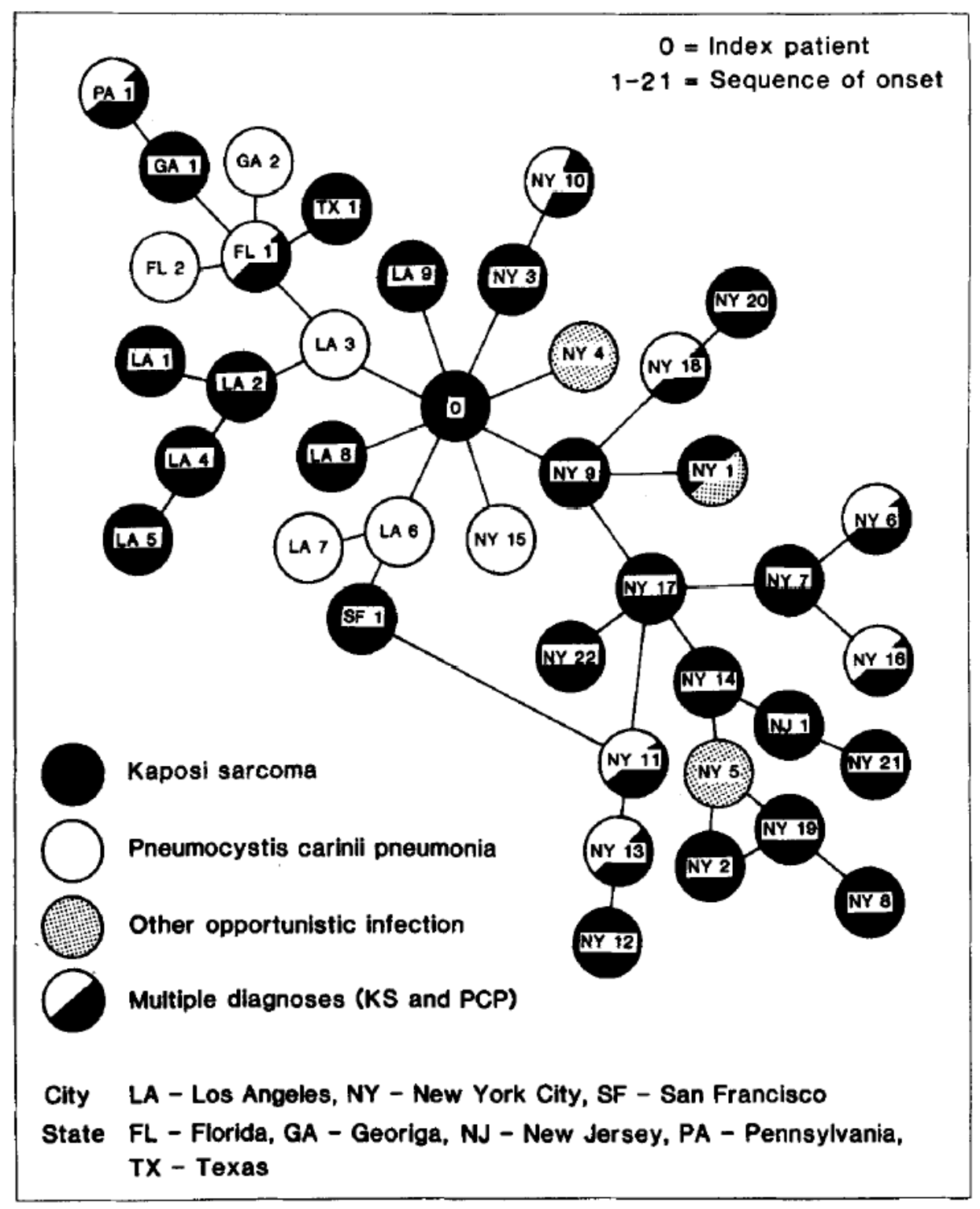

Figure 1: Graph tracing 40 early AIDS cases to Gaetan Dugas.

"Cluster of cases of the acquired immune deficiency syndrome. Patients linked by sexual contact". The American Journal of Medicine 76.3 (1984): 487-92

In "Esthetics and Loss" White declares that for the AIDS writer, "the body becomes central, the body that until recently was at once so natural (athletic, young, casually dressed) and so artificial (pumped up, pierced, ornamented). Now it is feeble, yellowing, infected - or boisterously healthy as a denial of precisely this possibility" (214). This body is an unequivocally gay one ("pumped up, pierced") and 
in The Farewell Symphony it is this body, so obsessively detailed by the narrator, that becomes the site of history. The novel's preoccupation with masculine, gay bodies specifically genitals and bodily fluids - acquires a biological and historical significance. This shift in signification is dealt with explicitly early in the novel,

After I had sex with Rod on the fold-out couch bed, his dog came bounding in and licked our milky stomachs clean. Today even a drop of sperm is rich with death, a mortal culture, but then porno magazines referred to it as a "soothing cream" and we liked to taste it, swallow it, smell it, rub it over our cheeks and murmur with a smile, "The fountain of youth.” (43)

The narrator continues: "if someone had a big cock we called it "The Dick of Death," an expression no one would dare use today"(43). Gay masculinity becomes pathological, a "mortal culture" in both senses of the word. Yet, White never moralises. Again, his preoccupation with semen and penises is matter of fact and serves as a confrontation of the realities of the disease rather than an indictment of promiscuity.

The American edition of The Farewell Symphony erases the only sex scene in the novel in which the transmission of HIV is explicitly acknowledged. (Canning 103) The narrator, who now knows that he is HIV-positive "fucked - no, raped Stanley [a French hustler] without a rubber and came in his ass, the surest way of communicating the virus" (483). He wonders "is Stanley alive today? Or did I murder him? I sometimes think I'll see a vagrant hanging out near the Gare du Nord covered with lesions, his face an old man's" (483). The scene is visceral and challenging to read, turning the narrator's rape fantasies back on himself and replicating Shilts' infamous account of a malevolent Dugas knowingly infecting others. Actual rape is distressing, the worst thing that the narrator does, and illustrates the degree to which the novel's erotic preoccupation with power takes place within the realm of fantasy - it is the erotic play of relative equals. The scene also throws into stark relief the difference between conscious and inadvertent transmission. It highlights the absence of moralising in the encounters that precede the narrator's knowledge of his HIV status. Although I argue that the web of sexual contacts that the novel traces implicate the transmission of HIV, they do so stripped of any imputations of guilt. It is this exception which proves the rule. Larry Kramer

${ }^{4} \mathrm{~A}$ decision White, rightly, attributes to a particular brand of American puritanism. 
condemned The Farewell Symphony's representation of promiscuous sexuality as immoral in the light of the AIDS epidemic, claiming that:- "It is impossible for me to believe that this book embodies what AIDS really represents to Edmund or that this is the kind of tribute he wishes to leave to all his dead friends and lovers... I found this book an irresponsible piece of work indeed" (64). Ironically, Kramer is one of the only critics to be perceptive in recognising that the novel's representation of promiscuous sexuality is the means through which it represents AIDS. However, an analysis of White's only scene of conscious HIV transmission draws attention to how devoid of Kramer's retrospective moralising the novel is. Unprotected sex is Edenic and joyous, clearly written in light of the epidemic but not expecting impossible levels of historical foresight from its characters.

An inversion of values takes place within the novel, resonant with the narrator's encounter with a scholar of Blake's Songs of Innocence and Experience (99), whereby promiscuous sexual experience becomes a marker of innocence. Gay life in the 1970s becomes a pre-lapsarian cultural childhood, simultaneously marked by the unwitting transmission of a deadly epidemic. This is made most explicit in a passage that inverts the popular logic of the 1980s, inscribing the heterosexual body with disease and refiguring the gay one as childlike and robust:

Adult men - all those aggressive, out-of-shape, heavy-breathing heterosexuals - might carry syphilis or at least gonorrhoea in their bodies, we thought, contracted through their drunken, half-hard thrusting, the toil of making money, war, babies. But we were big, bucolic gay boys, and our brief transactions were redolent of summer camp, irresponsible as a groan heard in a shadowy forest or as transfiguring as the mystery of light glowing on a lake glimpsed through a rood-screen of leaves. (43, italics mine)

The narrator's initial confrontation of the possibilities of the sexually transmitted nature of AIDS reads as a lament to this Edenic boyhood:- "could the disease be contained in sperm itself? If so, then we were all lost, since we were bathed, daily, in a sea of sperm" (444). The representation of unsafe sex is oddly childlike: bodily fluids and the possibilities of the anonymous experience are rendered innocent. One encounter finishes with the retrospectively disarming passage: "we laughed and hugged each other and smeared out spit, sperm and urine over each other's bodies" (231). In contrast, experienced, post-AIDS gay culture is comparatively chaste. This 
is exemplified in the novel by the newly popular, and oddly sexless, phone sex line. Its description is desperate, stripped of the celebratory nature of earlier sexual encounters and inscribed with the same "heavy breathing" pathology of the heterosexual male: "seven or eight other men, all shouting out their home numbers or their dimensions or sexual tastes or just listening, breathing heavily" (480). Sex is replaced by masturbation, "fucking the dead," a perverse return to the teenage years that only exaggerates the inversion of sexual values brought about by AIDS. History and societal change plays out on the everyday scale of sexual practice.

David Bergman notes that "just as 'the love that dare not speak its name' became the love that won't stop talking about itself, so, too the disease that no one wished to discuss has become the subject on everyone's lips... To the silence that was death now comes the babel which is itself a plague" (Gaiety 122). This paradoxical relationship between telling and not telling profoundly shapes the rhetoric of AIDS and understandings of its literary representation. The notion that AIDS constitutes a crisis of representation, the point beyond which narration is no longer possible, coexists with the familiar ACTUP slogan "silence = death". This generates a cultural climate that exhorts speech even as it deems it impossible. The persistent notion that AIDS must fundamentally reshape literary form has been noted and White, too, invokes a similar rhetoric in "Esthetics and Loss" when discussing the impossibility of humorous AIDS writing: "humor suggests that AIDS is just another calamity to befall Mother Camp, whereas in truth AIDS is not one more item in a sequence but a rupture in meaning itself' (216). This sense of AIDS as rupture and blockage is shadowed by the equally prevalent notion of an "epidemic of signification" (11), articulated by Paula Treichler, an outpouring of discourse and material on the subject that multiplies exponentially in step with the virus.

This tension between speech and silence is embedded in The Farewell Symphony, a novel that superficially declares itself unable to represent AIDS yet, in many ways, about nothing but AIDS. The idea of a crisis of representation, established from those very first comments about the articulation of the narrator's lover's death being "a challenge I may well fail" (2), is proven to be disingenuous and contradictory. The novel's form itself reflects the tension between telling and not telling - at once realist, lush and detailed, it is also metafictional and self- 
conscious, blurring the boundaries of fiction and autobiography. The conflict within the novel matches conflict in the reception of AIDS fiction - a critical consensus about the limits of speech has co-existed with a preponderance of lengthy, realist and richly detailed novels about AIDS. The novel form, rather than imploding under the weight of the unspeakable, has constituted a primary means of engaging with the crisis. Indeed, White's finely wrought prose becomes an outpouring of speech and detail that attempts fully to capture the pre-AIDS sexual moment, creating Davidson's “vernacular, collectivized databank." White's indebtedness to ideas of a gay sensibility and canonical predecessors such as James, Proust and Wilde emphasises continuity rather than rupture. Moreover, the representation of AIDS through the sexual culture of the 1970s becomes an act of verbal reclamation rather than silence, a resistance of "unremembering." What appears to be evasion is representation itself. In embracing the literary tactics of an older generation, White refuses to self-police memories of a gay past and cultural models situated in the "essentialism" of the gay liberation movement.

The notion of a crisis of representation is perhaps, then, a rhetorical one, akin to the popular Renaissance poetic trope of claiming to be unable to articulate the beauty of a lover, before proceeding to do so at great length. David Bergman writes that "although White criticises himself for being silent about AIDS, it would, perhaps be more accurate to say that AIDS silenced him, that for once the fluency that marked his writing... escaped him" (Violet 249). White toys with this belief in a lack of fluency, questioning “whether I'll have the courage to tell [Brice's] story in this book" and establishing this task as "a challenge I may well fail" (4). Yet while Brice's story is treated sparingly in this novel (only to be taken up again three years later in The Married Man), White's profession of inarticulacy must be understood as a narrative device. The narrator's brief account of Brice's death ends with rhetorical deference to a crisis of representation, "I can't go on," (502). Yet this statement is, remarkably, followed by exactly the events that the narrator claims to be incapable of representing: "I can't tell this story, neither its happy beginning nor its tragic end, the all-night ride through the snowy Atlas mountains in a freezing ambulance, Brice's angry hateful words to me, the look of his face, dead, when I awakened at dawn, his mouth open, his eyes startled, as though he'd seen something dreadful and I'd not been there, conscious to share it with him- " (502) The proliferation of detail is written as a hastily scribbled list, a pretence towards the impossibility of its 
articulation. Yet the dash that finishes the sentence rather than a full stop seems to mark not the limits of what the narrator can say but a wilful and self-censoring end to an overflowing of speech. Metafictional asides on the purpose of the novel and the limits of representation proliferate in the last section of the book and are quite different in nature from the narrator's earlier consideration of the craft of writing; they are instead outwardly focussed and anxious. The purported function of the novel shifts, from the failed project of telling the "histoire" of the narrator's relationship with Brice, to a kind of empathetic activism: "I wanted to see if the old ambition of fiction, to say the most private, uncoded, previously unformulated things, might still work, might once again collar a stranger, look him in the eye, might demand sympathy from this unknown person but also give him sympathy in return" (495). The novel finally becomes "a monument of words for Joshua," the narrator's best friend, a purpose that seems deliberately inadequate - sincere, certainly, but unfit for the novel which it describes. This reaching after purpose and a means of making sense of the text becomes a dramatised crisis of representation. However, as before it seems largely rhetorical.

The representation of AIDS itself in the novel is largely continuous with the language of the preceding chapters. The disease unfurls in the familiar confines of the richly detailed gay everyday that the novel has established - there is no character with AIDS in the novel who is not gay and male. Indeed, the first character in the narrative to "become ill" is a man at the gym, an anonymous yet familiar Clone figure "always snapping towels at buttocks" (364). AIDS plays out on the familiar canvas of the gay male body, which is rendered with the same meticulous prose as in the previous sexual encounters. The specific body parts that were once surprisingly erotic now become the markers of disease, the narrator's description of Brice highlighting "the bulb at the base of his spine where the coccyx had worn through, red and inflamed" (235-236) and "his cheekbones [which] looked as though they'd burst through the translucent yellow parchment of his skin" (236). Just as the narrator's sensual delight in the human body is rendered in terms of unexpected metaphors (with balls like seedless grapes and walnuts), so too is the bodily alienation of AIDS. Joshua is described as having a "face was so white, covered with still whiter patches on the temples, that he seemed carved out of a mushroom, a big pale shelf of mushrooms growing out of the roots of a tree in wet ground" (498). The obsessive lens that was turned on the gay male body "pumped up so 
laboriously" throughout the seventies now records its collapse. The anonymous man at the gym deflates, "all the steroids and food that had made his body so immense melted away, as though a butcher were rendering fat from a prize pig" (442) and the narrator's neighbour "shed[s] the massive body he'd earned through years of lifting weights" (462). AIDS proves representable on remarkably similar terms as the sexual culture that preceded it and does not initiate a wholesale collapse of the aesthetic prose style of the earlier chapters.

The AIDS crisis is situated in the everyday processes of care and bodily functioning, domestic details which are contiguous with realism rather than destructive. This is, arguably, the domain of the novel rather than its antithesis. The Farewell Symphony renders the historical figure of Michel Foucault prosaic, displacing him from a body of theory to a physical body. He becomes "[thin] and [weak] and racked by a constant cough," "trudging back and forth from the kitchen to the salon to serve dinner without vegetables" (465). Complete rupture of the everyday and of narration itself is impossible, even as White rhetorically toys with it. While the novel does not detail the intricacies of caring for the sick at length, when it does the experience is familiar and domestic. White declares himself largely uninterested in detailing the "ups and downs of the illness," a narrative he considers to have been "done so much" (Canning 89). Yet the small sections of the novel which do concern the everyday process of care focus on the prosaic indignity of losing control of the body. He recounts that in his last days Brice "lost control of his body, he was covered in shit," the narrator having to "mop [his lover] up as best [he] could and put him in clean clothes" (502). These spare but affecting "half scenes" of AIDS effortlessly counter the assumption that the disease resists representation. The starkness of the scenes narrating Brice's decline belie the notion of unrepresentability by paradoxically approaching the disease head on in the iteration of facts rather than the self-conscious grappling with the purpose of the narrative. Indeed, the story of "Brice" (itself a representation of White's relationship with Hubert Sorin) is articulated in The Married Man, published just three years after The Farewell Symphony. Here, the "ups and downs" of the disease are articulated in far greater detail and the "failed" challenge of narration is reattempted successfully. 
The Farewell Symphony is a far more sophisticated AIDS novel than it appears. The novel's engagement with the dilemmas of representation obscures and draws out its confrontation with AIDS. The bulk of the plot is devoted to the period directly before AIDS, a fact that is undoubtedly motivated by the act of imaginatively reclaiming this moment in gay history. However, this grounding in the postStonewall moment provides an extended and complex epidemiological history of AIDS. The novel, though it does present AIDS directly, also achieves a remarkably dense plotting of the invisible transmission of HIV as something quite distinct from the familiar narrative of illness and decline which marks the majority of AIDS novels. The form of the novel, its episodic plotting, is directly indebted to both the promiscuous culture of the 1970s and the establishment of a finely wrought, and initially elusive, chain of causation leading directly into the representation of AIDS. The male sexual body, so central to the novel's representation of the gay moment of the 1970s, is also a clinical, biological entity. Genitals and bodily fluids are both lovingly detailed and erotic, as well as harbouring an unseen pathogen. Similarly, the same muscle-bound body is both actively created by Clone culture and wasted by the disease which emerges from it. There is no rupture between the 1970s and the 1980s - the bodies and practices of the sexual revolution constitute AIDS. Moreover, this body and this moment are not queer. The intensely masculine, often essentialist, vision of what constitutes gay, male sexuality resists a queer reading and instead demands an historically grounded treatment. The novel's representation of AIDS occurs within the framework established by post-Stonewall gay culture and must be considered on its terms. The explicitness of the novel's sexuality, its historical and cultural precision, and unapologetically lush realism render a queer reading inappropriate. Hollinghurst, like White, is deeply invested in a constructed canon of gay antecedents and it is in the reapplication of this tradition that a distinctly gay, aesthetic of AIDS can be detected. Further, the fusion of this literary tradition with the post-Stonewall moment creates a way of reading which is, rather than regressive, a move forward to new levels of precision and insight into AIDS writing. 


\title{
The Line of Beauty
}

\author{
"There were times when it appeared to Dorian Gray that the whole of history was merely \\ the record of his own life, not as he had lived it in act and circumstance, but as his \\ imagination had created it for him, as it had been in his brain and in his passions. He felt he \\ had known them all, those strange terrible figures that had passed across the stage of the \\ world and made sin so marvellous, and evil so full of subtlety. It seemed to him in some \\ mysterious way their lives had been his own." \\ Oscar Wilde - The Picture of Dorian Gray (101)
}

As is typical in Alan Hollinghurst's oeuvre, The Line of Beanty is deeply attuned to its relationship with the canon. Hollinghurst's novels actively select and reapply a gay male literary tradition. Just as The Swimming Pool Library takes as its central muse Ronald Firbank, The Line of Beanty is overtly guided by the figure of Henry James. Yet I argue that a second, less explicitly signalled writer is equally important in shaping the novel: Oscar Wilde. The influence of Wilde in the text has not received critical attention but beneath the numerous unambiguous references to James there exists an equally rich series of allusions to both Wilde's work and his biography. The protagonist, Nick Guest's, continual characterisation of his aesthetic persona as Jamesian is, in fact, haunted by the unacknowledged but far more historically correct figure of Wilde. The historically charged tension between these two figures in the text shapes the aesthetic modes with which the novel negotiates the representation of AIDS. The novel's use of a "selective tradition" of curated gay predecessors provides it with specific artistic strategies with which to articulate AIDS. The negotiation of the concept of a "crisis of representation" through the use of the aesthetic frameworks provided by earlier writers secures the disease within the historical context of gay male experience and transcends the concept of inexpressibility in its emphasis on continuities with a gay past. 
"I felt that you would be coming today."

"How so?"

"I had a presentiment."

Anonymous - Teleny, or The Reverse of the Medal (89)

Raymond Williams' concept of the "selective tradition" is a particularly valuable way of understanding the process of gay canon building in The Line of Beauty. Williams argues that the historical archive is constantly winnowed from the time of publication. Nobody, not even "the fastest reader" (50) or the specialist, is capable of absorbing more than a fraction of the material produced in a given time period. Thus any claims about, for example, the nineteenth century novel are a product of selection "for value and emphasis" (50). Most importantly, the resulting selective tradition "will always tend to correspond to its contemporary system of interests and values, for it is not an absolute body of work but a continual selection and interpretation" (52). As such, the canon is far from stable. Rather it is "continual selection and re-selection of ancestors" and involves multiple "reversals and rediscoveries" (52). The process of selection is hard to predict, the future value and relevance of a work largely "unforeseeable" (52). The curation of gay, literary antecedents operates as a further selective tradition within the orthodox canon. Gregory Woods notes that the development of a gay male canon has been undertaken in earnest since the last third of the $19^{\text {th }}$ century (3). It is, indeed, associated with the Oxford of Walter Pater and Wilde himself. Wilde's defence of "the love that dare not speak its name" in the dock cited Plato, Michelangelo and Shakespeare as antecedents, and he shared with Pater and John Addington Symonds the invocation of an Classical Greek tradition of same-sex desire. This process reimagined the canon in accordance with the politics and mores of an emerging homosexual self in the $19^{\text {th }}$ century. This selection of literary antecedents is the active curation and re-application of ways in which to narrate and comprehend the present. ${ }^{1}$

Hollinghurst's writing is a contemporary manifestation of this winnowing process in its signalling towards earlier homosexual writers such as Ronald Firbank,

\footnotetext{
${ }^{1}$ It should not be assumed, however, that this process is indicative of an ahistorical, essentialist homosexuality. Rather, shifting understandings of homosexuality inflect the selection of earlier texts.
} 
E M Forster and James. Aestheticism has been inextricably associated with homosexuality since the Wilde trials, indeed, in The Line of Beanty Nick speaks of himself as being "out" as an aesthete at Oxford (255) and his identification as a "James man" is imagined as "a kind of coming out" (54). The Line of Beauty reiterates the continued centrality of aestheticism to the gay selective canon and its continual resonance with modern understandings of homosexuality. Neil Bartlett's genredefying study of Wilde, Who Was that Man? (1988), articulates an intimate model of the way in which this selective tradition operates in gay literature, and, more speculatively, lived experience. Echoing Wilde’s aphorism that life imitates art, Bartlett traces the uncanny resemblance between Dorian Gray and Alfred Douglas despite Wilde's meeting him after the book's publication. Bartlett asks, “in what sense could I say that Lord Alfred Douglas 'inspired' Dorian Gray, or that Dorian Gray... conspired in the creation of Lord Alfred Douglas?" (197) Extrapolating from these uncanny details, he creates a model of literary prefiguration in which "stories not only record a glittering and disturbed past; they also predicted the details of a sordid and anxious future" (198). Gay men "wrote their own lives in the personae of dead or foreign authors" and develop citational identities crafted from a selective tradition that promised that "it had all happened, in typically similar ways, before" (200). Bartlett describes himself as seeking the face and ancestry of his own lover in Wilde's London (197), just as Symonds read his own life into that of Michelangelo (200) and Wilde wrote "nightmarish burlesques of the very scenes that he was later to play out for real" (208).

Bartlett's sense of a gay selective tradition is both active and personal. It straddles the borderline between the literary and the lived, the historical and the inconsequential. Just as The Line of Beanty's epigraph cites Alice in Wonderland's King of Hearts vacillating between "important - unimportant - unimportant - important," so too does the selective tradition and the novel itself shift between an "archeology of gossip" and mainstream history. James and Wilde serve as gay antecedents according to a "contemporary system of interests and values" - that is their ability to speak to the specific experience of gay men in the 1980s. Hollinghurst has discussed his ongoing struggle to represent AIDS in way that was artistically satisfying ("On Writing" 504) and I argue that it is through the deployment of James and Wilde as distinctly gay, aesthetic models, both stylistically and in a more speculative prefigurative sense, that this artistic problem is resolved. It is through invoking gay 
literary antecedents that Hollinghurst develops a framework for overcoming the now familiar concept of the crisis of representation. Moreover, Nick's representation in the novel presents a study in microcosm of the citational identity building process outlined by Barlett. The use of literary predecessors both grounds the work in a coherent historical narrative of gayness originating in the late-nineteenth century and enables a distinctly personal, "gossipy" sub-history to exist at the margins of the mainstream. Just as the gay canon is extrapolated, in many cases, from the canon, driven by conjecture and biographical speculation, the novel's history of AIDS is driven by the hints and gestures that exist parallel to the familiar historical narrative of Thatcherism.

Writing on The Line of Beauty, Robert MacFarlane cites Michael Wood's comment that the novel offers "a record not of the 'fictional lives of real people' but of the real lives of people who came extraordinarily close to existing" (178). Consequently, the novel operates as a canvas across which numerous shifting referents play, skirting and manipulating historical truth and direct imitation in favour of impressionistic glimpses. Gerald Fedden and the imagined constituency of Barwick appear to slide seamlessly into History and come extraordinarily close to existing. A particularly striking example of this semi-historical imagination is the ghostly presence of Conservative politician Nicholas Eden, son of Prime Minister Anthony Eden, and the first prominent English AIDS casualty. The cause of Eden's death in 1985 was glanced at by the broadsheets, only to be revealed in the tabloids. Complementing this "official” history is Eden's quiet long-term relationship with an antiques dealer (Fraser 11). The resonances between Eden's biographical details and The Line of Beauty are numerous, yet diffused. Indeed, considering the degree to which he was enmeshed in the novel's sphere of interest, the absence of direct reference to Eden in the novel would be surprising if his character was not distributed more widely across the text. Eden's semi-closeted political life in the Conservative party has shades of Nick's flamboyant acquaintance Polly Tompkins, a rising star in the party and, while openly gay among friends, conveniently married to a party staffer. The discreet, but unsuccessful, management of Eden's illness has its clearest correspondence in Wani Ouradi, Nick's wealthy lover. Until the revelation of Wani's illness appears in the popular press, much as Eden's did, “absolute discretion reign[s]" (441). Nevertheless, the limitations of moneyed tact and image management are revealed in both instances. Eden's relationship with an antiques 
dealer is echoed by Nick's first lover Leo and his former partner, antiques dealer Old Pete, both of whom die of AIDS. The presence of Eden is at once insistent and intangible, since there is no one character who corresponds to him, but readily identifiable elements of his biography shift across the text. Official history and gossip both shape the text ("important - unimportant"). The fact, for example, of Eden's relationship with an antiques dealer exists on the very margins of history, as half-forgotten gay knowledge.

This complex patchwork of influence offers a way of reading the influence of James and Wilde on the novel. David James rightly points out that Hollinghurst's tribute to James is not pastiche, since it is "a specific mode of responding actively to Impressionist aesthetics rather than passively rehearsing or mimicking their surface effects" (496). This response to stylistic influence is also true with regard to content. The novel does not (and cannot) simply transpose details of James' or Wilde's fiction into the context of the 1980s and the AIDS epidemic. Rather, as in the case of Nicholas Eden as a historical precedent, the influence of both authors works diffusely and actively to create something recognisably new while retaining key stylistic hallmarks.

As the subject of the protagonist's thesis, James is a continual and explicit presence in the novel. Moreover, James is an integral element of Nick's sense of self, shaping and filtering his experience. Echoing Bartlett's concept of gay men writing "their own lives in the personae of dead or foreign authors," Nick self-consciously constructs a persona as a "James man." Yet Nick's relationship with The Master is often oddly superficial. Any intimation of the details of his thesis is wilfully oblique. Nick states that "he'd developed a reluctance that was Jamesian in itself to say exactly what its subject was" (213). Henry Hitchings notes that the topic of Nick's thesis (style in Henry James) is "suspiciously open-ended" and "more a subject for an old fashioned essay rather than a doctorate" (21). Indeed, Nick's relationship with James is more personal than scholarly since Nick is "at the height of a youthful affair with his writer, in love with his rhythms, his ironies, and his idiosyncrasies, and loving his most idiosyncratic moments best of all" (208). Nick is particularly preoccupied by Jamesian style, particularly the "great unfolding sentences" of the later James (139). But this interest in the formal is largely disconnected from its 
significance. It becomes, as Lord Kessler remarks, "style tout court" (54). There are occasional intimations of a more rigorous engagement with James in Nick's thesis, though references to this are passing and oblique. It is disclosed that "there was a lot to do with hidden sexuality," which suggests that his work may be something like Sedgwick avant la lettre. Further, there are gay tensions surrounding Nick's comment to the Jamesian bachelor Kessler that his primary interest is "style that hides things and reveals things at the same time" (54).

Usually, however, this critical interest is subsumed to the construction of a Jamesian persona through the curation and quotation of James' oblique syntax. The narrator notes that "it was one of Nick's routines to slip... plums of periphrasis from Henry James's late works into unsuitable parts of his conversation” (208). James' comments become gay markers, recycled as descriptors for Nick's sexual conquests. A trick is described as "a trifle too punctually, though not yet lamentably, bald" (207), a nugget whose provenance is revealed to be "from The Outcry... a novel by Henry James that no one's ever heard of” (208). This gleeful sense of mastery and ownership produces a desire to update and "queer" James. Nick wonders of James "if he had fingered so archly at beards and baldness, the fine paired saliences of his own appearance, what flirtings and flutterings might he not have performed to conjure up Ricky's solid eight inches?” (209) His answer - "Oh, it was... of a dimension” (209). Nick's self-consciously stylistic curation of James as a personal archetype is further exemplified in his affected fondness for dictating letters and "improvis[ing] long supple sentences rich in suggestion and syntactic shock, rather as the older Henry James, pacing and declaiming to a typist, had produced his most difficult novels" (396).

Shadowing this aesthetic preoccupation with James is the less obvious, but no less insistent, presence of Wilde. Whereas James is unambiguously introduced into the novel as Nick's “hero" (6), Wilde's name is never mentioned. But references to Wilde are liberally distributed throughout the novel, betraying Nick's occasionally detailed knowledge of his work. An upcoming "trendy" (141) deconstructionist production of Lady Windermere's Fan is mentioned throughout the first section of the novel and enables a glimpse at the extent to which Nick is familiar with Wilde's oeuvre. On the assumption that Toby Fedden's girlfriend Sophie will be playing the titular character, Nick observes to himself that "[he] could see her as the self- 
righteous young wife clipping rose stems in her Westminster drawing room; and delivering those awful soliloquies she has" (129). This attentiveness to the play's content is reinforced when he later learns that "she'd been cast as Lady Agatha, a role which famously contained but the two words 'Yes, mamma" (141). This level of detail reveals a more than glancing familiarity with the text. Nick also echoes Lady Tipper's distaste for a "ghastly" production of Richard Strauss' adaptation of Salome. Finally, Nick quickly recognises Wilde in his identification of the unintentional traces of The Importance of Being Earnest's Lady Bracknell in Gerald Fedden's remark “to lose one child..." (479) The number of these references to Wilde, and Nick's knowledge of his work, establish him as a key, yet deceptively unacknowledged figure in the novel.

Further, the work of identity construction that Nick so self-consciously associates with James is equally, if not more, driven by Wilde. The novel's incessant characterisation of Nick as an aesthete has far stronger cultural resonances with Wilde than James. Both Andrew Eastham and Julie Rivkin note that Nick's equation of Aestheticism with James is somewhat inappropriate. For Eastham, the identification of James with aesthetic autonomy is "common enough" but when placed in the specific context of Aestheticism as a movement, it is "an extraordinary misreading" (510). Rivkin similarly notes that Nick's grounding of his identity as an aesthete in the figure of James is "disingenuous" (289). But neither of these critics explores the role of Wilde in this process of "misreading". Wilde is the archetypal aesthete, far more famously and unequivocally associated with the movement than James, whose relationship with Aestheticism was complex and fraught. Moreover, the concept of Aestheticism as lived experience, a process of self-construction, is indebted to the Wildean sense of the detached, leisured professional critic outlined in "The Critic as Artist". Yet this influence is suppressed by Nick and ironized by the narrator. While Nick engages in a process of identity construction reminiscent of Bartlett's model, his citation of gay antecedents is self-deceptive.

IV

The twin muses of James and Wilde in the novel, one overt and the other covert, are undergirded by a distinct cultural heritage. James was publically hostile towards Oscar Wilde and grew to disavow associations with Aestheticism, despite being identified as an initial proponent of the movement in the United States. Following their first documented meeting in 1882, James described Wilde to a friend as "a 
fatuous fool, a tenth-rate cad" and "an unclean beast," comments Wilde's biographer Ellmann attributes to homosexual anxiety (Wilde 171). Ellmann states that "James's homosexuality was latent, Wilde's was patent" and suspects that James strategically distanced himself from a man and a movement that was becoming too openly homosexual (Wilde 171). This narrative of animosity based on homosexual panic alone has been challenged by Michele Mendelssohn. Mendelssohn has detailed the intensive personal and literary relationship which existed between the two authors, which was characterised by both antipathy and mutual fascination. She notes that James' work can be considered part of an American prehistory of Aestheticism and grappled with its popular incarnation before Wilde remade the movement in his own image (32). Indeed, James had already published The Portrait of a Lady (1881), with its incisive portrait of the morally bankrupt aesthete Gilbert Osmond, by the time he encountered Wilde. Their social worlds "intersected like Venn diagrams" (Mendelssohn 223), as did far more of their cultural concerns than is apparent from James' public statements. Further, both writers demonstrated a long-standing fascination with one other. Wilde actively sought opportunities to review James (Mendelssohn 141) and, while initially praising his work (27), would characterise it as lacking in passion and as drearily realist $(141,135)$.

While initially attracted to Aestheticism and enthusiastic about meeting Wilde, James' personal distaste for him resulted in a series of denunciations. James attended the premiere of Lady Windermere's Fan and found it "infantine... both in subject and form" (Ellmann, Wilde 345) and offered a withering judgement of its author: "the unspeakable one had responded to curtain calls by appearing with a metallic blue carnation in his buttonhole and a cigarette in his fingers" (Ellmann, Wilde 347). More galling was the fact that James' resounding theatrical failure Guy Domville was replaced at the St James Theatre by Wilde's The Importance of Being Earnest (Mendelssohn 163). The Wilde trials appear to have fascinated James, who followed the events in detail and corresponded at length on the subject (Mendelssohn 198). ${ }^{2}$ A letter to Edmund Gosse is emotionally charged and brutally dismissive in its pointed use of inverted commas: "But the fall - from nearly 20 years of a really unique kind of 'brilliant' conspicuity (wit, 'art', conversation - 'one of our 2 or 3 dramatists \&c,') to that sordid prison cell \& this gulf of obscenity over which

2Incidentally, one of the “other" James novels of 2004, Colm Toibin's The Master, deals with this aspect of James and Wilde's relationship in detail. 
the ghoulish public hangs \& gloats - it is beyond utterance of irony or any pang of compassion!" (Mendelssohn 208) Whether homosexual panic motivated James' preoccupation with the Wilde trials is conjectural. However, he did publically disassociate himself from Wilde in refusing to sign a petition to release him from prison early on the grounds of his not having been a close friend (Ellmann, Wilde 463).

This historical relationship is replicated within the narrative of The Line of Beauty. That Wilde is not directly named in the novel is a product of its focalisation through Nick himself. If Nick is appropriating Wildean Aestheticism under the mantle of James, then the lack of acknowledgement of Wilde's influence makes sense. In reiterating James' own misgivings about Lady Windermere's Fan, Nick replicates James' distancing of himself from Wilde. At the same time his knowledge of the play gestures towards a similarly Jamesian fascination with it. This condemnation of Wilde, on a surface level, reinforces Nick's affinity with James. Yet the clear indebtedness of Nick's Aesthetic persona to a Wildean model ironises this moment and rather accentuates his unacknowledged debt. More subtly, the James novel which Nick selects to adapt into film, The Spoils of Poynton, originated in a deliberate erasure of Wildean influence. Conceived of before and written after Wilde's trial, Mendelssohn convincingly argues that the novel was subject to a strategic wiping of references to Wilde in order to diminish any potential drawing of parallels between the authors (197-201). James struggled with the novel for two years, yet four months after the Wilde trials, decided upon the removal of Poynton's treasures as an effective climax to the narrative (201). Mendelssohn attributes this moment of inspiration to the very public bankruptcy auction of Wilde's effects, a suitably Aesthetic collection including rare books, "old Persian carpets" "oriental curiosities" and "old blue and white china," much like the exquisitely tasteful contents of Poynton itself (199). Further, James had initially titled the novel The House Beautiful, a phrase popularised during the late nineteenth century to characterise the tasteful, modern home and a rejection of vulgarity and excessive ornament (Mendelssohn 201, 212). Wilde's 1882 American lecture tour prominently featured an extraordinarily widely publicised talk on "The House Beautiful," which re-appropriated the concept for Aesthetic purposes (Mendelssohn 201-202). The renaming of the novel appears to have been a carefully managed disavowal of connections with Wilde in the wake of his trial, even as its plot is grounded in the 
historical details of his public disgrace. In invoking a novel which in itself is both inspired by and publically rejects Wilde, the novel's representation of Nick's own echoing of this very trope creates a curious, ironic doubling. Bartlett's model of gay literary inheritance - that "it had all happened, in typically similar ways, before" (200) - is relevant. There is something beyond "misreading" at work. Rather, the novel constructs a subtler, unacknowledged interplay of historical tensions and Aesthetic values. The historical relationship between James and Wilde underpins the intertextual one which exists in The Line of Beauty. The distinction between the Aestheticism of James and Wilde is subtle and fraught, splintering along the lines of the relationship between the ethical and the aesthetic. It is precisely this fracture which the novel is most concerned with thematically, and the point on which Nick's misattribution of a Wildean Aestheticism to James is most mistaken.

Nick's self-concept as an aesthete can be better understood as a misattributed Wildean detachment and amoralism than an ironic and subtle Jamesian critical consciousness. It is Wilde the celebrity aesthete, distilling and repackaging the critical work of Pater, Whistler and others, who most resonates with Nick's understanding of Aestheticism in practice. Nick's Aestheticism can often appear scant, flimsy and predicated upon a received, de-historicised version of Wilde. Nick speaks to this idea of Wilde in two quips. In response to a remark from Toby Fedden that "now it all makes sense," Nick replies "Oh, I hope it doesn't make that," prompting the Fedden family to "laugh at his droll murmur and the hint of a paradox" (305). The paradox is a quintessentially Wildean rhetorical gesture. Indeed, it is virtually inextricable from Wilde as the quotable originator of a particular breed of camp humour. Nick echoes the Wildean trope of inverted moral values in his response to Catherine Fedden's confusion of the French delit for delice. Catherine's response to Nick's correction that "delight is delice, delit is a misdemeanour," "well, it's bloody close," is met by Nick's quip that, "well, they often are" (351). Nick feels "rather pleased with himself," a self-satisfaction which suggests his sense of playing the role of the aesthete with aplomb. Aestheticism as a performance of the self, "the ironist as archshowman" as Eastham puts it (510), manifested itself most acutely in Wilde. Further, Wilde as marketable Aestheticism personified is, if anything, more acutely relevant in 
the contemporary period, in which precisely the inverted and playful Wildean wit that Nick emulates has become something of a brand.

The novel's central motif of the ogee curve, the eponymous line of beauty, echoes the celebration of the decorative arts espoused in both "The Critic as Artist" and "The Decay of Lying". Wilde states that, "for the cultivation of temperament, we must turn to the decorative arts: to the arts that touch us, not to the arts that teach us" (2009). He argues that the abstractly formal nature of decorative art is uniquely positioned to act upon the imagination (1009). "The Decay of Lying" identifies decorative art as a sort of instinctive, first principle of human creativity and decries the intrusion of "Life" into the artwork, as it "shatter[s] the perfection of the form" (929). This "worship of form" is almost directly mirrored by Nick in an extended meditation on the line of beauty itself: "the ogee curve was pure expression, decorative not structural; a structure could be made from it, but it supported nothing more than a boss or the cross that topped an onion dome" (200). Art as uselessness and uselessness as virtue, expressed most flippantly in Wilde's epigrammatic preface to The Picture of Dorian Gray, characterises Nick's aesthetic principles more accurately than the typically guarded, Jamesian response to Aestheticism. The persistent focus on furniture and interiors to the novel, which are described, in fact, in much more detail than literary works, solidifies this Wildean preference for the decorative. ${ }^{3}$

Alan Sinfield describes Wilde's own self-fashioning as a synthesis of the aesthete as marginalised bohemian and a decadence of the leisured class (98). In opposition to "middle-class, philistine, masculine practicality," the leisured decadent embodied an effeminate, amoral uselessness dependent on financial solvency (98). Wilde's fusion of class identities are relevant to Nick's own role as pet aesthete to the moneyed. Nick praises his own capacity to integrate into the upper class, observing of his use of Wani's flat: "he felt that he took to it well, the comfort and convenience, the discreet glimpsed world of things that the rich had done for them" (199). This "fantasy of prosperity that he could share" (199) is driven by a firm rejection of his middle-class origins. He is "ashamed of the smallness of [the] drinks" (277) his parents present Gerald and of his father the "elbow-patched old man, with his Volvo estate full of blanket-wrapped mirrors and Windsor chairs" (33). Sinfield

\footnotetext{
${ }^{3}$ As well as toying with familiar notions of the gay man as connoisseur of the decorative, particularly interiors.
} 
notes that "most aristocrats were not interested in art, except perhaps as conspicuous consumption" (99). As such, Wilde's model of the leisured dandy becomes that of artistic adjunct to those with the financial capital to facilitate the removal of the critic from the baser world of "vulgarity and means-ends living" (98). As Bartlett writes of homosexual men in both the late nineteenth and twentiethcentury, this stance is a specifically gay one:

To be a connoisseur is to be a member of an elite - not necessarily the elite of the wealthy, though always close to it in inspiration at least. We may no longer pose as aristocrats; but the crucial point is that we still see ourselves as somehow above or apart from the world of production, licensed to play. There is a new "aristocracy," bigger and easier to enter than the old one (you can do it), one of sensibility, by which I mean one that understands how pleasure works and how it can be obtained. (181)

In keeping with this Victorian (and homosexual) model of aesthetic patronage, Nick's job is essentially that of hired taste for Wani's fledgling vanity Ogee project. The Thatcherite context may be different, with the Ouradis representing the immigrant nouveau-riche, yet the role of aesthete as party to, yet not of, the upper classes persists. This role is made clear in Nick's interaction with Bertrand Ouradi, the model of philistinism, who on hearing that Nick's role was that of "Antoine's aesthete," remarks "well, we need our aesthetes" and "seemed to gesture at the shiny paintings and Empire torcheres as necessary trappings of his position" (209). The integration of the aesthete with the ruling class is not lost on Nick, who imagines that Bertrand "had an aesthete of his own, he seemed to say, on a small retainer" (210).

Wilde's most playfully amoral and aphoristic work offers a framework through which Nick self-consciously constructs his persona and "play[s] the aesthete" (247). "The Critic as Artist" idealises the critic as detached, supremely leisured and morally decadent. Eastham notes that Nick, while citing James' comment that "it is art that makes life," effectively substitutes artistic consumption for creation and becomes instead a "diaphanous site of artistic impressions" (512). For Wilde, the work of art is of less importance than the critical posture itself since "it treats the work of art simply as a starting-point for a new creation" (985). The "aesthetic temperament" is cultivated by inaction: "it is to do nothing that the elect 
exist. Action is limited and relative. Unlimited and absolute is the vision of him who sits at ease and watches" (996) Wilde rejects the possibility of art's coexistence with politics and instead advocates that the aesthete distance themselves from the public sphere: "Who that moves in the stress and turmoil of actual existence, noisy politician, or brawling social reformer... can seriously claim to be able to form a disinterested intellectual judgment about any one thing?" (999) This artistic position is acknowledged to be unpopular and difficult - something of a martyrdom. Yet the concept of the aesthete as part of an intellectual elite, "the flawless type," pervades the essay. Sinfield's association of Aestheticism with the leisure class is manifested in Wilde's demands for an aesthetic autonomy and uselessness that can only be facilitated by external indulgence, claiming of the aesthete that "you must not ask of him to have any aim other than the perfecting of himself' (1010).

Nick's self-styling as a political innocent, oblivious to the realities of money, is highly attuned to Wilde's model of the ideal critic. As with Wilde, the posture is held defensively. It is a shoring up of the perfect state of contemplation in the face of "philistine... practicality." Nick's insistence on his ability to exist at arm's length from the realities of Thatcherism while living in the home of a Conservative MP is the delusion that drives the narrative's eventual collapse. This fallacy is influenced by Wilde's faith in art as escapism: "[art] can help us to leave the age in which we were born, and to pass into other ages, and find ourselves not exiled from their air. It can teach us how to escape from our experience" (998). Again, in conversation with Bertrand Ouradi, Nick is pressed on his thoughts about Gerald's political prospects and responds, “oh - oh, I don't know... I don't know anything about politics” to which Bertrand replies with a twitch "I know you're the bloody aesthete..." (221) This defensiveness is soon restated when questioned about Ogee's finances, with Nick blushing and exclaiming 'I'm the aesthete, remember! I don't know about the money side of things" (223). Nick observes that "Bertrand's little challenges were designed to show him in a very passive light" (223), which emphasises the extent to which Aestheticism has been co-opted by an inescapable "gaying" following the Wilde trials. Similarly, Ouradi touches upon the tenuousness of Wildean uselessness in the neoliberal eighties, jarring as it does with both a Thatcherite valorisation of pragmatic usefulness and conservative homophobia. 
Nick's politics are glanced side-on and characterised by strategic avoidance and ineffectuality. When confronted with Lady Partridge describing a journalist who "talked a lot of rot at dinner on... the coloured question," Nick replies with "generous ambiguity" that "a lot of rot certainly is talked on that subject" (78). When unconstrained by social decorum, in the "eternal secret" of the voting booth, Nick "made his cross very frowningly for the Green man" (394). This gesture of secret and ineffectual political rebellion ("he knew the Conservative was bound to get back in") is not particularly distinct from his earlier evasions. For Nick, this amoralism results in the observation to his lover Leo that "there is a sort of aesthetic poverty about conservatism, isn't there," adding that "that blue's an impossible colour," to which Leo (diplomatically) replies "I wouldn't say that was their main problem" (104). Nick's self-consciously decadent rejection of the ethical in favour of the aesthetic has the ring of Wilde to it, and is intended playfully. Yet it becomes an unsettling gesture in the context of Thatcherism.

I have covered the Wildean aspects of Nick's sense of self in such detail here partly because the resonances have not been noted in the existing scholarship, but primarily to indicate the instability and complexity of the novel's relationship with James. James' position at the forefront of the narrative accentuates the ways in which Nick's attribution of a Wildean Aestheticism to James jars with the conflicted stance that James' novels and criticism take towards the movement. This is not simply a character-building gesture, but rather creates the larger irony of placing an aesthete character who perceives himself as Jamesian, yet is in fact covertly influenced by Wilde, within the wider framework of a novel with a Jamesian moral logic. Nick's own misreading serves as a focal point for the novel's wider engagement with the selective tradition. It introduces a productive tension into the way in which the novel deploys gay predecessors as vehicles for representing AIDS in the twenty first century.

Associating James with Aestheticism is certainly not wrong and Nick's "misreading" of James is a subtle one. James continually returned to the subject across his oeuvre and took a sustained interest in the movement. Beyond simply following the salacious details of the Wilde trial, James read, for example, the work of Pater and considered the movement theoretically (Ellmann, “Aesthetes" 209). 
Both Freedman and Ellmann argue that James' ambivalent stance towards Aestheticism was not a wholescale rejection of the movement but rather disappointment at the lack of a "more convincing advocate" for it (Ellmann, "Aesthetes" 228) and the advancement of his own "surpassing Aestheticism" as an amendment to the pre-existing, inadequate model (Freedman xxi). Jamesian Aestheticism can be remarkably similar to Wilde's. There is a lot of Wilde in his comment in "The Art of Fiction" that "there are bad novels and good novels, as there are bad pictures and good pictures; but that is the only distinction in which I see any meaning" (174). James further insists that "the only obligation to which in advance we may hold a novel without incurring the accusation of being arbitrary, is that it be interesting" (170). There is an unmistakably pithiness here and a clear correspondence with the aphoristic preface of The Picture of Dorian Gray and its assertion that "books are well written, or badly written. That is all" (3).

Nick operates as a Wildean character within a Jamesian narrative, following the precedent set by The Tragic Muse and, to a lesser extent, The Portrait of a Lady and "The Author of Beltraffio". James' most extended representation of Aestheticism is The Tragic Muse, whose aesthete, Gabriel Nash, is generally regarded as a portrait of Wilde (Mendelssohn 117). ${ }^{4}$ As both Kingston and Eric Haralson note, Nash has the “conspicuous and aggressive perfection" of Wilde’s spoken English (James, Tragic 20) and espouses a classically Wildean aesthetic philosophy (Kingston 61, Haralson 191). The reader's first impression of him is of the connoisseur, Nash stating that "we pay too much attention to the ugly; we notice it, we magnify it. The great thing is to leave it alone and encourage the beautiful" (27). In light of James' public stance on Wilde, it is the positivity of the portrayal of Nash which is most striking. Ellmann and Kingston both argue that Nash is allowed to articulately defend himself against the charges often levelled at Wilde (Ellmann, “Aesthetes” 221; Kingston 67). He is, however, socially unstable, "a gentleman, but a gentleman unlike any other gentleman [Biddy] had ever seen" (20). Further, the eventual, quasi-magical dissolution of his unfinished portrait and transient nature of his lifestyle render him marginalised and, at times, barely present in the narrative. This social instability is

\footnotetext{
${ }^{4}$ Some critics have considered him to be a representation of James himself, or a fusion of both men. This instability is of particular note when considering James' ambivalent response to Aestheticism since he nonetheless hovers at the edges of the movement and intersects with it in certain key ways. Nash is physically suggestive of James, "fair and fat and of the middle stature" with "a round face and a short beard, and on his crown a mere reminiscence of hair" (20). Angela Kingston believes this choice to be, once again, suggestive of a desire to distance himself from Wilde (62).
} 
not explicitly condemned by James. Rather, it serves as leverage in Nash's role in bringing out the artistic potential in the novel's hero, Nick Dormer. Yet James does not, indeed cannot, argue that an aesthete (and quite probably homoerotic) figure such as Nash can exist comfortably within mainstream society. Nonetheless, Nash is extraordinarily sympathetically portrayed in light of the personal vehemence James publically displayed towards Wilde.

Conversely, James' more famous aesthete (and villain), Gilbert Osmond, is unambiguously negative. Like Nash, Osmond defies convention: "he suggested, fine gold coin as he was, no stamp nor emblem of the common mintage that provides for general circulation; he was the elegant complicated medal struck off for a special occasion" (202). He is "languid," supremely tasteful, and "dressed as a man dresses who takes little other trouble about it than to have no vulgar things" (202). His central belief, "that life was a matter of connoisseurship," (229) is rendered horrific rather than enlightening. Osmond's disdain for vulgarity and love of beauty generates the acquisitiveness that governs his disastrous marriage to Isabel Archer. Freedman describes Osmond's Aestheticism as a redirection of libidinal energies from healthy objects to the art object, his taste constituting the hollow, amoral centre of his personality (149-150). Similarly, the central aesthete figure of "The Author of Beltraffio," Mark Ambient, is implicated in a ghoulish narrative in which his wife wilfully enables the death of their son in order to prevent his having any influence over him. It has been convincingly argued that it is Ambient's homosexuality which is so threatening (Haralson 195-197), yet the story nonetheless situates a socially disruptive immorality within Ambient's work itself. This representation of Aestheticism as actively hostile - a malevolent presence articulates the fraught ambivalence with which James negotiated the movement. The artistic potentiality of Nash is moderated by the more ominous presence of Osmond and Ambient, limiting the extent to which a positive Aestheticism can be comfortably associated with James.

James' stance on morality - the ways in which the aesthetic and the artistic are inextricably bound to the societal - is more subtle than the simplified Wildean Aestheticism adopted by Nick, or indeed Nash. Like Wilde, James decries Victorian didacticism and, in particular, the fondness for happy endings which constitute "a distribution at the last of prizes, pensions, husbands, wives, babies, millions, 
appended paragraphs and cheerful remarks" (168). This dislike of moralising is wedded less to the stereotype of the morally disinterested aesthete and instead to the artist as a highly attuned and sensitive chronicler of reality. Vivian Jones characterises James' mature concept of the moral as less a concern with morality per se than the paradoxes and dangers of living the moral life (66). In "The Art of Fiction" James states that "the essence of moral energy is to survey the whole field," an expansive authorial sensitivity outlined as such: "it is an immense sensibility... It is the very atmosphere of the mind... it takes to itself the faintest hints of life, it converts the very pulses of the air into revelations" (172). Perhaps the most succinct expression of this moral sensibility is when James notes in his preface to The Portrait of a Lady "the perfect dependence of the 'moral' sense of a work of art on the amount of felt life concerned in producing it" (Art of Fiction 45). "Morality" is not a sufficiently precise term for what James means here since his artistic philosophy differentiates itself from the tediously dogmatic implications of moralism. Rather, the heightened attentiveness of the novelist as master artist and drawer of character generate an awareness of the social currents that shape relationships. Eastham characterises this moral sensibility using James' own concept of “operative irony," a "rich and edifying" mode that "suggests moral certainties from the rhetorical strategy that we might most expect aesthetic ambiguities" (511). This "operative" irony is distinguished from the "inoperative" ironic posture of Aestheticism, identifiable in both the Aesthetic movement of the nineteenth century and the wilful amoralism of Nick himself. It is not the heightened appreciation of beauty itself which James decries but Aestheticism divorced from its context.

Nick's sense of himself is not always attuned to the subtleties of James' moral argument. The novel gestures towards Nick's misreading of the subtleties of James in his response to a particular phrase from the novelist's memoir A Small Boy and Others. As Nick reads the book by the poolside, "he noted droll phrases for later use: 'an oblong farinaceous compound' was James's euphemism for a waffle compound was sublime in its clinching vagueness" (312). This preoccupation with contextless style (style tout court) is similarly applied to James' line describing the impact of the death of Edgar Allan Poe, "the extremity of personal absence had just overtaken him" (313). Nick's delight in the phrase is in its genteel form and repression since, "at times the Master was so tactful he was almost brutal" (313). This phrase, however, is radically re-evaluated by Nick in the light of Leo's death 
from AIDS and develops a hitherto unacknowledged emotional charge: "What was it? The extremity of personal absence had just overtaken him. The words, which once sounded arch and even facetious, were suddenly terrible to him, capricious, wise, and hard. He understood for the first time that they'd been written by someone whose life had been walked through, time and again, by death" (411). This specific incident of Nick actually misreading James points towards the wider implications of misattributing a playful amoralism to James. Yet Nick's "misreading" is more than simply reading James through an inappropriate lens. Rather, it extends to his inability to recognise his own position within the novel's Jamesian moral framework. Nick is allowed to outline the nature of James' moral sensibility, but one of the novel's primary ironic effects is that it is precisely the instances in which he reads James correctly that he fails to recognise himself in them. When asked what James would have made of the guests at the Feddens' dinner party, Nick observes that: "He'd have been very kind to us, he'd have said how wonderful we were and how beautiful we were, he'd have given us all incredibly subtle things to say, and we wouldn't have realised until just before the end that he'd seen right through us" (140). It is notable that Nick's use of the inclusive "us" implicates him in the elite social circle, yet his comments themselves suggest his privileged position as external observer. In both identifying himself with the Fedden's milieu, while recognising his own contingency, Nick enters into a double bind that prohibits his full apprehension of the irony of his statement. Similarly, when asked if James called everyone beautiful and marvellous he responds: “oh, beautiful, magnificent...wonderful. I suppose it's really more what the characters call each other, especially when they're being wicked. In the later books, you know, they do it more and more, when actually they're more and more ugly - in a moral sense" (208). The Line of Beauty is a novel rich in multiple layers of irony and these remarks, which neatly summarises Nick's narrative arc itself, are typical. The novel's relationship with its antecedents is complex and not marked by the simple ironic pattern of Nick's misunderstanding James. Rather it is characterised by ambiguity and the ironic identification of partial-truths. 
The Line of Beanty's negotiation of AIDS through the cultural lens of the late nineteenth century returns us to the familiar concept of the crisis of representation. In a short essay describing the process of writing the novel, Hollinghurst discusses the "artistic problem" of representing AIDS in fiction ("On writing" 504). He describes his relative lack of engagement with the topic before The Line of Beauty not as "resistance to a certain expectation that a gay writer would treat this urgent subject, but more because I couldn't see a way to do it that satisfied me artistically" (504). This comment cites the familiar discourse of a crisis of representation and the insurmountability of AIDS as a viable topic for the literary novel. Although Hollinghurst does not directly discuss the ways in which The Line of Beanty resolved this representational crisis, I argue that it is the deployment of a selective tradition of gay literary ancestors that allows for the negotiation of the topic and effectively refutes the idea of AIDS as unrepresentable. Hollinghurst does state, with regard to The Line of Beauty, that "I did many things that would have horrified the Master, but were not I hope inconsistent with paying homage to him" (506). This statement, though not explicit, is highly suggestive of the potentiality of James (and, as I have argued, Wilde) to be actively redeployed in the context of contemporary gay culture. The novel reimagines those aspects of the authors' work that correspond to the “contemporary system of interests and values". James' own preoccupation with authorial craft, exemplified in the prefaces, is pertinent here. As David James notes, the novel's engagement with James combines an awareness of his role in the gay canon with "a more hands-on view of usable aims" (506). The use of James and Wilde as antecedents offers a practical solution to some of the technical questions attendant on writing AIDS.

This use of literary antecedents is not, however, straightforward. Rather, the novel allows its influences to play and shift upon the text in much the same way as the historical details discovered above. Elaine Showalter, in her study of the correspondences between the fin-de-siècles of the nineteenth and twentieth centuries, suggests that AIDS occupies a position similar to that of syphilis in the late Victorian period (188). While there is certainly a similar clustering of images of deviant sexuality surrounding both diseases, there is nothing in the work of James or Wilde that corresponds to AIDS in this direct a manner. While the discussion of illness in 
The Wings of the Dove and bodily decay in The Picture of Dorian Gray are relevant to AIDS, it is for the patterns and modes of representation that the two authors establish that I read these works in relation to The Line of Beauty. The late nineteenth century (and more specifically the 1890s) has a clear resemblance to the 1980s. Showalter's parallel fin-de-siècles are characterised by a heightened attention to sex and gender, and the constructing of new understandings of homosexuality in particular, as well as a millenarian fear of the apocalyptic consequences of a decadent society (4). Yet the mirror that reflects the fin de siècle is, as Eastham describes it, refracted (516). The reflections of both the literary, biographical and contextual details of Wilde and James manifest themselves in unexpected and inverted ways.

\section{VIII}

It is the moral logic of The Line of Beauty that is properly Jamesian, rather than, as David James puts it, the "mimicking [of] surface effects" (496). While Hollinghurst's prose is certainly "fine writing" it does not replicate the oblique syntax of James. Instead, the novel "re-activat[es] the theories that James put forward in a practical way" (David James 506). The novel is something of a contemporary morality tale and exhibits a clearly plotted rise and fall and a keenly ironic sense of its characters' flaws. Importantly, this plotting is predicated on relatively little "real" action. The most direct reference to a specific work by James in the novel is Nick's observation that: "Rachel was standing by the mantelpiece, Lionel sitting in an armchair, and for a second Nick thought of the scene in The Portrait of a Lady when Isabel discovers her husband sitting while Mme Merle is standing, and sees at once that they are more intimate than she realised" (446). It is precisely this delicately drawn positioning of individuals in relation to one another and the profundity of subtle social interactions which characterises the Jamesian plot in which both nothing and everything happens. The novel briefly refers to "the adverb game," a parlour game that requires participants to perform an action in the manner of a certain adverb, and for those watching to guess the correct verb (396). This game offers something of an analogy to the Jamesian model that Hollinghurst re-appropriates. It is the how that is central, rather than the what, the manner in which an act is performed rather than the act itself.

Similarly, the shape of the novel as a morality tale depends upon this similarly charged minutiae of human interaction. The two central facts of the novel's 
denouement, Gerald's affair with his secretary and Nick's relationship with Wani, are exposed with properly Jamesian lightness of touch (in spite of their decidedly unJamesian sexual nature). It is the sight of "Penny's hand, like an amorous teenager's, tucked in the back pocket of Gerald's trousers" (289), which alerts Nick to their relationship. Similarly, it is the discovery of a "rubber johnny floating in the lav" $(344,455)$ at the Feddens' holiday home which makes Catherine aware of the relationship between Nick and Wani, leading to its eventual exposure in the press. The question of what Nick actually does to warrant his expulsion from the Fedden's home is similarly oblique. During their final confrontation over Nick's leaving the house it is noted that "at no point did Gerald say what he considered Nick actually to have done" (481). Nick is essentially guilty of nothing more than being gay and having a relationship with Wani, and the Feddens already knew the former. It is the publicity and the breach of decorum that shifts the relationship between Nick and the family irrevocably. It is now incorporated into the narrative of "an old homo trick" (481), postulating a class based envy of the Fedden's position and a pseudoFreudian understanding that "they can't breed themselves, they're parasites on the generous fools who can" (477). As in James, action is often limited but highly symbolically loaded. It is the intricate negotiation of what does occur, its passing through the consciousness of the author, which provides the central dynamic of The Line of Beauty.

The strategy of deploying James to represent AIDS is particularly relevant to the centrality of the discovered condom to the novel's plot development. It is far too fraught a sexual detail to constitute a simple transposition of Jamesian style, but instead re-appropriates the subtlety of gesture that characterises James' writing. Further, the condom as a marker of homosexuality is extremely historically bound and implicates the culture of AIDS into the very shape of the narrative arc. Condoms serve as a recurring motif throughout the novel in differentiating between pre- and post- AIDS society and serve to bridge the gap between the summers of 1983 and 1986. One of the first indications of a major rupture in gay culture between the first and second sections of the novel is a remark from an older fellow swimmer at the outdoor baths that "you have to be careful, don't you, with these awful rubber johnnies, I never thought the day would come..." (188) From the second section onward condoms are suddenly unremarked upon and ubiquitous in Nick's sexual encounters, a detail which draws into focus the potential readerly 
distress and dramatic irony that characterises the earlier passages of unprotected sex with Leo. The condom as a marker of the irreparable break between "before" and "after" is again emphasised in Wani's taste in porn. Nick notices that he is watching "what they were already calling a 'classic', from the days before the antiseptic sheen of rubbers were added to the porn palette - Wani had hated that development, he was an aesthete at least in that" (484). This heightened attention to the condom as a marker for a wider shift in gay culture and a shorthand for catastrophe makes the discovery of the "rubber johnny floating in the lav" a highly historicised signifier. An integral part of the cultural baggage of AIDS sets the novel's eventual collapse in motion, weaving AIDS into the (Jamesian) structure of the novel itself.

\section{IX}

\footnotetext{
"In the meanwhile, my story, in veiled words, had appeared in every newspaper. It was too dainty a bit of gossip not to spread about at once like wildfire."
}

Anonymous - Teleny, or The Reverse of the Medal (158)

Nick and Wani resonate strikingly with the figures of Wilde and Lord Alfred Douglas, particularly as articulated in De Profundis. As is typical in The Line of Beanty, correspondences with historical precedents are not simply one-to-one but are dispersed and inexact. These correspondences gesture towards their antecedents even as they warp and shift. Wani and Nick share characteristics of both men. It is in this respect that Bartlett's model of specifically gay prefiguration is most strikingly relevant to The Line of Beauty. The selective tradition has not just a literary impact but, in a curious way, the biographical details of gay antecedents are replicated within the novel. The homosexual domesticity depicted in De Profundis, which is characterised by a fraught relationship with money and patronage and the pursuit of pleasure, in the form of fine dining and rent boys, is reimagined in the Thatcherite context of The Line of Beauty. The novel refracts the historical figures of Douglas and Wilde: Wani is both benefactor and beautiful, though petulant, lover, Nick the financially supported but more seriously literary minded partner.

Taken in isolation, the details that connect Wilde's relationship with Douglas and Nick's with Wani appear tangential. Yet the layering of allusions, combined with the repeated references to Wilde throughout the text, establishes De Profundis as a key ghostly presence in the novel. This is the marginal history, part-gossip, fluctuating 
between the important and the unimportant, that governs the operation of the gay selective tradition. The historical details that the novel echoes from Wilde's life are not literary but domestic. When outlining the financial costs of their relationship, Wilde tells Douglas that "I spent on you more than $f^{5} 500$ in actual money" (50), a detail that recurs in The Line of Beauty in the scene in which Wani "sat down, plucked the top off his Mont Blanc and made out a cheque to Nicholas Guest for $£, 5000$ ”, (201). The specificity of this detail suggests a relationship with De Profundis which is more than merely passing. Indeed, the dynamic of benefactor and recipient plays out throughout the novel, Wani characterising their relationship to Tristao, their threesome partner with the aside, "Nick? He's just a slut... He takes my money" (387). Further, Wani's own tastes replicate a preference for rent boys, the "blackmailing companions" who steal Wilde's letters to Douglas from his suit pockets (83). Just as "Douglas was fascinated by young men who for a few pounds and a good dinner would prostitute themselves" (Ellmann, Wilde 366), Wani's sexual fantasies centre on the figure of the, preferably heterosexual, rent boy. Nick, explaining his proclivities to Catherine, cites his fondness for threesomes - "he gets me to pick people up for him. Or we get a rent boy in, you know" (352) - and, while talking with Bertrand, mischievously recalls "the skinhead rent boy they'd had in last week for a threesome" (249). Wani's aristocratic fascination with rough trade in particular echoes the "rough but ready boys" (Ellmann, "Oscar Wilde" 368) favoured by Wilde and Douglas. It is with a particular delight that he suggests to Nick that a man at the ponds "could be a lot of fun... I should have thought. He's very common" (190)

The hedonism of Nick and Wani's relationship is of particular note. Wilde's central lament to Douglas in De Profundis is the wilful frittering of his money on fine dining and luxury, stating that "out of reckless dinners with you nothing remains but the memory that too much was eaten and too much was drunk" (51). In light of Wani's illness, Nick recalls their own experiences in an elite restaurant: "thinking of nights here the year before, both cubicles sometimes carelessly busy with the crackle of paper and patter of credit card... the nights sped by in unrememberable brilliance" (437). The detail of memory loss strikingly connects the two passages. Both recount the bankruptcy of the relationship at its height in the aftermath of tragedy, in Wilde's case his imprisonment and in Nick's Wani's impending death. Further, Wani's family dynamic recalls that of Douglas'. Nick's characterisation of 
Bertrand, when explaining the need to keep the relationship secret, is telling: "his father's a psychopath" (345). The resonances with the monstrous Marquess of Queensberry are apparent, even more so in the revelation that Wani's elder brother died when he was "knocked down by a lorry in the street, in Beirut" (281). For Nick, this incident comes to represent "the family mystery, hardly glimpsed, far stronger and darker than their little sexual conspiracy" (281). Similarly, Douglas' elder brother died prematurely and supposedly accidentally; he was "found dead in a ditch with his gun lying discharged beside him" ("De Profundis" 66). The correspondences between the two family situations serve to consolidate the existing parallels between the biographical and the fictional relationships, even if they have limited relevance in themselves.

These parallels generate a potent narrative of prefiguration, the sense that "this has all happened before". Perhaps the most memorable section of the unexpurgated De Profundis is its recounting of Wilde's and Douglas' successive illnesses. While visiting Brighton, Douglas contracted influenza and Wilde, by his account, "waited on you, and tended you, not merely with every luxury of fruit, flowers, presents, books, and the like that money can procure, but with that affection, tenderness and love that, whatever you may think, is not to be procured with money" (62). When Wilde himself subsequently fell ill, Douglas "le[ft] me entirely alone, without attendance, without anything" (62), lamenting that "I had really robbed you of your desire for more enjoyments, and diminished your actual capacity for fresh delights" (63). Wilde's request for attention is deemed pathetic by Douglas, who declares that "it was an ugly moment for you... uglier than you imagine" (65). Wilde fixates upon the heartless remark from a subsequent letter from Douglas that: "when you are not on your pedestal you are not interesting. The next time you are ill I will go away at once" (65, italics Wilde's). Douglas' contemptuous response to illness and its compromise of the hedonistic pattern of their relationship weighs upon The Line of Beauty's representation of disease. The novel represents only Wani's sickness and, albeit briefly, Nick's role in caring for him, which mirrors the first half of De Profundis but establishes a historical precedent for the subsequent reversal of circumstances. Both Wilde and Douglas recover from their illness and there is no clear-cut correspondence here. Yet the prospect of Nick falling ill himself is strikingly foreshadowed by this intertextual relationship and weighs upon the final scene of Nick's intuitive sense that his HIV test will be positive. Nick's disgrace 
similarly resonates with Wilde's biography, as the public disclosure of his homosexuality in the news media forcing his expulsion from elite society.

The use of De Profundis, a text that in many ways charts the collapse of Wilde's Aesthetic philosophy, as an intertextual referent adds to the layers of irony that shape the novel's stance towards history. In De Profundis, Wilde re-evaluated the very philosophies that shape Nick's sense of self and recognised that "I used to live entirely for pleasure. I shunned suffering and sorrow of every kind. I hated both. I resolved to ignore them as far as possible: to treat them, that is to say, as modes of imperfection. They were not part of my scheme of life. They had no place in my philosophy" (109). His assertion of the centrality of suffering to the human experience and the bankruptcy of the purely aesthetic mode constitutes a striking reversal of the received, decadent Wilde: "Prosperity, pleasure and success, may be rough of grain and common in fibre, but sorrow is the most sensitive of all created things. There is nothing that stirs in the whole world of thought to which sorrow does not vibrate in terrible and exquisite pulsation" (91). In crafting a Wildean sense of self but disavowing its origins, Nick prohibits himself from the apprehension of the entirety of the Wildean canon. The novel's allusions to De Profundis create further layers of irony in a narrative already rich with ironic complexity, placing Nick and Wani in the position of Wilde and Douglas before the Fall (as it were), unaware of the pre-existing narrative pattern presented by Wilde's later work. As in James' work, the aesthetic posture is revealed as morally limited in the face of wider ethical and political concerns. Wilde's assertion that suffering constitutes the necessary counterpoint to pleasure and that the record of human experience be sufficiently attuned to darker complexity corresponds to the Jamesian concept of moral logic.

\section{$\mathrm{X}$}

'Well, on faded damask couches, on huge pillows made out of priest's stoles, worked by devout fingers in silver and in gold, on soft Persian and Syrian divans, on lion and panther rugs, on mattresses covered over with a variety of cat's skins, men, young and good-looking, almost naked, were lounging by twos and threes, grouped in attitudes of the most consummate lewdness."

Anonymous - Teleny, or The Reverse of the Medal (114)

The fictional depiction of the materiality of AIDS is a central representational difficulty of the "artistic problem" of AIDS. It is regarding the diseased body itself 
that the productive tension established between James and Wilde throughout The Line of Beauty is particularly potent. Both writers offer two strikingly different approaches to the diseased body. As practical models for the craft of writing bodily decay, they cannot comfortably co-exist within a single work. James' most detailed portrait of disease, The Wings of the Dove, offers a determinedly non-physical depiction of illness that resists both diagnosis and any description of the disease's bodily effects. Wilde's most iconic work of fiction, The Picture of Dorian Gray, on the other hand, obsessively centres on the image of bodily decay. While James' approach to disease is generalised, Wilde's is historically grounded and charged with the sexual politics of an emergent modern homosexuality. The negotiation of both authors within The Line of Beanty speaks to the wider question of representing AIDS as a historically specific, gay male phenomenon - replete with contextual and bodily detail - and the converse desire to integrate the disease into universalising narratives of illness and death.

In spite of a proliferation of theories as to the "correct" diagnosis of The Wings of the Dove's Milly Theale, the specific disease that kills her is wilfully absent from the novel. Writing in 1894, James' notebook outlines the germ of the story by describing a heroine "suddenly condemned to death (by consumption, heart-disease, or whatever)" (Wings 511). The lack of import placed on the nature of the disease is unchanged in the novel itself. James' focus is on the machinations of the human relationships that cluster around the figure of the sick young woman and the existential matter of the prospect of death for a "young creature... on the threshold of a life that has seemed boundless" (511). Diagnosis is deliberately withheld from both the reader and the majority of the characters. Milly is struck (but seemingly untroubled by) the fact that the famous doctor Sir Luke Strett "hadn't after all pronounced her anything" (179). The closest that the novel comes to diagnosis is the speculative conversation between Kate Croy and Merton Densher. Merton's question "is it a bad case of lungs?" met by Kate's conjecture that it is "not lungs, I think. Isn't consumption, taken in time, now curable?” (254) Their conclusion that Milly simply has something "past patching" is of greater importance to the narrative. It is not what she has but "if her case was grave" (180), if she will "at any rate suffer" (176) that is relevant. James treats the actual practice of medicine with the lightest touch, particularly in the striking scenes of Milly's consultations with Sir Luke in which the medical relationship is reimagined as a friendship. The reader only sees Sir 
Luke's advising Milly to "live" (176), to "make up your mind to [happiness]" and "accept any form in which happiness may come" (173). Milly attributes a kind of telepathic genius to Sir Luke and states that "he asked me scarcely anything - he doesn't need to do anything so stupid" (165). Specific clinical care is only gestured at in Sir Luke's scant and ambiguous request to "obey a small prescription or two that will be made clear to you" (175). Kate's comment that Milly "won't smell, as it were, of drugs, she won't taste, as it were, of medicine. No one will know" (255), is the key assertion of the immateriality of disease in the novel. The bodily experience of disease is buried, by Milly herself as well as in the narrative discourse, and suffering is witnessed second-hand.

In contrast, The Picture of Dorian Gray's central fixation is the visibly decaying body. The visual focus engendered by the painting at its heart continually underscores the visible, bodily manifestations of age and sin. Unlike James' delicate shaping of the negative space around the body, the body itself figures centrally in Wilde's novel. Dorian is meticulously described, both as erotic object and as monstrously decayed. Dorian's predictions of the fate of his portrait become an extended listing of the physical markers of age and decay:

-the cheeks would become hollow or flaccid. Yellow crow's feet would creep round the fading eyes and make them horrible. The hair would lose its brightness, the mouth would gape or droop, would be foolish or gross, as the mouths of old men are. There would be a wrinkled throat, the cold, blueveined hands, the twisted body- (86)

Similar, detailed lists of the physical attributes of the portrait recur throughout the novel, maintaining the obsessive visual presence of the body. Although describing, in this case, an imagined figure or a portrait, Wilde's description is highly tactile: flaccid, wrinkled skin suggests the feeling of the body under the fingers, whilst the twisted body conveys a body alive and in motion. Dorian's actions are manifested in very precise physiological changes in the portrait, the death of Sibyl Vane specifically "warp [ing] his red lips" (64) and "marring the fine lines of the mouth" (74). While Dorian is not suffering from any particular illness, Wilde's attention to these highly specific manifestations of decay nonetheless evokes the listing of symptoms. 
Unlike Wilde's obsession with physicality, James' approach to illness is interested in the negative space that surrounds the object, the drawing of disease without reference to the thing itself. James' stylistic approach is aptly characterised by his brother William as the attempt:

-to avoid naming it straight, but by dint of breathing and sighing all round and round it, to arouse in the reader who may have had a similar perception already (Heaven help him if he hasn't!) the illusion of a solid object, made... wholly out of implacable materials, air and the prismatic interferences of light, ingeniously focused by mirrors upon empty space. (qtd. Richard Poirier 10)

This model of Jamesian style is of particular relevance when representing AIDS in fiction, which brings with it expectations of unspeakableness. The idea that AIDS cannot be spoken at all is clearly false, yet it is the oblique and the slantways that often dominates both authors' depiction of the disease. In his preface to The Wings of the Dove, James acknowledges similar ideas that illness is unrepresentable and expresses his hesitancy at "the placing in the strongest light a person infirm and ill a case sure to prove difficult and to require much handling” (Art of Fiction 289). James suggests that as subject matter, illness is "one of those chances for good taste, possibly even for the play of the very best in the world, that are not only always to be invoked and cultivated, but that are absolutely to be jumped at from the moment they make a sign" (Art of Fiction 289). In line with the assertion in "The Art of Fiction" that the novelist be free to treat any subject they wish, James argues, not against the representation of illness due to its difficulty, but for it for precisely this reason. Reimagined in this way, the fictional representation of AIDS becomes a testing ground for craft and subtlety - dramatically shifting the focus of the novel to the aesthetic. AIDS is a spur to art rather than its silencing.

The novel's representation of AIDS simply cannot have the same level of ambiguity as The Wings of the Dove, it is far too historically grounded, yet it must negotiate similar aesthetic questions. While the first sections of the novel are lavish in their meticulous descriptions of the erotic body, the ill body is glanced sidelong. Instead, in the case of Leo and Wani, the novel outlines the space around its ill characters. Sigrun Meinig has observed the similarities between the representation of illness in the two novels, but her case can be expanded (53). The scene in which the 
reader first encounters a sick Wani echoes The Wings of the Dove in that it is the reactions of others, the negative space surrounding Wani, which outlines his condition. Nick is interrupted just before he is able to explain Wani's condition to the film producers they are dining with and his appearance marked instead by their murmured "Oh my god..." (429) As in The Wings of the Dove, the magnitude of Wani's condition is conveyed through his effect on other people. Wani "command[s] attention now by pity and respect as he once had by beauty and charm. The claim to attention was constant, but it had turned fiercer and quieter" (431). James' representation of the bodily effects of disease is similarly mediated. Merton Densher's final revelation as to the physical nature of Milly's suffering, though second-hand, is the closest the novel comes to articulating it: "the facts of physical suffering, of incurable pain, of the chance grimly narrowed, had been made, at a stroke, intense, and this was to be the way he was now to feel them" (432).

The Line of Beauty's prose is noticeably spare in its minimal representation of Wani's condition. The detail of Wani now walking with a stick relies on the casualness of its delivery for its emotive impact, as we discover merely that a waiter holds "his stick for him as she helped him off with his coat" (429). The absence of adornment and explanation is as brutal as it is prosaic in its indication of how weakened Wani now is. Physical details now lack the sensuality of both the earlier erotic passages and the Wildean model of representing physical decay. While still attuned to physical sensation, the detail of Nick feeling "the knobs of [Wani's] spine through the wool of his suit" is stark and unadorned (429). The novel manages the tension between acknowledging the specific nature of AIDS and retaining the obliqueness of the Jamesian model in phrases designed to catch the reader who, as William James describes, "may have had a similar perception already." Wani's face is "gaunt and blotched" (432) and suggests Kaposi's Sarcoma to the reader familiar with the symptomology of AIDS but with a level of ambiguity that stops short of an extended clinical description. ${ }^{5}$

While James' scenes of diagnosis and medical care make little or no mention of disease itself, The Line of Beanty nearly excludes these scenes altogether. The reader encounters Wani's illness fully formed - it emerges in the gap between the second and third sections. There is very little discussion of the prosaic realities of medical

${ }^{5}$ A common opportunistic infection in AIDS patients, Kaposi's Sarcoma is a skin cancer which manifests as darkened lesions on the skin. 
care. The closest that the novel allows the reader is Nick and Wani's "most intimate moment for many months" when Wani brings up his nouveau cuisine in the restaurant bathroom and Nick "wonder[s] if he should wipe Wani's face for him" (437). Wani's nurse, resentfully paid "a thousand pounds a minute," is dismissed as "madly left-wing" and though "candid and practical, fired up by the crisis of AIDS" he is treated with the disdain of hired help (485). The transposition of the medical relationship into the social register resonates with Milly's insistent characterisation of Sir Luke as confidante and friend. Nick's own diagnosis is purely speculative, a projected future, and, coming at the very end of the novel, is not confirmed. Nick's prediction of his diagnosis is purely intuitive: "it came over him that the test would be positive" (500). It resembles Milly's intuitions of mortality before visiting Sir Luke, most pointedly her revelation that "I shall never be better than this" in front of the Bronzino portrait which uncannily resembles her and yet is "dead, dead, dead" (157). Nick's imagined diagnosis is the most direct confrontation of his own relationship with AIDS in the novel, yet it too evades the specific. Instead, in panning outward to the imagined interior of the doctor's office, the narrative focuses on the space around the fact of the diagnosis, "breathing and sighing all round and round it". Nick imagines that "the words that were said every day to others would be said to him, in that quiet consulting room whose desk and carpet and square modern armchair would share indissolubly in the moment. There was a large tranquil photograph in a frame, and a view of the hospital chimney from the window" (500) The echoes of The Wings of the Dove are again pertinent. Milly's attention to the "commodious "handsome" room" filled with "brawny Victorian bronzes" characterises her consultation with Sir Luke (169). As in The Line of Beauty, the furniture acquires an emotive resonance inextricable from the disease itself. Milly's own consulting room closes in upon her and initiates her into the world of the mortally ill: "she had come to see the world, and this then was to be the world's light, the rich dusk of a London 'back', these the world's walls, those the world's curtains and carpet" (169).

This use of interiors as a vector for emotional conflict plays out across the novel. The Line of Beauty's insistent focus on furniture and interior design again reiterates the tension between materiality and the negative space that surrounds objects. The same split between physicality and empty space, the object and the response to it, which characterised James and Wilde's writing of the body, manifests 
itself in their representation of things. While Nick celebrates The Spoils of Poynton as "a novel about furniture," it is, in fact, marked by an avoidance of the specific materiality of the actual spoils. Fleda's first sighting of Poynton is characterised by a far more Jamesian focus on the affective properties of the house than the contents themselves, although these are acknowledged as the epitome of late nineteenthcentury taste. While there are references to "the brasses that Louis Quinze might have thumbed... Venetian velvets just held in a loving palm" (19), the house is more often described in terms of its mistresses' sensibility and as a manifestation of eclecticism, taste and intuitive style. The house is "the record of a life" and the expression of the self in the "art of the treasure-hunter, in selection and comparison refined to that point" (18). In contrast, The Picture of Dorian Gray contains a near obsessive cataloguing of objects. In passages that become tedious in their wealth of detail, Wilde meticulously outlines the perfumes, jewels and textiles collected by Dorian. In contrast to James' understated “old velvet brocade" (7, 52), Wilde describes a "cope... of green velvet, embroidered with heart shaped groups of acanthus-leaves, from which spread long-stemmed white blossoms, the details of which were picked out with silver thread and coloured crystals" $(11,97)$.

While conscious of the societal context of class dynamics and vagaries of taste, Nick's responses to objects are swept along by a Wildean sensual appreciation of materiality and detail. Furniture, as filtered through Nick, is described in terms of surface and touch, with a particular emphasis on the gilded and lacquered. Mirrors are a perennial motif in the novel and MacFarlane notes that this also extends to reflective, gleaming surfaces. He cites references to "dark polished wood," "the glassy polish of the table top," "gleaming red veneer" and "gilt ballroom chairs" (180). Indeed, one of the first things we learn about Nick is that "like his hero Henry James... he could 'stand a great deal of gilt."' $(6)^{6}$ Nick's tenuous position as a class outsider, the aesthete as hired taste, renders his appreciation of the material trappings of wealth more self-conscious and detailed than that of the upper classes. Bartlett characterises the practice of listing and collecting in Wilde's writing as a specifically gay strategy and an expression of lack: "can a list ever actually give us the pleasures it describes and promises, or can it only ever seek to choke the hunger that gapes beneath it by amassing a junkshop of unconvincing details?" (175) Rather, "all its verbal luxuries actually achieve is to remind us that this is not enough" (175). This

${ }^{6}$ The pun, in light of later events, is obvious. 
cataloguing of objects is almost pornographic or at least, "the activity of the listing itself is erotic" (177). Bartlett suggests that the explicitly sexual bodies of Teleny, a pornographic novel attributed to Wilde, constitutes the unspoken extension of the sumptuous lists of The Picture of Dorian Gray: "after the succession of furnishings and objets d'art, this is surely the missing chapter of The Picture of Dorian Gray, the chapter Wilde could never write, the key to Dorian's kleptomania, the true source of our hunger" (178). In the context of AIDS, Nick's Wildean focus on the materiality of furniture becomes an indirect way of articulating the explicitly gay, ill body and suggests the details of bodily decay that the narrative evades.

As in The Wings of the Dove, death happens offstage in The Line of Beauty. James delivers the fact of his central character's death through Merton's discovery in a London street that "our dear dove then, as Kate calls her, has folded her wonderful wings" (473). Similarly, Nick learns of Leo's death through his sister and his access to the event is further mediated through photographs. The act of viewing the photographs is described - "he looked at a couple of the pictures and then handed them back" (405) - yet their contents remain obscured. When Nick later recalls them, the narrative continues to avoid specific bodily details and instead describes Leo's facial expressions and a more generalised ill body: "he'd been sixty for a week before he died. He was in bed, in a sky-blue hospital gown; his face was hard to read, since AIDS had taken it and written its message of terror and exhaustion on it; against which Leo seemed frailly to assert his own character in a doubtful half smile" (410). While the visual representation of death is obscured, Leo's death is accompanied by a heightened attention to the material surroundings of Wani's flat, where Nick receives Leo's sister and learns of his death. The flat, once a gleaming archetype of contemporary, postmodern design, "full of eclectic features, lime-wood pediments, coloured glass, surprising apertures" (199), is radically reframed in the light of the news. Now, "the piping on the sofa cushions was rubbed through where Wani had sprawled incessantly in front of the video. The crimson damask was blotted with his own and other boys' fluids" (410), the latter detail rich in allusive significance in the context of AIDS. The virus, or at least its potential vehicle, has permeated the interior itself. Further, "Nick felt furious with Wani for fucking up the cushions. The Georgian desk was marked with drink stains and razor etchings that even the optimistic Don Guest would have found it hard to disguise" (410). That Wani's flat represents one of the few contemporary interiors in the novel 
allows the disease to be located within the present day and highlights the inability of the novel to fully replicate the ahistorical representation of disease in The Wings of the Dove. The premature decay of the furniture of Wani's flat, only a few years old, is far more symbolically redolent of AIDS than the antiques that proliferate in the interiors of the Feddens. Nick's attentiveness to the irreparable damage to Wani's possessions becomes a way of confronting materiality. His tactile response to the furniture prompts him fully to experience his grief at Leo's death: "Nick fingered the little abrasions and found himself gasping and whooping with grief' (410). The language here is sexual and redolent of AIDS, recalling the "abrasions" through which the virus enters the body. Wani "fucks up" the cushions. The furniture comes to stand in for Leo's undescribed body, glimpsed second-hand through photographs, and the unseen body of Wani himself. It is almost directly after this description of Wani's decaying possessions, as Nick writes a letter to Leo's mother, that he considers that he may soon be "sitting down to write a similar letter to the denizens of Lowndes Square" (411), Wani's parental home. This is the first reference the novel makes to Wani's illness. Its juxtaposition with the symbolically loaded discussion of material objects intimates Wani's radically altered body, contributing an allusive richness to the sidelong glimpses afforded in later scenes.

XI

As evidenced by the novel's recourse to the Wildean regard for the material when confronted by the physicality of AIDS, the Jamesian narrative model is not sufficient in articulating the specific, historically bound nature of the disease. Instead, there is a tension between the figures of Wilde and James and their cultural significance as markers of the explicitly and implicitly gay. AIDS is a social disease, in contrast with the highly individualised decline of Milly Theale, which limits the potential for The Wings of the Dove to serve as a complete literary model. Nick's misattributed Aestheticism can be seen as a defensive strategy in light of the cultural politics that underscore the literary and personal relationship between James and Wilde. While Sinfield argues that Wilde is a key, if not the primary, originator of the very shape of modern homosexual culture (2-3), James' sexuality has been consistently characterised as repressed, conflicted and unconsummated. Ellmann states that we "cannot be sure that he had a sex life in any customary meaning of the term" (“Aesthetes" 209), whilst Haralson quotes Lynda Zwinger's comment about "the 
sexuality James' sex would have had had he had any" (193). This closeted, latent sexuality is far more socially manageable an archetype for Nick than the exuberance now associated with Wilde's homosexuality. While the word "aesthete" certainly carries a codified series of cultural associations (effeminacy, homosexuality, idleness), to detach this persona from the more traditional Wilde and attach it to James as Nick does, is, as Eastham notes, "partly to conceal his gay identity" (512). The conservative, upper class milieu of the novel facilitates such a gesture, which in the world of what Nick calls "actually existing gayness" (106) would seem old-fashioned and illogical. The literary and sexual politics of Wilde and James have obviously shifted since the late nineteenth century, yet within The Line of Beauty the conflict that underpins their historical relationship survives into the contemporary moment remarkably whole. The invocation of James becomes a way of existing within the highly charged and socially rigorous environment of a Conservative MP and his aristocratic wife and a way of annulling the more strikingly dissident sexuality of Wilde in favour of the fraught and celibate Master.

Nick's sense of himself as a gay man is, at least initially, old-fashioned. It is framed by Whitmanesque "radiant images of gay activity, gathering in a golden future for him, like swimmers on a sunlit bank" (25). Further, "proper queens, whom he applauded and feared and hesitantly imitated, seemed often to find something wrong with him" (26). Before exploring London's contemporary gay scene, James mediates and contains Nick's coming out process. He is "out" as an aesthete and a James man before he is as gay. In the first section of the novel gay sex is repeatedly characterised as "vulgar and unsafe," but at first by Rachel Fedden with regard to the exposure of an MP's liaison with a rent boy (25). The phrase is repeated three more times as a sort of coda for the intrusion of gay sexuality into the rigorous confines of the Fedden's social world. It comes to describe the prospect of bringing Leo home (34), the act itself (174) and finally Nick's cruising at a public bathroom the afternoon before the Feddens host the Prime Minister (370). It is suitably Jamesian, at least with regard to the received concept of his sexuality as closeted, rigorously discreet and unconsummated. It is the public exposure of homosexuality, rather than its existence itself, which causes Nick's disgrace.

Nick's strategic positing of Jamesian homosexuality, mediated by decorum and strict social management, is abruptly challenged by the presence of AIDS. When 
Leo's sister, Rosemary, seeks to trace all of his sexual contacts, the task distresses Nick in its "angular attention to business". Nick discovers that "his shyness and resentment went for nothing in the new moral atmosphere, like that of a hospital, where everything was found out" (400). AIDS cannot be subsumed by familiar strategic obfuscations, made obvious in the revelation of the cause of gay family friend Pat Grayson's death in spite of Rachel's carefully management of information (335). Rosemary's presentation of the sheaf of envelopes Leo received in response to his personal ad confronts Nick with a microcosmic view of the wider gay community. The disease is newly visible as a distinct entity moving through a web of sexual contacts. A chain of transmission is established: Leo's last lover Bradley is revealed to be unwell and old Pete's death is confirmed. (402) Nick's own position in this chain is painfully apparent, in spite of his response that "I'm fine. I was lucky. And then I was...careful.” (402)

Nick's inextricability from the epidemiology of AIDS only accentuates his prior evasion of it. His breakup with Leo, unremarked upon until this point, is revealed to have been his shying away from the realities of the disease. The fiction of Leo dumping him is "the painful story he'd told himself at the time, to screen a glimpse he'd had of a much worse story, that Leo was ill” (401). The retreat from "actually existing gayness" into Wani's closeted, elite social world is re-emphasised as a mode of escapism and an evasion of the urgency of the gay cultural moment. Before his diagnosis, Wani treats AIDS with customary disdain. He is "courteous but cold" in replying to the question of whether he'd known George, the figure whose death is remarked on at the baths, stating simply that "I've never been here before" (182). The callousness of his reaction, swiftly followed by Nick's change of subject, "how's the water?" (182), indicates the wilful avoidance that shapes both Nick and Wani's initial response to the disease. Perhaps the novel's most painful moment is Nick's avoiding a patently ill Leo at a pub, an event which is, again, only disclosed after his death. Nick sees a figure who reminds him of Leo, only to find "a sadness in the likeness". The man is "much too skinny, really, to excite him" (423). Nick's sexual appraisal is brutal in its dismissal of the physical manifestations of AIDS. The realisation that the figure is, in fact, Leo, newly gaunt and greying, prompts Nick to ignore him with "simply an instinct, a reflex, that made him turn away" (424). Nick acknowledges this automatic desire to absent himself from the 
"grim doubts about what was happening to him" to be cowardly and yet it is consistent with Nick's prior evasion of the disease.

Nick's discussion of safe sex with the insensitive, wealthy Tippers is notable in its difference from Nick's usual disengagement with the wider politics of AIDS. Nick defuses the conservative narrative of the inevitability of AIDS in a quietly elegant manner: “even if you know it's going to happen, it doesn't make it any less awful when it does" (338). In contrast to his cowardly avoidance of Leo, Nick is strikingly brave here. The subject is painful, and Nick raises the possibility of avoiding it: "He felt the large subject massing, with its logic and momentum. There would be the social strain of coming out to such people in such a place, and the wider matter of AIDS concerning them all, more or less" (339). The decision to engage the repugnant Tippers with a level-headed frankness is one of Nick's most laudable actions, particularly in his subtle normalisation of his own homosexuality: "it's a hard way to have to learn... but yes, we are learning to be safe" (339). The contrast between this scene and the strategic evasion of the disease throughout the rest of the novel emphasises the general absence of a more nuanced and sensitive engagement with the disease as a social force.

Nick's general unwillingness to directly confront the disease presents, in a novel written primarily in free indirect discourse, the artistic problem of representing AIDS in its wider context. Of the two authors who shape the narrative, Wilde's writing offers a far more viable model of representing explicitly gay experience than James's. Sinfield's characterisation of Wilde as our primary cultural referent for modern homosexuality enables his narrative strategies to better correspond, in this case, to the "contemporary system of interests and values". Wilde represents Dorian's physical degeneration, at least in part, as the product of a dissident homosexuality outlined using the familiar narrative mode of gossip. Basil Hallward's lengthy listing of Dorian's activities is quite literally an "archeology of gossip," arrived at via a network of contacts and disclosures. Basil asks "why is it that so many gentlemen in London will neither go to your house nor invite you to theirs?" and reveals that when told by "Lord Staveley" that "you were a man whom no pure-minded girl should be allowed to know" he discovers that Dorian's actions were "horrible!" (104) The sexual indiscretion alluded to in this accusation is heightened by further intimation of homosexuality. Basil asks "why is your friendship so fatal to young 
men?" (104) He then lists Dorian's sexual contacts who are, importantly for their reimagining in the context of AIDS, marked by death and disgrace:

There was that wretched boy in the Guards who committed suicide. You were his great friend. There was Sir Henry Ashton, who had to leave England, with a tarnished name. You and he were inseparable. What about Adrian Singleton, and his dreadful end? What about Lord Kent's only son, and his career?... What about the young Duke of Perth? What sort of life has he got now? What gentleman would associate with him? (104-105)

This list contains both the minor character of Adrian Singleton and men who exist in name only and represent a clandestine homosexual culture. The list is also, as Bartlett notes "dangerously topical and almost specific" in its allusion to the Cleveland Street scandal - the 1889 discovery of a homosexual brothel frequented by the aristocracy "that... featured boys in the Guards and a disgraced Lord who had to leave England" (Bartlett 112). Homosexual culture again emerges through the medium of gossip and half-truths, existing on the margins of orthodox history.

The Wildean approach to detailing London's gay culture via the medium of gossip and allusion is evident in the novel's treatment of the impact of AIDS on the wider gay community. The first character to die of AIDS is, as in The Farewell Symphony, an anonymous character in the gay social circle. Another bather at the outdoor baths tells Nick that "George has gone, then. Steve's just told me, went last night" (182), a comment that replicates the chains of hearsay that outline Dorian's sexual activities. The novel, while taking place within the context of the gay culture of the 1980s, largely hones its focus onto Nick's individualised experience. The novel's intimation of the emergence of AIDS within the community is shaped by hints and gestures, reliant upon the reader's capacity to integrate subtle cues with a body of gay cultural knowledge. The first suggestion of AIDS in the novel is Leo being "a bit off colour" with a "chesty thing... [he] couldn't seem to shake... off" (101). This knowledge adds an ominous weight to the next disclosure that his exlover has "not been well, old Pete" (102). Pete later appears with "drawn features" and causes Nick to remember "that Pete had been ill, though he didn't know in what way" (109). These details serve as gossipy fragments of the disease's emergence and are reliant upon the historical hindsight of the informed reader. 
The most emblematic figure of the impact of AIDS on the gay community is "the Spaniard," a semi-anonymous character of no relevance to the wider plot who, like the figures cited by Basil Hallward, becomes indicative of a pattern of decline and death. Nick first interacts with this figure at the ponds and he, appropriately, engages him on a point of gossip: “don't I see you at Bang last week?” Nick struggles to recognise him:

- it took him a moment to realise that he used to see him at the Y, last year perhaps, in the showers there; and a moment more to confirm that as Nick had grown slowly and unseriously heavier, the Spaniard, if that's what he was, black-haired and lean, with large rosy nipples, had grown perceptibly thinner, into an eerily beautiful, etched-out version of himself - (186)

Nick reads him as a confrontational figure who is wilful in his appearance in public while visibly ill and who seems "to challenge him to see it, but not to allude to it in any way, unless by a lingering, fearful glance" (186). Like the gestures towards illness in the first section, AIDS is not named and instead, its implication relies upon readerly nous. As in the case of the similarly emblematic minor character, Dennis, in The Farewell Symphony, the Spaniard's reappearance in the narrative is unexpected. Amongst the responses to Leo's personal ad, Nick finds “a Spanish guy who'd turned up everywhere, who'd been a nice dark thread in the pattern of Nick's early gym days and bar nights, almost an emblem of the scene for him, its routine and compulsion, and he knew he must be dead" (405). His role as stand-in for the gay community is now directly acknowledged and apprehended through a gay network of gossip and hints.

While James' representation of illness informs the depiction of the disease, Jamesian aesthetics are inadequate to articulating the social experience of AIDS. Wilde's covert presence in the text serves as a reminder of the historically bound specifics of gay culture beneath Nick's attempted ahistorical and decorous homosexuality. The recourse to Wildean methods of lavish detailing and the articulation of homosexual culture through the mode of gossip enables the novel to gesture towards the broader social experience of AIDS. Wilde's unacknowledged presence is particularly relevant in the novel's recourse to interiors as a proxy for the inability to articulate the ill 
body. Nick's acknowledgement of Wilde is suppressed and evaded. Its emergence in the form of a partial adherence to the Wildean aesthetic of lavish detailing is therefore apt. AIDS cannot be articulated solely through the individualising framework of The Wings of the Dove, though its negotiation of the traumatic physicality of AIDS offers a limited aesthetic strategy for the novel's representation of individual sickness. The historical conflict and mutual fascination between the figures of James and Wilde generates a productive tension within the novel's aesthetics, continually bringing into focus the novel's negotiation of both universality and historically bound homosexuality. Moreover, the narrative resonates with the highly personal concept of historical precedents outlined by Bartlett in its parallels with the biographical details of De Profundis. As a means of negotiating AIDS, the concept that this has all happened before allows the disease to enter a wider gay cultural narrative. The selective tradition generates continuity, placing Hollinghurst in relation to the constantly winnowed and reimagined model of gay literary inheritance, and by extension, gay history itself.

The question of morality, specifically the more expansive and subtle Jamesian variety, is particularly fraught with regard to the treatment of AIDS. Dogmatic moralising is, as in James' fiction and Wilde's criticism, artistically irrelevant. While the novel deals with a pattern of decadence and its traumatic aftermath (reminiscent of cultural narratives of the fin-de-siècle), the placement of the crudely moralising statement "I mean they must have seen it coming" (338) in the mouth of the crass Sally Tipper emphasises the extent to which this is not a narrative that seeks to attribute AIDS to any specific moral cause. While Nick's narrative arc is a clear indictment of the privileging of the aesthetic over the political realities of Thatcherism, AIDS is containable within a similarly clear-cut moral framework. Rather, as in James, the actions of the characters, their interpersonal dynamics and the tragedy of the disease itself are passed, as it were, through the author's moral consciousness. The novel's explicit signalling of a gay selective tradition exaggerates artistry and places the aesthetic of the novel at the forefront of the reader's engagement with the text. As David James argues, the text moves beyond postmodernism to something with more integrity and sincerity than pastiche. James suggests that it is "not against James's oeuvre that we should measure Hollinghurst's work, but against James's theories of what fiction can still become" (504). The novel's reassertion of the capacities of the moral consciousness of the author 
become a way of reasserting the integrity and viability of the realist novel after postmodernism. The novel (and its "morality") is not regressive, but rather forward thinking. It is intertextual without succumbing to the superficialities of the postmodern metafictional narrative. The representation of AIDS is neither a source of melodrama, moralism nor inarticulacy. Rather, it is negotiated through a selfaware engagement with the selective tradition, a look backwards which becomes a means of articulating a disease of the contemporary period. 


\section{Conclusion}

"There they seemed to be looking for somebody, for they either turned round and scanned the persons they met, or stared at men seated on the benches that are along the quay."

Anonymous - Teleny, or The Reverse of the Medal (78)

One notices, in the last few years, a clustering of films attempting to represent and narrate the AIDS epidemic. What is it, precisely, that has engendered this collective return to the AIDS moment? Why, in 2014, film The Normal Heart, a work situated in the highly specific political wrangling of early AIDS organisations? If queer theory is reimagined as not simply an intellectual development but a historically contingent rejection of a gay past, then this return could signal that, perhaps, we are ready to be gay once more. This is not a question of simply doubling back, or, indeed, working through queer theory. It is, much like Hollinghurst's relationship with a selective gay tradition, a looping, circling play of historical and cultural referents. We can strip the critical enterprise of anxiety over essentialism and hegemonic gay culture, if only for a moment, and instead inhabit this world. The continuity of a gay aesthetic and culture is potent rather than debilitating. Gay ancestors can be mobilised, toyed with, lingered over, their echoes traced. They can help us stage a return to openly gay male writing. We can return once more to gay bodies, gay aesthetics. While AIDS may have precipitated the disconnection between the present moment and a gay past, a return to gay male AIDS writing can also be a means of bridging the gap.

Much of my project has been one of imaginative reconstruction. I have traced the ghostly outlines of gay New York and gay London. Gay history is in the skeletons of the Hudson piers, the traces of the Mineshaft lurking behind newly renovated boutiques, now, even, in the empty AIDS ward of the recently closed St Vincent's Hospital. It takes place in the outlines of Nicholas Eden, the knowledge that this place was once the Everard Baths. It is a process of tapping into a collective cache of gay memories and half-secrets. A return to the moment of the 1970s and ' 80 s need not romanticise or moralise. This return is neither a desire for a utopian vision of sexual possibility nor a condemnation of essentialism and hedonism. It is, though, immersive and affective. This is, after all, a lost world. AIDS is one of the great traumas of the twentieth-century: in total, over 300,000 gay men have died from AIDS in the United States. (Centers for Disease Control) Truly, these men are a lost generation and a re-appropriation of the language of the First World War feels 
justified. AIDS effected the devastatingly precise elimination of a radical and unprecedented sexual culture.

These men have a right to beauty. An aesthetic, affective approach to the literature of AIDS honours a culture which embraces the beautiful. Theodor Adorno's suggestion that an aversion to aestheticism is the product of a "petit bourgeois hatred of sex" (256), might also be applied to the critical aversion to both the aesthetic appraisal of AIDS writing and overtly gay male literary eroticism. Further, the ethics of AIDS literature returns us to Adorno's aporia, trapped between the need to write suffering and the inevitability of its aestheticisation:

The so-called artistic rendering of the naked physical pain of those who were beaten down with rifle butts contains, however distantly, the possibility that pleasure can be squeezed from it... The aesthetic stylistic principle, and even the chorus's solemn prayer, makes the unthinkable appear to have had some meaning; it becomes transfigured, something of its horror removed. By this alone an injustice is done the victims, yet no art that avoided the victims could stand up to the demand of justice. (252)

In the case of the AIDS novel, it is precisely in the aesthetic itself that justice is done. An immersive, obsessive interest in the aesthetics and bodies of a lost world is a loving act. Beauty - style even - is not discontinuous with representing AIDS, but necessary to its reimagining. 


\section{Works Cited}

Adorno, Theodor W. "Commitment." Can One Live After Auschwitz?: A Philosophical Reader. Ed. Rolf Tiedemann. Stanford: Stanford UP, 2003. 240-258. Print.

Auerbach, D.M, W.W. Darrow, H.W. Jaffe, and J.W. Curran. "Cluster of Cases of the Acquired Immune Deficiency Syndrome. Patients Linked by Sexual Contact". The American Journal of Medicine 76.3 (1984): 487-92. Print.

Barthes, Roland. A Lover's Discourse. Trans. Richard Howard. New York: Hill, 1978.

---. “An Introduction to the Structural Analysis of Language.” New Literary History 6.2 (1975): 237-272. Print.

---. Roland Barthes. Trans. Richard Howard. New York: Farrar, 1977. Print.

Bartlett, Neil. Who Was That Man?: A Present for Mr Oscar Wilde. London: Penguin, 1988. Print.

Bergman, David. Gaiety Transfigured: Gay Self Representation in American Literature. Madison: U of Wisconsin P, 1991. Print.

---. The Violet Hour: The Violet Quill and the Making of Gay Culture. New York: Columbia UP, 2004. Print.

Bersani, Leo. Homos. Cambridge: Harvard UP, 1995. Print.

---. "Is the Rectum a Grave?" AIDS: Cultural Analysis, Cultural Activism. Ed. Douglas Crimp. Cambridge: MIT Press, 1987. 197-222. Print.

Best, Stephen and Sharon Marcus. "Surface Reading: An Introduction." Representations 108 (2009): 1-21. Print.

Cady, Joseph. "Immersive and Counterimmersive Writing About AIDS: The Achievement of Paul Monette's Love Alone." Writing AIDS. Ed. Timothy F. Murphy and Suzanne Poirier. New York: Columbia UP, 1993. 244-264. Print.

Canning, Richard. Gay Fiction Speaks. New York: Columbia UP, 2000. Print. 
---. "The Literature of AIDS." The Cambridge Companion to Gay and Lesbian Writing.

Ed. Hugh Stevens. Cambridge: Cambridge UP, 2011. 132-147. Print.

Castiglia, Christopher and Christopher Reed. If Memory Serves: Gay Men, AIDS and the Promise of the Queer Past. Minneapolis: U of Minnesota P, 2012. Print.

Centers for Disease Control. "HIV in the United States: At A Glance." Centers for Disease Control. 25 Nov 2014. Web. 19 February 2015.

Cunningham, Michael. The Hours. New York : Farrar, 1998. Print.

Davidson, Guy. Queer Commodities: Contemporary US Fiction, Consumer Capitalism, and Gay and Lesbian Subcultures. New York: Palgrave Macmillan, 2012. Print.

Dellamora, Richard. Apocalyptic Overtones: Sexual Politics and the Sense of an Ending. New Brunswick: Rutgers UP, 1994. Print.

DeLynn, Jane. "Patient Zero". Vital Signs: Essential AIDS Fiction. Ed. Richard Canning. Cambridge: Carroll, 2007. 293-304. Print.

Denneny, Richard. "AIDS Writing and Gay Culture.” Confronting AIDS Through Literature: The Responsibilities of Representation. Ed. Judith Pastore. Urbana: U of Illinois P, 1993. 36-54. Print.

Eastham, Andrew. "Inoperative Ironies: Jamesian Aestheticism and Postmodern Culture in Alan Hollinghurst's The Line of Beauty." Textual Practice 20.3 (2006): 509-527. Print.

Edelman, Lee. "The Mirror and the Tank." Writing AIDS. Ed. Timothy F. Murphy and Suzanne Poirier. New York: Columbia UP, 1993. 9-37. Print.

---. "The Plague of Discourse: Politics, Literary Theory, and AIDS.” The Postmodern Turn: New perspectives on social theory. Ed. Steven Seidman. Cambridge: Cambridge UP, 1994. 299-312. Print.

Ellmann, Richard. "Henry James Among the Aesthetes." Proceedings of the British Academy 69. (1983): 209-228. Print.

---.Oscar Wilde. London: Penguin, 1988. Print. 
Felman, Shoshana and Laub, Dori. Testimony: Crises of Witnessing in Literature, Psychoanalysis and History. New York: Routledge, 1992. Print.

Ferro, Robert. Second Son. New York: Crown, 1988. Print.

Fraser, John. "Secrecy Over Earl's Death Strengthens AIDS Theory." Globe and Mail 27 Aug 1985: 11. Print.

Freedman, Jonathan. Professions of Taste: Henry James, British Aestheticism, and Commodity Culture. Stanford: Stanford UP, 1990. Print.

Garcia, Tristan. Hate: A Romance. London: Faber, 2011. Print.

Golding, Paul. Senseless. London: Picador, 2004. Print.

Gooch, Brad. The Golden Age of Promiscuity. New York: Knopf, 1996. Print.

Gunn, Thom. The Man with Night Sweats. London: Faber, 1992. Print.

Gurganus, Allan. Plays Well With Others. New York: Knopf, 1997. Print.

Halperin, David M. How to be Gay. Cambridge: Harvard UP, 2012. Print.

Haralson, Eric. “The Elusive Queerness of Henry James' 'Queer Comrade': Reading Gabriel Nash of The Tragic Muse." Victorian Sexual Dissidence. Ed. Richard Dellamora. Chicago: U of Chicago P, 1999. 191-210. Print.

Hitchings, Henry. “The Double Curve.” TLS 5271 (2004): 21-22. Print.

Holleran, Andrew. Chronicle of a Plague, Revisited: AIDS and Its Aftermath. New York: Da Capo, 2008. Print.

Hollinghurst, Alan. "Alan Hollinghurst on Writing The Line of Beauty." The Line of Beauty. London: Picador, 2004. 504-506. Print.

---.The Line of Beauty. London: Picador, 2004. Print.

---. The Swimming Pool Library. London: Chatto, 1988. Print.

Jagose, Annemarie. Queer Theory: An Introduction. New York: New York UP, 1996. Print. 
James, David. "Integrity After Metafiction." Twentieth Century Literature 57.3 (2011): 492-515. Print.

James, Henry. The Art of Criticism: Henry James on the Theory and the Practice of Fiction. Ed. William Veeder and Susan M Griffin. Chicago: U of Chicago P, 1986. Print.

---.The Art of the Novel: Critical Prefaces. New York: Scribner's, 1937. Print.

---. "The Author of Beltraffio.” 1884. Collected Stories: Volume One. London: Campbell, 1999. 729-776. Print.

---. The Portrait of a Lady. 1881. Ware: Wordsworth Editions, 1996. Print.

---. “The Spoils of Poynton.” 1897. London: Penguin, 1971. Print.

---. The Tragic Muse. 1890. London: Penguin, 1982. Print.

Jenkins, Nicholas. “Elegiac Allemande.” TLS 4909 (1997): 23. Print.

Jones, Vivien. James the Critic. London: MacMillan, 1985. Print.

Kakutani, Michiko. "For Gay Writers, Sad Stories.” New York Times. 12 Mar 1993. C1, C29. Print.

Kingston, Angela. Oscar Wilde as a Character in Victorian Fiction. New York: Palgrave Macmillan, 2007. Print.

Kramer, Larry. The Normal Heart. 1985. London: Hern, 2011. Print.

---. “Queer Theory's Heist of Our History.” The Gay \& Lesbian Review Worldwide 16.5 (2009): 11-13. Print.

---. "Sex and Sensibility." The Advocate 734 (1997): 59-70. Print.

Kruger, Steven F. AIDS Narratives: Gender and Sexuality, Fiction and Science. New York: Garland, 1996. Print.

Kushner, Tony. Angels in America: A Gay Fantasia on National Themes. 1991-1992. New York: Theatre Communications Group, 2003. Print. 
Lesjak, Carolyn. "Reading Dialectically." Literary Materialisms. Ed. Mathias Milges and Emilio Sauri. New York: Palgrave Macmillan, 2013. 17-47. Print.

Luckhurst, Roger. The Trauma Question. Abingdon: Routledge, 2008. Print.

MacFarlane, Robert. "Alan Hollinghurst, The Line of Beauty." The Good of the Novel. Ed. Liam McIlvanney and Ray Ryan. London: Faber, 2011. 170-185. Print.

Mars-Jones, Adam and Edmund White. The Darker Proof: Stories from a Crisis. London: Faber, 1987. Print.

Mars-Jones, Adam. Monopolies of Loss. London: Faber, 1992. Print.

McRuer, Robert. The Queer Renaissance: Contemporary American Literature and the Reinvention of Lesbian and Gay Identities. New York: New York UP, 1997. Print.

Meinig, Sigrun. "Out of Line: Illness and Aesthetics in Alan Hollinghurst's The Line of Beauty and Henry James' The Wings of the Dove." Interfaces 26 (2006-2007): 47-58. Print.

Mendelssohn, Michele. Henry James, Oscar Wilde and Aesthetic Culture. Edinburgh: Edinburgh UP, 2007. Print.

Miller, D.A. Bringing Out Roland Barthes. Berkeley: U of California P, 1992. Print.

---. “Sontag's Urbanity." October 49 (1989): 91-101. Print.

Monette, Paul. Afterlife. New York: Crown, 1990. Print.

---. Borrowed Time: An AIDS Memoir. San Diego: Harcourt, 1988. Print.

---. Halfway Home. New York: Crown, 1991. Print.

---. Love Alone: Eighteen Elegies for Rog. New York: St. Martin's, 1989. Print.

Moore, Patrick. Beyond Shame: Reclaiming The Abandoned History of Radical Gay Sexuality. Boston: Beacon, 2004. Print.

Moretti, Franco. “Network Theory, Plot Analysis.” New Left Review 68 (2011): 80102. Print. 
Murphy, Timothy F. "Testimony.” Writing AIDS. Ed. Timothy F. Murphy and Suzanne Poirier. New York: Columbia UP, 1993. 306-320. Print.

Pastore, Judith. Introduction. Confronting AIDS Through Literature: The Responsibilities of Representation. Ed. Judith Pastore. Urbana: U of Illinois P, 1993. 1-12. Print.

---. "What are the Responsibilities of Representing AIDS?" Confronting AIDS Through Literature: The Responsibilities of Representation. Ed. Judith Pastore. Urbana: U of Illinois P, 1993. 15-35. Print.

Pearl, Monica B. AIDS Literature and Gay Identity: The Literature of Loss. New York: Routledge, 2013. Print.

Penney, James. After Queer Theory: The Limits of Sexual Politics. London: Pluto, 2014. Print.

Picano, Felice. Like People in History. New York: Viking, 1995. Print.

Poirier, Richard. “In Praise of Vagueness.” LRB 17.24 (1995): 10-12. Print.

Poirier, Suzanne. Introduction. Writing AIDS. Ed. Timothy F. Murphy and Suzanne Poirier. New York: Columbia UP, 1993. 1-8. Print.

Radel, Nicholas. Understanding Edmund White. Columbia: University of South Carolina Press, 2013. Print.

Reed, Paul. Facing It: A Novel of AIDS. San Francisco: Gay Sunshine, 1984. Print. Rivkin, Julie. "Writing the Gay '80s with Henry James: David Leavitt's A Place I've Never Been and Alan Hollinghurst's The Line of Beauty." The Henry James Review 26.3 (2005): 282-292. Print.

Schaefer, Max. Children of the Sun. London: Granta, 2011. Print.

Sedgwick, Eve Kosofsky. Epistemology of the Closet. Berkeley: U of California P, 1990. Print.

---.ed. Novel Gazing: Queer Readings in Fiction. Durham: Duke UP, 1997. Print.

---. "Queer and Now." Tendencies. London: Routledge, 1994. 1-20. Print.

Self, Will. Dorian. London: Viking, 2002. Print. 
Shaw, Harry E. Narrating Reality: Austen, Scott, Eliot. Ithaca: Cornell UP, 1999. Print.

Shilts, Randy. And the Band Played On: Politics, People and the AIDS Epidemic. London: Penguin, 1987. Print.

Showalter, Elaine. Sexual Anarchy: Gender and Culture at the Fin de Siècle. New York: Viking, 1990. Print.

Sinfield, Alan. The Wilde Century: Effeminacy, Oscar Wilde and the Queer Moment. New York: Columbia UP, 1994. Print.

Sontag, Susan. Against Interpretation, and Other Essays. London: Deutsch, 1987. Print.

---. AIDS and Its Metaphors. New York: Farrar, 1989. Print.

Stevens, Hugh. "Normality and Queerness in Gay Fiction." The Cambridge Companion to Gay and Lesbian Writing. Ed. Hugh Stevens. Cambridge: Cambridge UP, 2011. 81-96. Print.

Teleny, or The Reverse of the Medal. 1893. Ware: Wordsworth, 1995. Print.

Toibin, Colm. The Master. London: Picador, 2004.

Treichler, Paula A. How to Have Theory in an Epidemic. Durham: Duke UP, 1999. Print.

Watney, Simon. Policing Desire: Pornography, AIDS and the Media. London: Comedia, 1987. Print.

Weir, John. The Irreversible Decline of Eddy Socket. Los Angeles: Allison, 1989. Print.

White, Edmund and Charles Silverstein. The Joy of Gay Sex. New York: Crown, 1977. Print.

White, Edmund. "Esthetics and Loss." The Burning Library: Essays. Ed. David Bergman. New York: Knopf, 1994. 211-217. Print.

---. The Farewell Symphony. London: Chatto, 1997. Print.

---. The Married Man. London: Chatto, 2000. Print.

---. States of Desire. London: Picador, 1980. Print. 
Wilde, Oscar. "The Critic as Artist." 1891. The Collected Works of Oscar Wilde. Ware: Wordsworth, 1997. 963-1016. Print.

---.“The Decay of Lying.” 1891. The Collected Works of Oscar Wilde. Ware: Wordsworth, 1997. 919-943. Print.

“De Profundis.” 1897. De Profundis and Other Prison Writings. London: Penguin, 2013. 45-161. Print.

---. The Picture of Dorian Gray. 1890. The Collected Works of Oscar Wilde. Ware: Wordsworth, 1997. 1-154. Print.

Williams, Raymond. The Long Revolution. London: Chatto, 1961. Print.

Woodhouse, Reed. "Keys to the Kingdom of White." The Harvard Gay \& Lesbian Review 5.1 (1998): 38. Print.

Woods, Gregory. A History of Gay Literature: The Male Tradition. New Haven, Yale UP, 1998. Print. 